\title{
Synthesis and Antiviral Evaluation of Base-modified Deoxythreosyl Nucleoside Phosphonates
}

Chao Liu, ${ }^{\dagger}$ Shrinivas G. Dumbre,${ }^{\dagger}$ Christophe Pannecouque, ${ }^{\ddagger}$ Brent Korba,${ }^{\S}$ Steven De Jonghe ${ }^{\dagger}$ and Piet Herdewijn*, $\dagger$

*E-mail: Piet.Herdewijn@kuleuven.be

${ }^{\dagger}$ KU Leuven, Rega Institute for Medical Research, Medicinal Chemistry, Herestraat 49, 3000 Leuven, Belgium

†U Leuven, Rega Institute for Medical Research, Department of Microbiology and Immunology, Laboratory of Virology and Chemotherapy, Herestraat 49, 3000 Leuven, Belgium

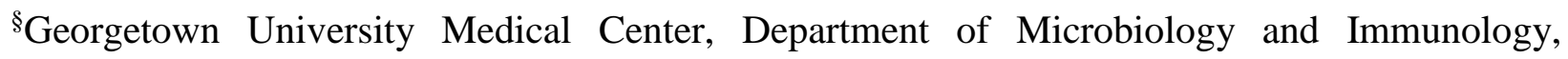
Washington, DC 20057, USA

ABSTRACT: L- $\alpha-2^{\prime}$-deoxythreosyl nucleoside phosphonates and their phosphonodiamidate prodrugs with a hypoxanthine, 2,6-diaminopurine, 2-amino-6-cyclopropylaminopurine, 7deazaadenine, 5-fluorouracil and 5-methylcytosine heterocycle as nucleobase were synthesized and evaluated for their inhibitory activity against HIV and HBV. The 2,6-diaminopurine modified analogue 23a displayed the most potent activity against HIV, with an $\mathrm{EC}_{50}$ value of $11.17 \mu \mathrm{M}$ against HIV-1 (IIIB) and an $\mathrm{EC}_{50}$ value of $8.15 \mu \mathrm{M}$ against HIV-2 (ROD). The application of the prodrug strategy on nucleoside phosphonate 23a led to a 200-fold boost in anti-HIV potency. None of the compounds showed any activity against HBV at the highest concentration tested.

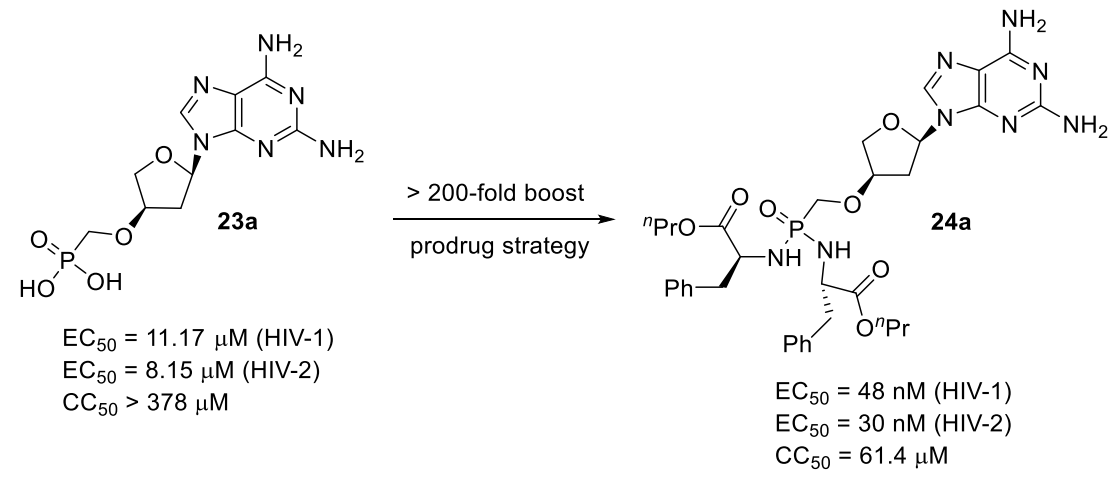




\section{Introduction}

Nucleoside phosphonates are a key class of drugs for the treatment of human immunodeficiency virus (HIV) and hepatitis B virus (HBV) infected patients. ${ }^{1}$ Examples of commonly prescribed nucleotide analogues are adefovir dipivoxil (a phosphonate nucleoside ester prodrug of adefovir), tenofovir disoproxil (an ester based prodrug of the nucleoside phosphonate tenofovir) and tenofovir alafenamide (a phosphonoamidate prodrug of tenofovir).
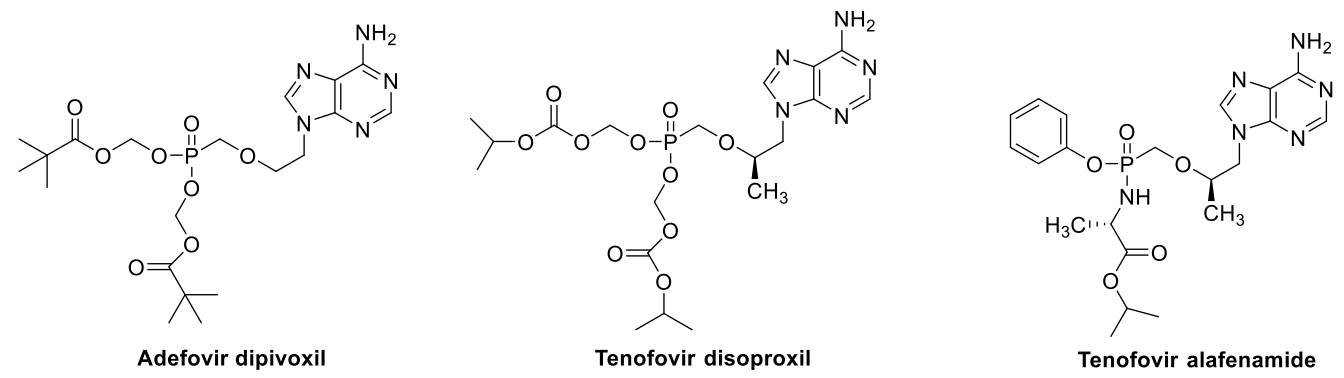

Fig. 1 Approved nucleoside phosphonate prodrugs.

Once inside the cell, nucleoside analogues undergo three consecutive phosphorylations yielding the biologically active triphosphate analogues, which can be incorporated in the viral genome, causing chain termination. The first phosphorylation step is very often inefficient and rate limiting in the conversion to the triphosphate. In theory, the administration of a nucleoside monophosphate analogue allows to circumvent this first phosphorylation. However, these nucleotides are potential substrates for phosphatases that cleave off the phosphate group. Replacement of this phosphate moiety by an isosteric and isoelectronic phosphonate group yields a chemically and metabolically stable nucleoside phosphonate that bypasses the initial enzymatic phosphorylation step. Moreover, nucleoside phosphonates have a long intracellular half-life, which allows infrequent dosing. In addition, the free phosphonate moiety allows to apply different prodrug strategies in order to boost antiviral potency and to optimize pharmacokinetics of the parent compound.

Structurally, nucleoside phosphonate analogues are divided in two major groups, the acyclic nucleoside phosphonates (ANPs) and the cyclic phosphonates (CNPs). ${ }^{2}$ The pioneering work of Dr. Holý in the 80ies led to the synthesis and antiviral testing of a wide variety of ANPs. It ultimately gave rise to marketing of three ANPs, i.e. cidofovir, adefovir and tenofovir (the latter two as their orally bioavailable prodrug forms, Figure 1). ${ }^{3}$ On the other hand, biologically active CNPs are described to a much lesser extent. The best-known examples are $\mathrm{d}_{4} \mathrm{AP}^{4}$ and its 
fluorinated counterpart $2^{\prime} \mathrm{Fd}_{4} \mathrm{AP}^{5}$, which are both endowed with promising anti-HIV activity (Figure 2). In previous studies, we reported the synthesis of series of L- $\alpha$ - 2 '-deoxythreosyl phosphonate nucleosides. ${ }^{6,7}$ Phosphonomethoxydeoxythreosyl adenine (PMDTA) and phosphonomethoxydeoxythreosyl thymine (PMDTT) (Figure 2) were the most potent congeners and they exhibited potent antiviral activity in vitro against HIV-1, HIV-2 and HBV. It has been demonstrated that PMDTA diphosphate is an efficient substrate for HIV-1 reverse transcriptase, whereas it is a poor substrate for human DNA polymerase $\alpha{ }^{6}$

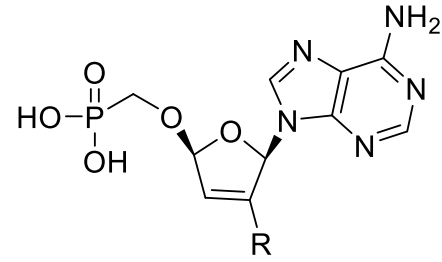

$\mathrm{R}=\mathrm{H}: \mathbf{d}$ 4AP

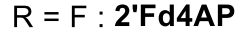

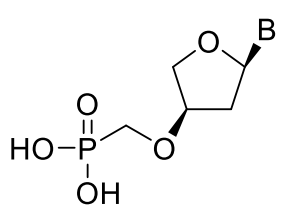

PMDTA: $\mathrm{B}=$ adenin-9-yl PMDTT: $B$ = thymin-1-yl

Fig. 2 Selected examples of biologically active cyclic nucleoside phosphonates.

The promising antiviral activity of this class of compounds encouraged us to further study the structure-activity relationship (SAR) of deoxythreosyl nucleoside phosphonates as antiviral agents. Up to now, all structural modifications that have been endorsed encompass modifications of the sugar moiety and includes a 2'-fluoro-threose sugar, 7,8 different stereochemistry of the phosphonomethyloxygroup at position 3', ' insertion of different substituents at positions 2 ' and 4' of the threose sugar moiety ${ }^{9}$ and different linkers between the phosphonate moiety and the threose unit. ${ }^{10}$ None of these sugar modified L- $\alpha-2^{\prime}$-deoxythreosyl phosphonate nucleosides displayed any antiviral activity.

To date, base-modified L- $\alpha-2$ '-deoxythreosyl phosphonate nucleosides have not been explored. However, modification of the nucleobase moiety has been shown to be a successful strategy in the discovery of biologically active nucleosides (Figure 3). Didanosine (ddI) and abacavir (ABC) are both marketed anti-HIV drugs and bear a hypoxanthine and 2-amino-6-cyclopropylaminopurine as nucleobase, respectively. ${ }^{11}$ Amdoxovir, with a 2,6-diaminopurine nucleobase, is a HIV reverse transcriptase inhibitor that underwent clinical trials. ${ }^{12,13}$ 5-Fluorouracil is the base moiety of the anticancer drug floxuridine, which is often used when colorectal cancer is advanced and has metastasized to the liver. ${ }^{14}$ Pyrrolo[2,3-d]pyrimidines (or 7-deaza-purines) have been extensively 
investigated. 7-Deaza-2'- $C$-methyladenosine is an inhibitor of HCV replication, ${ }^{15-17}$ and the structurally similar 7-deaza-2'-C-ethynyladenosine is a potent inhibitor of dengue virus type $2{ }^{18}$ 2'-Deoxy-2'-fluoro- $\beta$-D-arabinofuranosyl-5-methylcytosine (FMAC) is endowed with promising antiviral activity against herpes simplex virus. ${ }^{19,20}$ Herein, we present the synthesis and antiviral evaluation of novel base-modified L- $\alpha$-2'-deoxythreosyl nucleoside phosphonates with a hypoxanthine (Hx), 2,6-diaminopurine (DAP), 2-amino-6-cyclopropylaminopurine (cPrDAP), 7deazaadenine (7-deazaA), 5-fluorouracil (5FU) or 5-methylcytosine $(5 \mathrm{mC})$ heterocycle as nucleobase.

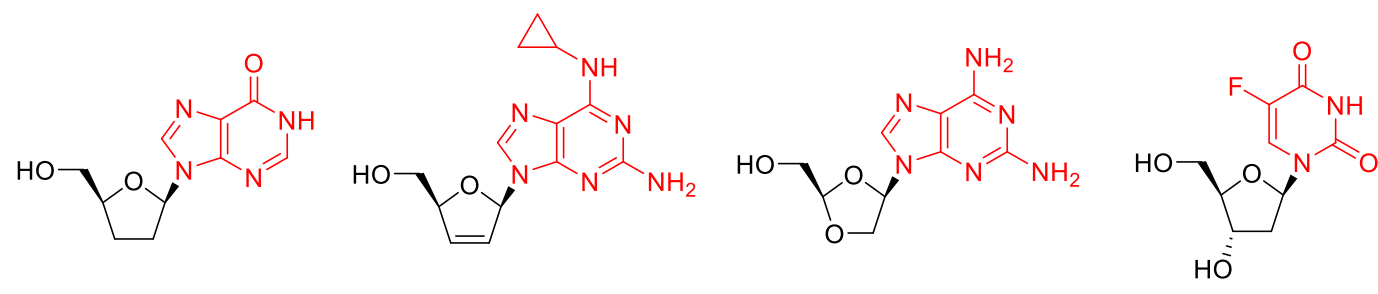

Didanosine

Abacavir

Amdoxovir

Floxuridine

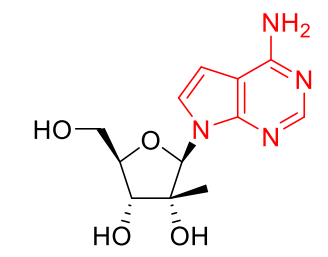

7-Deaza-2'-C-methyladenosine

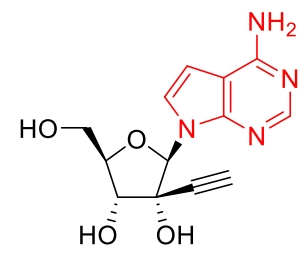

7-Deaza-2'-C-ethynyladenosine

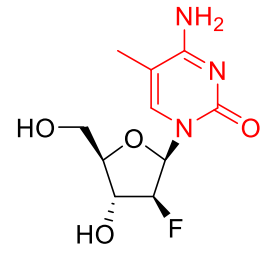

FMAC

Fig. 3 Selected examples of biologically active base-modified nucleosides.

The acidic phosphonate groups are ionized at physiological $\mathrm{pH}$, and hence, nucleoside phosphonates hardly penetrate the lipid-rich cell membrane, which hampers their antiviral activity. Our laboratory previously demonstrated that the corresponding aryloxyphosphonoamidate and phosphonobisamidate ProTides of PMDTA and PMDTT are endowed with low nanomolar activity against $\mathrm{HIV}$ and $\mathrm{HBV}^{7}$ Especially, the phosphonobisamidate prodrugs are attractive. In contrast with aryloxyphosphonoamidate prodrugs, phosphonobisamidate prodrugs avoid the formation of diastereomeric mixtures, as two identical amino acid esters are attached to the phosphorus centre. In addition, the byproducts of cleavage of this type of prodrug consist exclusively of non-toxic amino acids, whereas aryloxyphosphonoamidate prodrugs also release toxic phenol. Therefore, the base-modified L- $\alpha-2$-deoxythreosyl nucleoside phosphonates synthesized in this manuscript were converted to their corresponding phosphonobisamidate prodrug, using L-phenylalanine $n$-propyl 
ester as the amino acid motif, as this was shown before to be beneficial for anti-HIV and anti-HBV activity. $^{7}$

\section{Results and discussion}

\section{Chemistry}

Synthesis of a hypoxanthine L- $\alpha$-2'-deoxythreosyl phosphonate

The synthesis of a hypoxanthine containing $L-\alpha-2$-deoxythreosyl phosphonate nucleoside is shown in Scheme 1. A Vorbrüggen-type coupling of 6-chloropurine with the known 1',2'diacylated L-threose sugar $\mathbf{1}^{7,9}$ in the presence of TMSOTf and DBU afforded threoside 2 in $91 \%$ yield. Deprotection of the silyl protecting group with $\mathrm{Et}_{3} \mathrm{~N} \cdot 3 \mathrm{HF}$ gave nucleoside 3, which was subjected to sodium hydride mediated phosphonomethylation reaction to afford phosphonate nucleoside 4. Simultaneous deprotection of the 2'-benzoyl group and transformation of the 6chloropurine to hypoxanthine was achieved by refluxing 4 with 2-mercaptoethanol and sodium methoxide. The 2'-deoxygenation of $\mathbf{5}$ was carried out under standard Barton deoxygenation conditions. Finally, Lewis acid mediated cleavage of the phosphonate esters of $\mathbf{6}$ afforded nucleoside phosphonic acid 7. The bisamidate prodrug 8 was prepared from 7 using 2,2'dithiodipyridine and triphenylphosphine as activating agents and L-phenylalanine $n$-propyl ester as a coupling partner. 

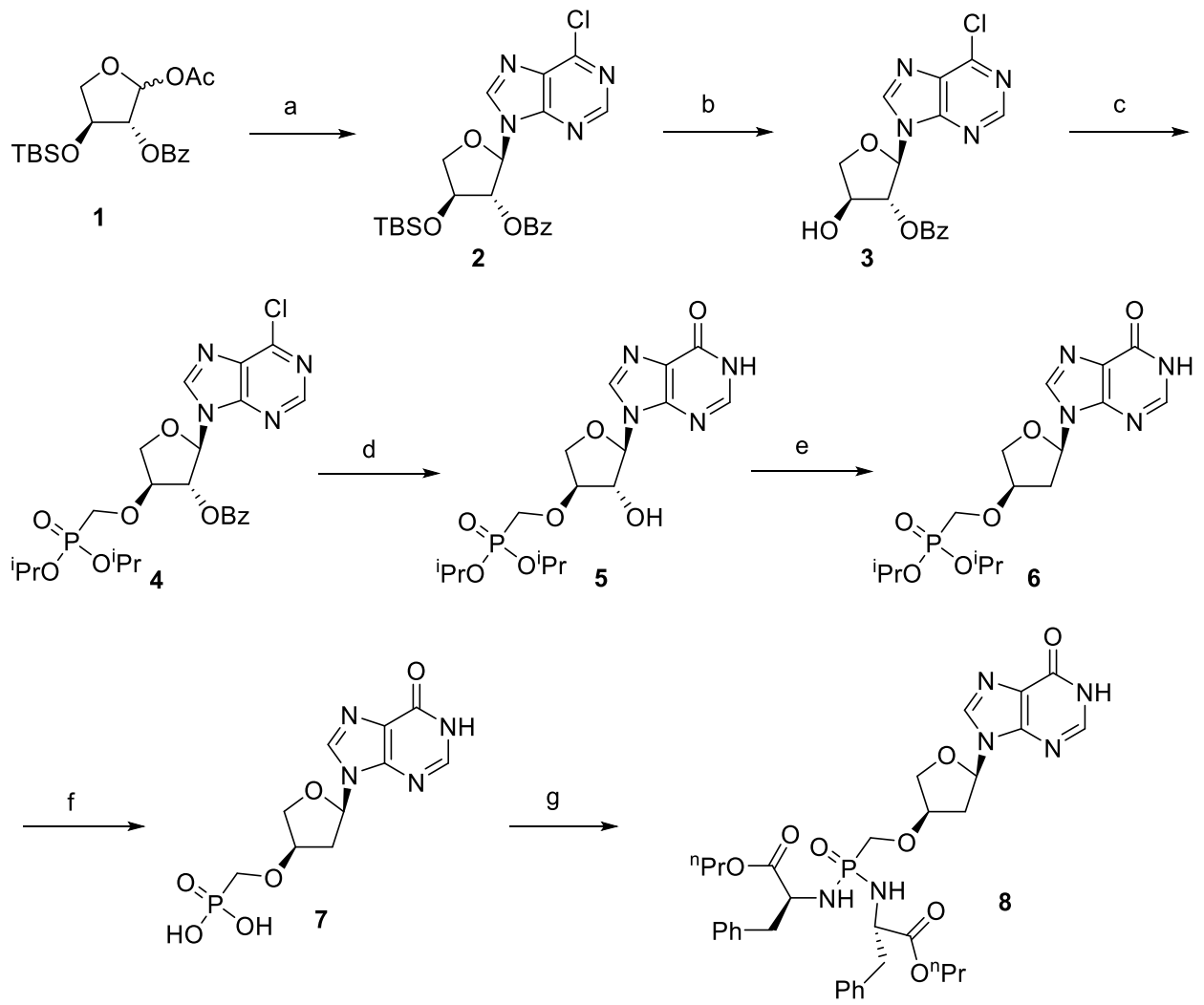

Scheme 1 Synthesis of a hypoxanthine L- $\alpha-2$ '-deoxythreosyl phosphonate. Reagents and conditions: (a) 6-chloropurine, DBU, TMSOTf, $60{ }^{\circ} \mathrm{C}, 1.5$ h, 91\%; (b) Et $3 \mathrm{~N} \cdot 3 \mathrm{HF}, \mathrm{THF}, \mathrm{rt}$, overnight, 98\%; (c) $\left({ }^{\mathrm{i}} \mathrm{PrO}\right)_{2} \mathrm{POCH}_{2} \mathrm{OTf}, \mathrm{NaH}, \mathrm{THF},-5$ to $0{ }^{\circ} \mathrm{C}, 30 \mathrm{~min}, 84 \%$; (d) 2 mercaptoethanol, $\mathrm{NaOMe}, \mathrm{MeOH}$, reflux, 20 h, 78\%; (e) (1) TCDI, DMAP, $\mathrm{CH}_{2} \mathrm{Cl}_{2}$, rt, overnight; (2) $\mathrm{Bu}_{3} \mathrm{SnH}$, AIBN, toluene, reflux, 20 min, 89\%; (f) $\mathrm{TMSBr}$, 2,6-lutidine, $\mathrm{CH}_{3} \mathrm{CN}$, rt, overnight, 40\%; (g) L-phenylalanine- $O$ - $n$ - $\mathrm{Pr}$ ester hydrochloride, $\mathrm{Et}_{3} \mathrm{~N}, 2$, 2'-dithiodipyridine, $\mathrm{PPh}_{3}$, pyridine, $60{ }^{\circ} \mathrm{C}$, overnight, $60 \%$.

\section{Synthesis of a 7-deazaadenine L- $\alpha$-2'-deoxythreosyl phosphonate}

For the synthesis of a 7-deazaadenine containing L- $\alpha-2$ '-deoxythreosyl phosphonate nucleoside, a similar strategy as for the synthesis of the hypoxanthine congener was initially envisioned (Scheme 2). Surprisingly, coupling of 6-choro-7-deazapurine with threose sugar 1 under Vorbrüggen glycosylation conditions failed to give the desired $N-9$ glycosylated nucleoside 9 . On the other hand, using 7-deaza- $N^{6}$-benzoyladenine as nucleobase furnished mainly the $N-1$ glycosylated nucleoside 11. The observation of HMBC correlations of $\mathrm{H}-1^{\prime}$ with $\mathrm{C}-2$ and $\mathrm{C}-6$ 
indicated that $\mathrm{N}-1$ was connected to the sugar moiety, and the observation of COSY correlations of the active hydrogen with H-8 and H-7 indicated that the active hydrogen was attached to N-9. Selective removal of the 2'-benzoyl group under basic conditions afforded nucleoside $\mathbf{1 2}$ in $79 \%$ yield. The structure of compound $\mathbf{1 2}$ was confirmed using the same approach as described for compound 11. Due to the particular properties of 7-deazapurine system, the nitrogen in pyrrole ring is rather inert against Lewis acid catalyzed glycosylation. Therefore, 6-chloro-7-iodo-7deazapurine (Scheme 3) was selected as a coupling partner as it has been often used for the synthesis of 6 and/or 7-substituted 7-deazapurine nucleoside analogues. ${ }^{21-24}$
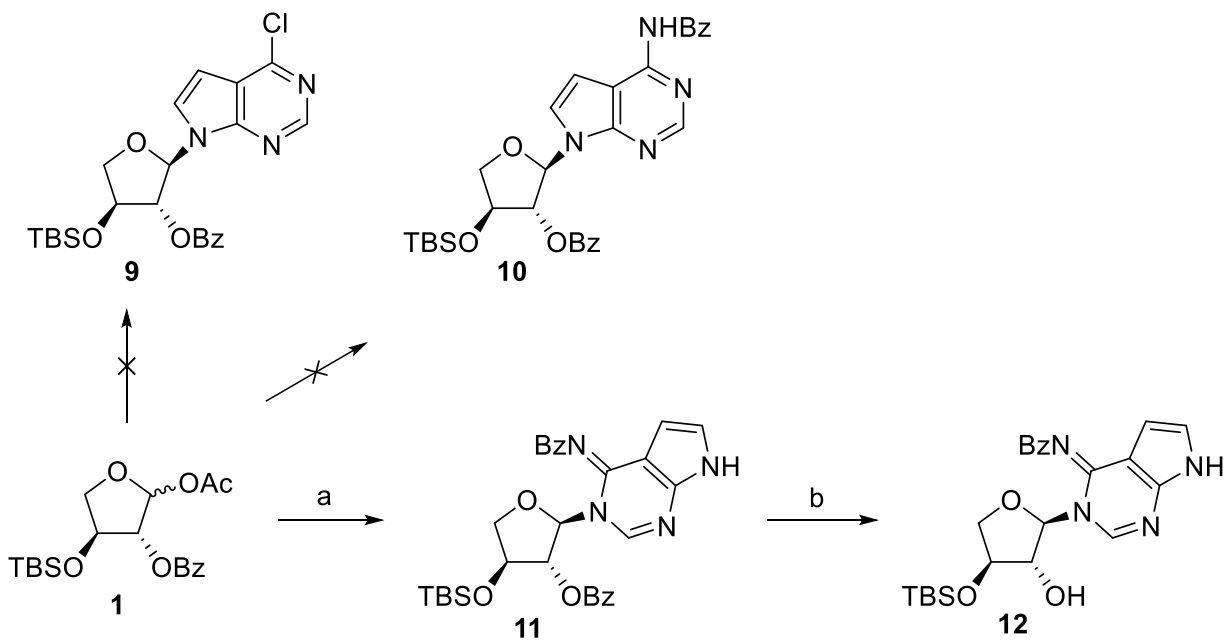

Scheme 2 Attempted synthesis of a 7-deazaadenine L- $\alpha$-2'-deoxythreosyl phosphonate. Reagents and conditions: (a) 7-deaza- $N^{6}$-benzoyladenine, BSA, TMSOTf, $95{ }^{\circ} \mathrm{C}, 1.5 \mathrm{~h}, 63 \%$; (b) $\mathrm{NaOH}$, $\mathrm{THF} / \mathrm{MeOH} / \mathrm{H}_{2} \mathrm{O}, 0{ }^{\circ} \mathrm{C}, 4 \mathrm{~h}, 79 \%$. 

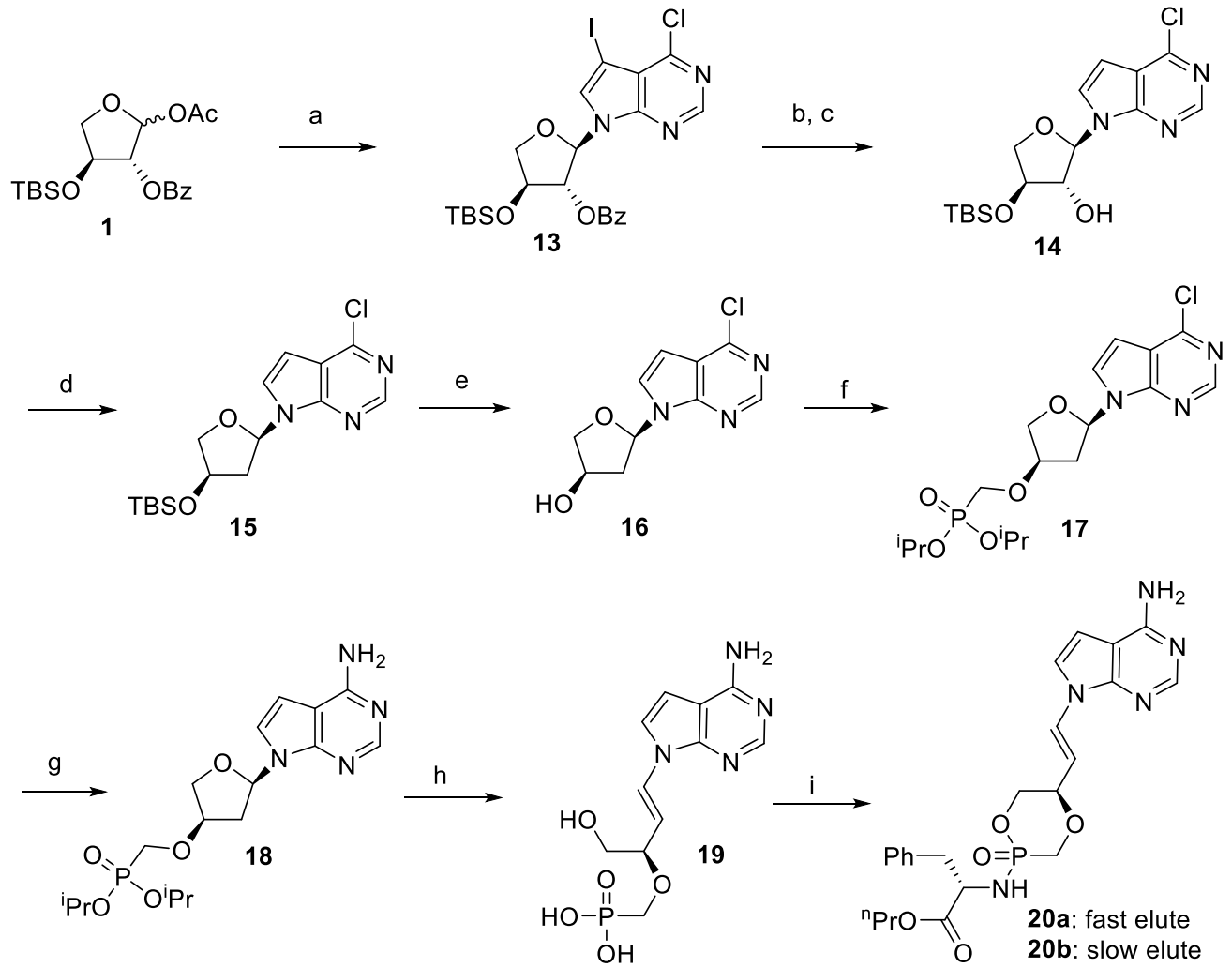

Scheme 3 Synthesis of a 7-deazaadenine L- $\alpha-2$ '-deoxythreosyl phosphonate. Reagents and conditions: (a) 6-chloro-7-iodo-7-deazapurine, DBU, TMSOTf, $60{ }^{\circ} \mathrm{C}, 1.5 \mathrm{~h}, 52 \%$; (b) ${ }^{\mathrm{i}} \mathrm{PrMgCl} \cdot \mathrm{Cl}$, THF, $-78^{\circ} \mathrm{C}, 20 \mathrm{~min}$; (c) $7 \mathrm{~N} \mathrm{NH}_{3}$ in $\mathrm{MeOH}$, rt, overnight, 91\% for 2 steps; (d) (1) TCDI, DMAP, $\mathrm{CH}_{2} \mathrm{Cl}_{2}$, rt, overnight; (2) $\mathrm{Bu}_{3} \mathrm{SnH}$, AIBN, toluene, reflux, 20 min, 80\%; (e) $\mathrm{Et}_{3} \mathrm{~N} \cdot 3 \mathrm{HF}, \mathrm{THF}$, rt, overnight, $83 \%$; (f) ( $\left.{ }^{\mathrm{P} P \mathrm{PO}}\right)_{2} \mathrm{POCH}_{2} \mathrm{OTf}$, $\mathrm{NaH}$, THF, -5 to $0{ }^{\circ} \mathrm{C}, 30 \mathrm{~min}, 84 \%$; (g) $7 \mathrm{~N} \mathrm{NH}_{3}$ in $\mathrm{MeOH}$, $120{ }^{\circ} \mathrm{C}, 16 \mathrm{~h}, 70 \%$; (h) TMSBr, 2,6-lutidine, $\mathrm{CH}_{3} \mathrm{CN}$, rt, overnight, 54\%; (i) L-phenylalanine- $O-n$ Pr ester hydrochloride, $\mathrm{Et}_{3} \mathrm{~N}, 2$, 2'-dithiodipyridine, $\mathrm{PPh}_{3}$, pyridine, $60{ }^{\circ} \mathrm{C}$, overnight, $36 \%$.

Vorbrüggen coupling of L-threose sugar 1 with 6-chloro-7-iodo-7-deazapurine afforded iodonucleoside 13 in 52\% yield. Deiodination of nucleoside 13 via selective iodine/magnesium exchange followed by cleavage of the 2'-benzoyl group with ammonia at room temperature afforded nucleoside 14 in 91\% yield. Removal of the 2' hydroxyl of 14 was accomplished under standard Barton deoxygenation conditions. Deprotection of the silyl group of 15, was followed by introduction of the phosphonate moiety affording the nucleoside phosphonate analogue $\mathbf{1 7}$. Treatment of 17 with $7 \mathrm{~N} \mathrm{NH}_{3}$ in methanol gave nucleoside 18. Treatment of 18 with a Lewis acid (TMSBr or TMSI) led to cleavage of the phosphonate ester groups, but, surprisingly, a concomitant 
unexpected sugar ring opening occurred, yielding an alkenyl type of acyclic nucleoside phosphonate 19 was formed. Based on the vicinal coupling constant $\left({ }^{3} J_{\mathrm{H}-1^{\prime}, \mathrm{H}-2^{\prime}}=14.4 \mathrm{~Hz}\right)$, the geometry of the double bond was found to be $(E)$. Finally, coupling of nucleoside 19 with Lphenylalanine $n$-propyl ester gave the cyclic phosphonamidates as a mixture of diastereoisomers (20a and 20b) in a ratio of ca. 2:1. The two isomers were successfully separated by reversed phase HPLC.

Synthesis of a 2,6-diaminopurine and a 2-amino-6-cyclopropylaminopurine L- $\alpha$-2'deoxythreosyl phosphonate

The 2,6-diaminopurine modified derivatives 22a and 22b (Scheme 4) were prepared by treatment of nucleoside $\mathbf{2 1}{ }^{8}$ with $7 \mathrm{~N}$ ammonia and cyclopropylamine, respectively. After cleavage of the isopropyl ester groups, the resulting nucleoside phosphonates 23a and 23b were condensed with the appropriate amino acid ester to afford the desired bisamidate prodrugs $\mathbf{2 4 a}$ and $\mathbf{2 4 b}$.

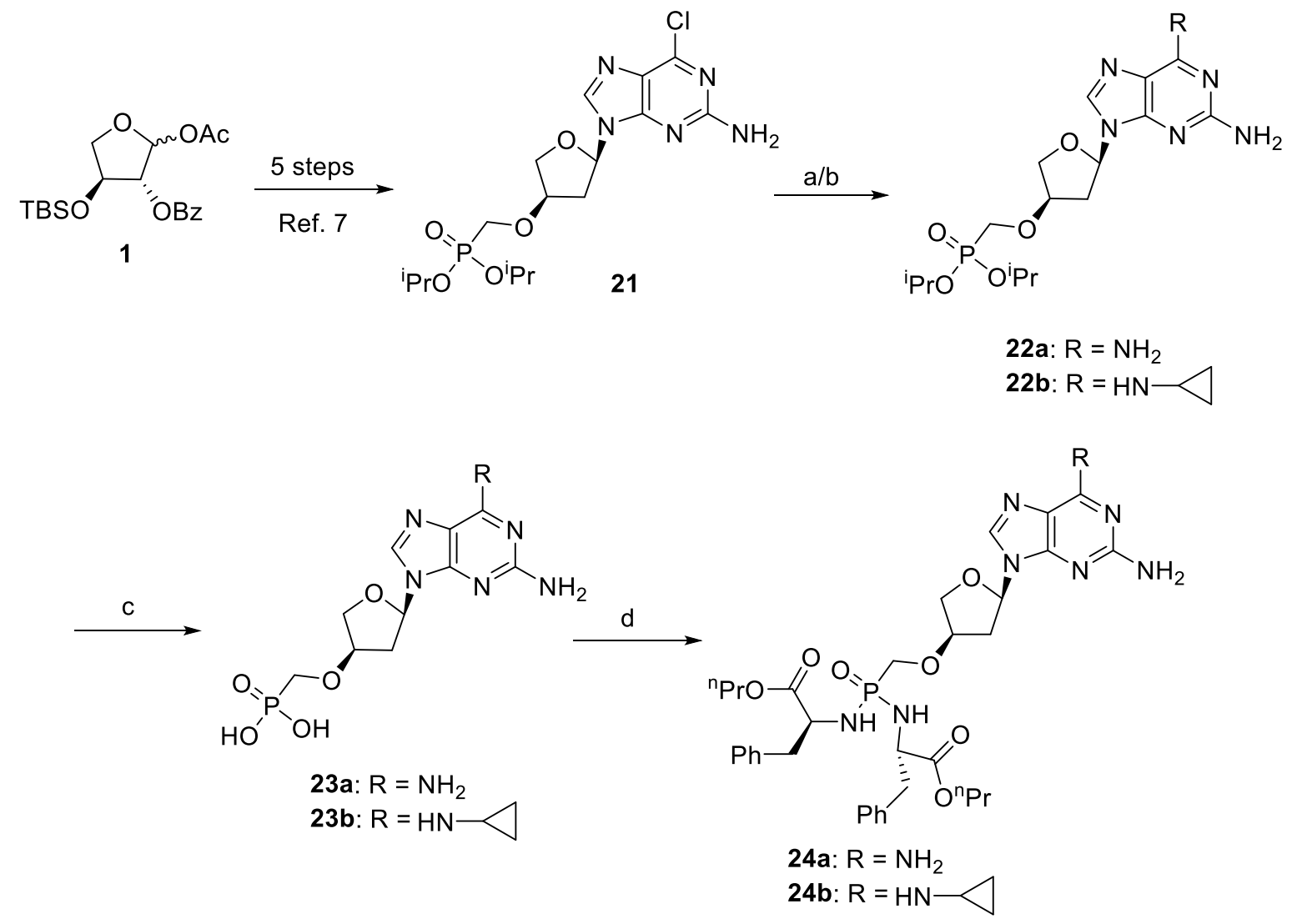


Scheme 4 Synthesis of a 2,6-diaminopurine and a 2-amino-6-cyclopropylaminopurine L- $\alpha$-2'deoxythreosyl phosphonate. Reagents and conditions: (a) $7 \mathrm{~N} \mathrm{NH}_{3}$ in $\mathrm{MeOH}, 100{ }^{\circ} \mathrm{C}, 4 \mathrm{~h}, 70 \%$; (b) cyclopropylamine, $\mathrm{CH}_{3} \mathrm{CN}, 100{ }^{\circ} \mathrm{C}, 4$ h, 91\%; (c) TMSBr, 2,6-lutidine, $\mathrm{CH}_{3} \mathrm{CN}$, rt, overnight, $60 \%$ for $\mathbf{2 3 a}$ and $62 \%$ for $\mathbf{2 3 b}$; (d) L-phenylalanine- $O-n$-Pr ester hydrochloride, $\mathrm{Et}_{3} \mathrm{~N}, 2,2^{\prime}-$ dithiodipyridine, $\mathrm{PPh}_{3}$, pyridine, $60{ }^{\circ} \mathrm{C}$, overnight, $53 \%$ for $\mathbf{2 4 a}$ and $67 \%$ for $\mathbf{2 4 b}$.

\section{Synthesis of a 5-fluorouracil L- $\alpha$-2'-deoxythreosyl phosphonate}

The 2'-deoxy threose nucleoside 29 (Scheme 5) was synthesized following a similar procedure as described for nucleoside phosphonate 6. While Lewis acid (TMSBr or TMSI) mediated hydrolysis of the phosphonate ester groups of $\mathbf{2 9}$ were unsuccessful, cleavage of the glycosidic bond did happen.
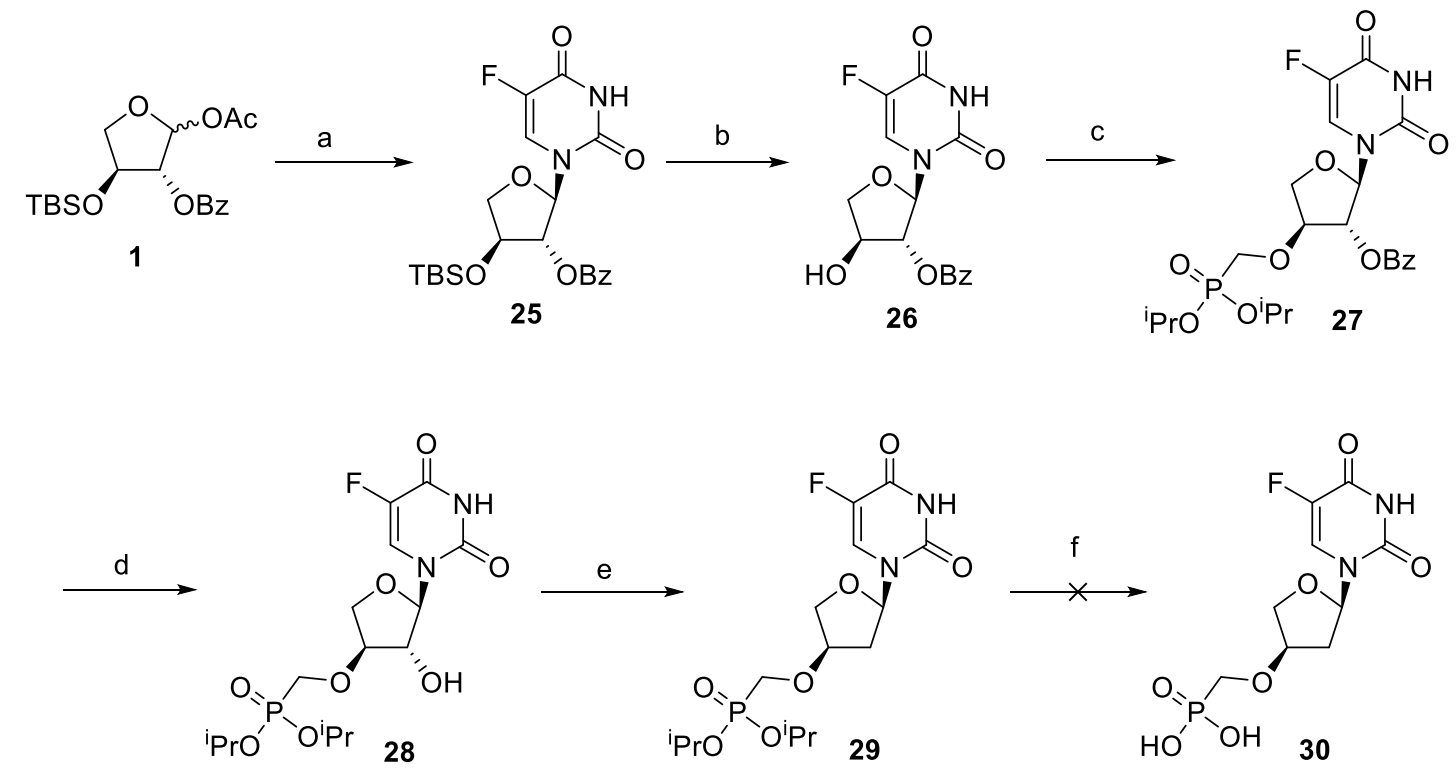

Scheme 5 Synthesis of a 5-fluorouracil L- $\alpha$-2'-deoxythreosyl phosphonate. Reagents and conditions: (a) 5-fluorouracil, BSA, TMSOTf, $60^{\circ} \mathrm{C}, 1 \mathrm{~h}, 88 \%$; (b) Et $\mathrm{t}_{3} \mathrm{~N} \cdot 3 \mathrm{HF}$, THF, rt, overnight, 90\%; (c) ( $\left.{ }^{\mathrm{i}} \mathrm{PrO}\right)_{2} \mathrm{POCH}_{2} \mathrm{OTf}, \mathrm{NaH}, \mathrm{THF},-5$ to $0{ }^{\circ} \mathrm{C}, 40 \mathrm{~min}, 52 \%$; (d) $2 \mathrm{~N} \mathrm{NH}_{3}$ in $\mathrm{MeOH}, \mathrm{rt}$, overnight, 94\%; (e) (1) TCDI, DMAP, $\mathrm{CH}_{2} \mathrm{Cl}_{2}$, rt, overnight; (2) $\mathrm{Bu}_{3} \mathrm{SnH}$, AIBN, toluene, reflux, 20 min, 92\%; (f) TMSBr or TMSI, 2,6-lutidine, $\mathrm{CH}_{3} \mathrm{CN}$, rt, overnight, no product.

In contrast, hydrolysis of the phosphonate ester functions of compound $\mathbf{2 8}$ afforded nucleoside phosphonate 31 (Scheme 6) from 28 under the standard Lewis acid conditions. Coupling of 31 
with L-phenylalanine $n$-propyl ester gave $39 \%$ of bisamidate prodrug $\mathbf{3 2}$ and ca.15\% of a single diastereomer of 2',3'-diol cyclized phosphonamidate prodrug 33. To avoid the formation of side product 33, the 2'-hydroxyl group was protected as a tert-butyldimetylsilyl (TBS) group by treatment of nucleoside $\mathbf{2 8}$ with TBSCl in the presence of imidazole furnishing the silyl protected nucleoside 34 in $89 \%$ yield. Hydrolysis of the phosphonate esters, was followed by coupling with the amino acid ester and removal of the silyl protecting group, giving rise to nucleoside $\mathbf{3 2}$ in a higher yield. Finally, 2'-deoxygenation of 32 under standard Barton deoxygenation conditions afforded bisamidate prodrug 36.

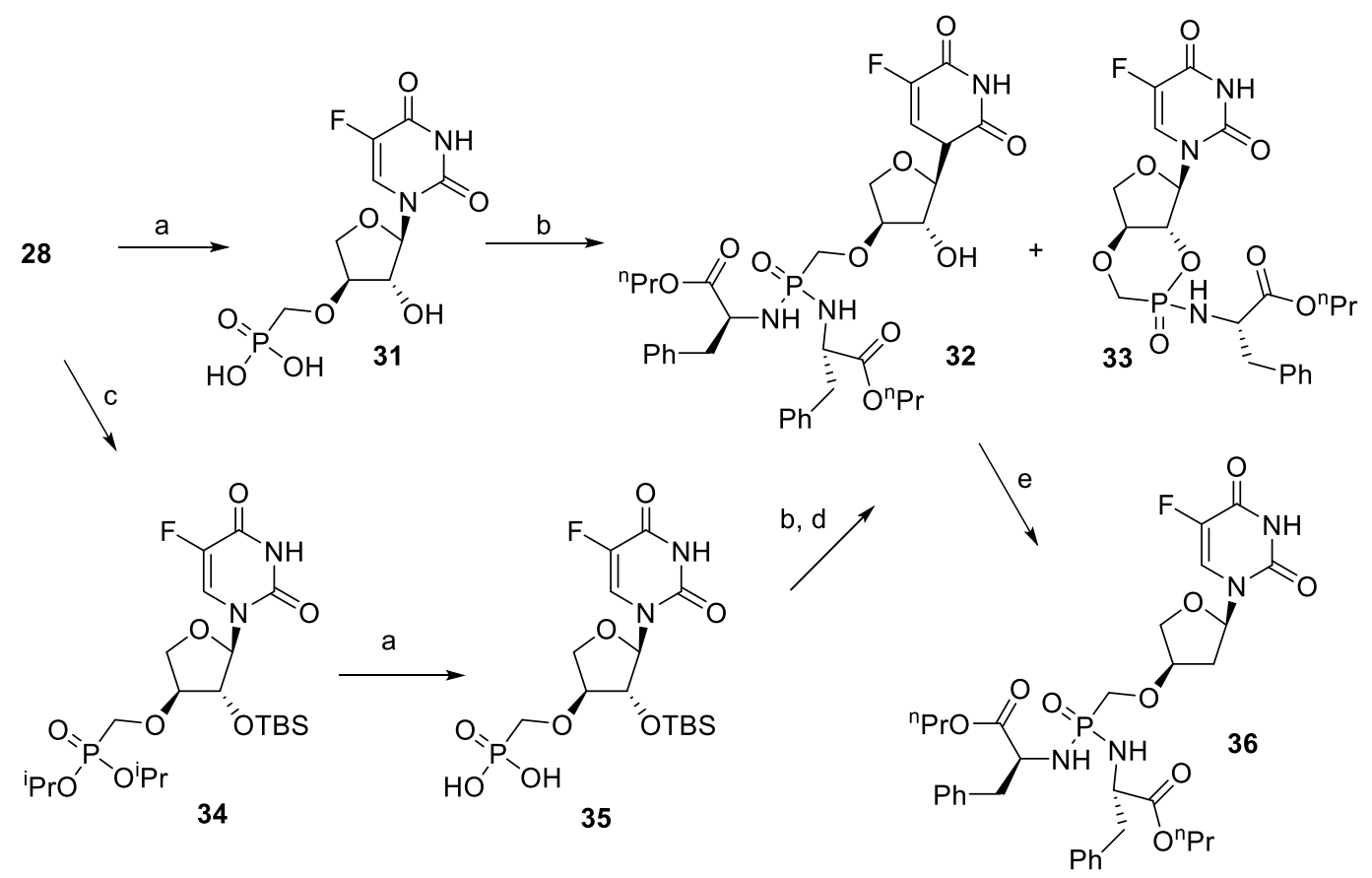

Scheme 6 Synthesis of a 5-fluorouracil L- $\alpha$-2'-deoxythreosyl phosphonate. Reagents and conditions: (a) TMSBr, 2,6-lutidine, $\mathrm{CH}_{3} \mathrm{CN}$, rt, overnight, 68\% for 31 and 67\% for 35; (b) Lphenylalanine- $O-n$-Pr ester hydrochloride, 2,2'-dithiodipyridine, $\mathrm{PPh}_{3}$, pyridine, $60{ }^{\circ} \mathrm{C}$, overnight, 39\% for 32 and 15\% for 33; (c) TBSCl, imidazole, DMF, rt, overnight, 89\%; (d) Et $3 \mathrm{~N} \cdot 3 \mathrm{HF}$, THF, rt, overnight, 69\% from 35; (e) (1) TCDI, DMAP, $\mathrm{CH}_{2} \mathrm{Cl}_{2}$, rt, overnight. (2) $\mathrm{Bu}_{3} \mathrm{SnH}, \mathrm{AIBN}$, toluene, reflux, $20 \mathrm{~min}, 90 \%$.

\section{Synthesis of a 5-methylcytosine L- $\alpha$-2'-deoxythreosyl phosphonate}

The synthesis of this derivative starts from the known thymidine nucleoside phosphonate $37 .{ }^{7}$ Treatment of $\mathbf{3 7}$ with $p$-toluenesulfonyl chloride $(\mathrm{TsCl})$ in the presence of $N$-methylpyrrolidine 
was followed by aqueous ammonia. Hydrolysis of the phosphonate esters of $\mathbf{3 8}$ was accomplished by treatment of $\mathbf{3 8}$ with TMSI in the presence of 2,6-lutidine to furnish target compound 39, which was condensed with L-phenylalanine $n$-propyl ester to afford prodrug $\mathbf{4 0 .}$

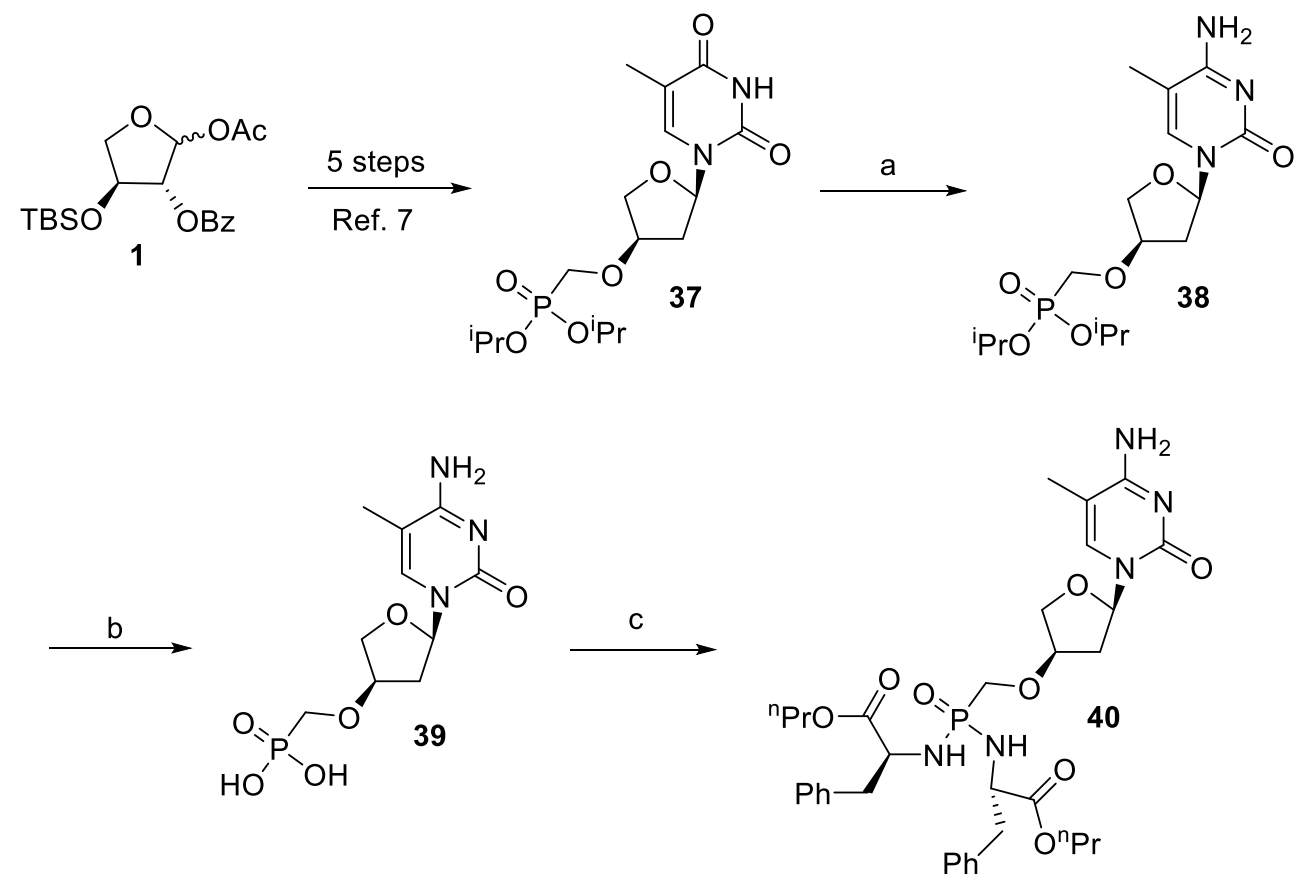

Scheme 7 Synthesis of a 5-methylcytosine L- $\alpha-2$ '-deoxythreosyl phosphonate. Reagents and conditions: (a) (1) TsCl, $N$-Methylpyrrolidine, $\mathrm{Et}_{3} \mathrm{~N}, \mathrm{CH}_{2} \mathrm{Cl}_{2}$, rt, 2 h. (2) aq. $\mathrm{NH}_{4} \mathrm{OH}$, rt, overnight, 75\%; (b) TMSI, 2,6-lutidine, $\mathrm{CH}_{3} \mathrm{CN}$, rt, overnight, 51\%; (c) L-phenylalanine- $O$ - $n$ - $\mathrm{Pr}$ ester hydrochloride, 2,2'-dithiodipyridine, $\mathrm{PPh}_{3}$, pyridine, $60{ }^{\circ} \mathrm{C}$, overnight, $30 \%$.

\section{Antiviral activity}

The nucleoside phosphonates, as well as their phosphonodiamidate prodrugs were evaluated for anti-HIV activity using the MTT method in MT-4 cells infected with a wild-type HIV-1 strain III $_{B}$ and a wild-type HIV-2 strain (ROD). AZT and Lamivudine were included as positive controls, whereas PMDTA and PMDTT were included as reference compounds. Cytotoxicity in the MT-4 cell line was determined simultaneously (Table 1). ${ }^{25,}{ }^{26}$ Most compounds completely lacked antiHIV activity, demonstrating that only the natural nucleobases adenine and thymine are tolerated for antiviral activity. The only exception is the 2,6-diaminopurine base modified analogue 23a, which exhibited anti-HIV activity at micromolar concentrations (EC50 of 11.2 $\mu \mathrm{M}$ against HIV-1 and $\mathrm{EC}_{50}$ of $8.15 \mu \mathrm{M}$ against HIV-2). This is an approximate two-fold drop in anti-HIV activity, 
when compared to PMDTA. No cytotoxicity was observed at the highest tested concentration $\left(\mathrm{CC}_{50}>378 \mu \mathrm{M}\right)$. Substitution of the 6-amino group in nucleoside 23a with a cyclopropylamino moiety afforded compound $\mathbf{2 3 b}$, which is completely devoid of antiviral activity. The application of a prodrug strategy led to a boost in anti-HIV potency. Compound $\mathbf{2 4 a}$, the bisamidate prodrug of 23a, showed a 230-fold increased activity against HIV-1 and a 270-fold improvement against HIV-2, displaying EC 50 values of 0.048 and $0.03 \mu \mathrm{M}$, respectively. Prodrug 24a was about 6 times more cytotoxic than the parent phosphonate 23a, but the potent antiviral activity still gives rise to favorable selectivity indexes $\left(\mathrm{CC}_{50} / \mathrm{EC}_{50}\right)$ of 1264 (for HIV-1) and 2095 (for HIV-2). Analogously, although no activity against HIV was observed for nucleoside phosphonate 23b, its prodrug (compound 24b) exhibited low micromolar activity with an $\mathrm{EC}_{50}$ of $3.63 \mu \mathrm{M}$ against $\mathrm{HIV}-1$ and an $\mathrm{EC}_{50}$ of $3.99 \mu \mathrm{M}$ against HIV-2. None of the other base modified analogues showed any activity against HIV. This lack of activity can be explained by either the fact that they cannot be converted to their diphosphate form or that once phosphorylated to the triphosphate analogue the compounds are poor substrates for HIV reverse transcriptase.

Table 1. In Vitro Anti-HIV activity and cytotoxicity of base-modified deoxythreosyl nucleoside phosphonates.

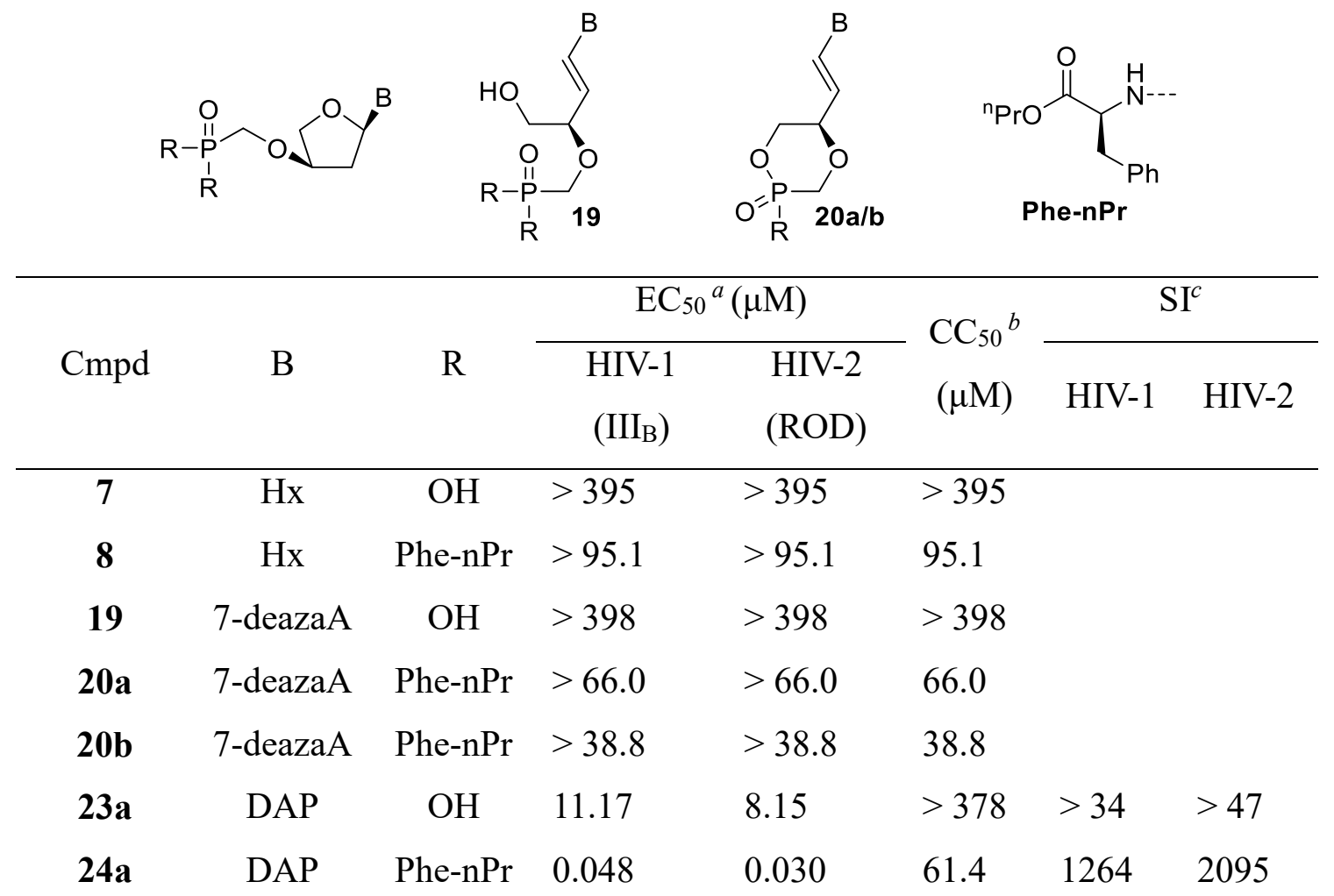




\begin{tabular}{|c|c|c|c|c|c|c|c|}
\hline $23 b$ & cPrDAP & $\mathrm{OH}$ & $>338$ & $>338$ & $>338$ & & \\
\hline $24 b$ & cPrDAP & Phe-nPr & 3.63 & 3.99 & 60.1 & 17 & 15 \\
\hline 36 & $5 \mathrm{FU}$ & Phe-nPr & $>64.0$ & $>64.0$ & 64.0 & & \\
\hline 39 & $5 \mathrm{mC}$ & $\mathrm{OH}$ & $>410$ & $>410$ & $>410$ & & \\
\hline 40 & $5 \mathrm{mC}$ & Phe-nPr & $\geq 23.4$ & 16.7 & 85.5 & $\leq 4$ & 5 \\
\hline PMDTA $^{7}$ & A & $\mathrm{OH}$ & 4.69 & 5.23 & $\geq 315$ & $\geq 67$ & $\geq 60$ \\
\hline $\mathbf{P M D T T}^{7}$ & $\mathrm{~T}$ & $\mathrm{OH}$ & 27.07 & 23.55 & 297 & 11 & 13 \\
\hline 3TC & & & 2.53 & 9.90 & $>87.2$ & $>34$ & $>9$ \\
\hline $\mathbf{A Z T}$ & & & 0.0075 & 0.0082 & $>7.48$ & $>1004$ & $>925$ \\
\hline
\end{tabular}

${ }^{a} \mathrm{EC}_{50}$ : effective concentration required to achieve 50\% protection of MT-4 cells against HIVinduced cytopathicity. ${ }^{b} \mathrm{CC}_{50}$ : cytotoxic concentration required to reduce the viability of mockinfected cells by $50 \% .{ }^{c} \mathrm{SI}$ : selectivity index, $\mathrm{CC}_{50} / \mathrm{EC}_{50}$

Given the potent activity of PMDTA and PMDTT against $\mathrm{HBV},{ }^{7}$ the anti-HBV activity of the nucleobase modified compounds was assessed in HepG2 2.2.15 cell line, which is a stable human hepatoblastoma cell line that contains two copies of the HBV wild-type strain ayw1 genome and constitutively produces high levels of $\mathrm{HBV} .{ }^{27}$ A quantitative blot hybridization assay was used to measure extracellular HBV DNA copy number associated with virions released from HepG2 2.2.15 cell. A tetrazolium dye uptake assay was used to measure cell viability and to calculate $\mathrm{CC}_{50}$ values. ${ }^{28,29}$ Unfortunately, none of these compounds showed any activity against $\mathrm{HBV}$ at the highest tested concentration $(100 \mu \mathrm{M})$.

\section{Conclusion}

In summary, a number of base-modified deoxythreosyl nucleoside phosphonates and their phosphonobisamidate prodrugs was prepared, and their anti-HIV and anti-HBV activities were evaluated. The 2,6-diaminopurine containing deoxythreosyl nucleoside phosphonate 23a exhibited the most potent activity against HIV-1 and HIV-2, with $\mathrm{EC}_{50}$ values of $11.2 \mu \mathrm{M}$ and $8.15 \mu \mathrm{M}$, respectively. The synthesis of a prodrug of nucleoside phosphonate 23a afforded phosphonobisamidate prodrug 24a that displayed an improved anti-HIV activity $\left(\mathrm{EC}_{50}=48 \mathrm{nM}\right.$ for HIV-1 and $30 \mathrm{nM}$ for HIV-2). None of the other base modified analogues exhibited potent activity against HIV and all studied deoxythreosyl nucleoside phosphonates completely lacked activity against HBV. 


\section{Experimental Section}

\section{General information}

All reagents and solvents were purchased from commercial sources and used as received. Moisture sensitive reactions were performed under an argon or nitrogen atmosphere using oven-dried glassware. Reactions were monitored by thin-layer chromatography (TLC) on precoated aluminum foil (silica gel matrix, with fluorescence indicator $254 \mathrm{~nm}$ ). ${ }^{1} \mathrm{H},{ }^{13} \mathrm{C}$ and ${ }^{31} \mathrm{P} \mathrm{NMR}$ spectra were recorded on a 300, 500 or $600 \mathrm{MHz}$ Bruker Advance spectrometer with tetramethylsilane as internal standard or referenced to the residual solvent signal, and $85 \% \mathrm{H}_{3} \mathrm{PO}_{4}$ for ${ }^{31} \mathrm{P} \mathrm{NMR}$. Twodimensional (2D) NMRs (H-COSY, HSQC, and HMBC) were used for the assignment of the intermediates and final compounds. Chemical shifts are reported in parts per million. Splitting patterns are described as singlet (s), broad singlet (brs), doublet (d), triplet (t), double of doublets (dd), and multiplet (m). High resolution mass spectra (HRMS) were recorded on a quadrupole orthogonal acceleration time-of-flight mass spectrometer (Synapt G2 HDMS, Waters, Milford, MA). Samples were infused at $3 \mu \mathrm{L} / \mathrm{min}$, and spectra were obtained in positive or negative ionization mode with a resolution of 15000 (fwhm) using leucine enkephalin as lock mass. Preparative high performance liquid chromatography (HPLC) purifications were carried out on a Phenomenex Gemini 110A column $(\mathrm{C} 18,10 \mu \mathrm{m}, 21.2 \mathrm{~mm} \times 250 \mathrm{~mm})$. Column chromatography was performed on silica gel $60 \AA$, $0.035-0.070 \mathrm{~mm}$ (Acros Organics).

1' $\alpha$-(6-chloropurin-9-yl)-2'-O-benzoyl-3'-O-tert-butyldimethylsilyl-L-threose (2). A solution of threose sugar $1(0.20 \mathrm{~g}, 0.53 \mathrm{mmol})$ and 6-chloropurine $(90 \mathrm{mg}, 0.58 \mathrm{mmol})$ in $6 \mathrm{~mL}$ of dry acetonitrile was treated with DBU $(0.24 \mathrm{~mL}, 1.58 \mathrm{mmol})$ followed by TMSOTf $(0.38 \mathrm{~mL}, 2.10$ mmol) at $0{ }^{\circ} \mathrm{C}$. The resulting reaction mixture was stirred at $60^{\circ} \mathrm{C}$ for $1.5 \mathrm{~h}$. The reaction mixture was then cooled to rt and poured into an ice-cold stirred mixture of sat. aq. $\mathrm{NaHCO}_{3}$ and $\mathrm{AcOEt}$ The organic layer was separated and washed with brine, dried over $\mathrm{Na}_{2} \mathrm{SO}_{4}$, and concentrated under reduced pressure. The residue was purified by column chromatography (20:1 to 10:1, $\mathrm{CH}_{2} \mathrm{Cl}_{2} /$ EtOAc) to obtain $2\left(0.23 \mathrm{~g}, 91 \%\right.$ yield) as a white solid. ${ }^{1} \mathrm{H}$ NMR (500 MHz, $\left.\mathrm{CDCl}_{3}\right): \delta$ 8.76 (s, 1H, H-2), 8.58 (s, 1H, H-8), 8.09 (d, J=8.2 Hz, 2H, ArH), 7.64 (t, J=7.4 Hz, 1H, ArH), 7.50 (t, J=7.4 Hz, 2H, ArH), 6.49 (s, 1H, H-1'), 5.60 (s, 1H, H-2'), 4.55 (d, J=3.0 Hz, 1H, H-3'), $4.39\left(\mathrm{dd}, J=9.9,3.6 \mathrm{~Hz}, 1 \mathrm{H}, \mathrm{H}-4 \mathrm{a}^{\prime}\right), 4.34$ (d, $\left.J=9.9 \mathrm{~Hz}, \mathrm{H}-4 \mathrm{~b}^{\prime}\right), 0.86$ [s, 9H, C(CH3) $\left.)_{3}\right], 0.16$ (s, $\left.3 \mathrm{H}, \mathrm{SiCH}_{3}\right), 0.06\left(\mathrm{~s}, 3 \mathrm{H}, \mathrm{SiCH}_{3}\right) .{ }^{13} \mathrm{C} \mathrm{NMR}\left(125 \mathrm{MHz}, \mathrm{CDCl}_{3}\right): \delta 165.0(\mathrm{CO}), 152.1(\mathrm{C}-2), 151.2$ 
(C-4), 151.0 (C-6), 144.2 (C-8), 134.0 (Ar-C), 131.8 (C-5), 129.9, 128.7, 128.6 (Ar-C), 88.5 (C$\left.1^{\prime}\right), 82.6\left(\mathrm{C}-2^{\prime}\right), 77.0\left(\mathrm{C}-4^{\prime}\right), 75.0\left(\mathrm{C}-3^{\prime}\right), 25.6\left[\mathrm{C}\left(\mathrm{CH}_{3}\right)_{3}\right], 17.9\left[\mathrm{C}\left(\mathrm{CH}_{3}\right)_{3}\right]$. HRMS: $[\mathrm{M}+\mathrm{H}]^{+}$calcd for $\mathrm{C}_{22} \mathrm{H}_{28} \mathrm{ClN}_{4} \mathrm{O}_{4} \mathrm{Si}$, 475.1563; found, 475.1560 .

$\mathbf{1}^{\prime} \boldsymbol{\alpha}$-(6-chloropurin-9-yl)-2'- $\boldsymbol{O}$-benzoyl-L-threose (3). To a solution of nucleoside $\mathbf{2}$ (0.16 g, 0.34 $\mathrm{mmol})$ in $4 \mathrm{~mL}$ of anhydrous THF at rt was added triethylamine trihydrofluoride $(0.11 \mathrm{~mL}, 0.67$ mmol). The reaction mixture was stirred at $\mathrm{rt}$ for overnight. The solvent was removed under reduced pressure and the residue was partitioned between ethyl acetate and sat. aq. $\mathrm{NaHCO}_{3}$. The organic layer was separated and washed with brine, dried over $\mathrm{Na}_{2} \mathrm{SO}_{4}$, and concentrated under reduced pressure. The residue was purified by column chromatography (5:1 to $\left.3: 1, \mathrm{CH}_{2} \mathrm{Cl}_{2} / \mathrm{EtOAc}\right)$ to obtain 3 (0.12 g, 98\% yield) as a white solid. ${ }^{1} \mathrm{H}$ NMR (600 $\left.\mathrm{MHz}, \mathrm{CDCl}_{3}\right): \delta 8.79(\mathrm{~s}, 1 \mathrm{H}, \mathrm{H}-2)$, 8.40 (s, 1H, H-8), 8.05-8.03 (m, 2H, ArH), 7.66-7.63 (m, 1H, ArH), 7.51-7.48 (m, 2H, ArH), 6.12 $\left(\mathrm{d}, J=1.7 \mathrm{~Hz}, 1 \mathrm{H}, \mathrm{H}-1^{\prime}\right), 5.96$ (d, $\left.J=9.4 \mathrm{~Hz}, 1 \mathrm{H}, \mathrm{OH}\right), 5.56$ (s, 1H, H-2'), 4.69-4.66 (m, 1H, H$\left.3^{\prime}\right), 4.40\left(\mathrm{~d}, J=10.3 \mathrm{~Hz}, 1 \mathrm{H}, \mathrm{H}-4 \mathrm{a}^{\prime}\right), 4.32$ (dd, $\left.J=10.3,4.0 \mathrm{~Hz}, \mathrm{H}-4 \mathrm{~b}^{\prime}\right) .{ }^{13} \mathrm{C} \mathrm{NMR}(150 \mathrm{MHz}$, $\left.\mathrm{CDCl}_{3}\right): \delta 165.9(\mathrm{CO}), 152.1(\mathrm{C}-6), 151.5$ (C-2), 150.2 (C-4), 145.3 (C-8), 134.1 (Ar-C), $132.7(\mathrm{C}-$

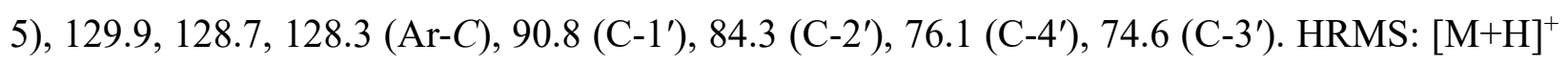
calcd for $\mathrm{C}_{16} \mathrm{H}_{14} \mathrm{ClN}_{4} \mathrm{O}_{4}, 361.0698$; found, 361.0700 .

$1^{\prime} \alpha$-(6-chloropurin-9-yl)-2'-O-benzoyl-3' $O$-diisopropylphosphonomethyl-L-threose (4). To a solution of 3 (5.60 g, $15.5 \mathrm{mmol})$ and diisopropylphosphonomethyl trifluoromethanesulfonate (6.62 g, $20.2 \mathrm{mmol})$ in dry THF (150 mL) was added NaH (60\% in oil, $0.75 \mathrm{~g}, 18.6 \mathrm{mmol})$ at $5{ }^{\circ} \mathrm{C}$. The reaction mixture was stirred at $0{ }^{\circ} \mathrm{C}$ for $0.5 \mathrm{~h}$. The reaction was quenched with $1 \mathrm{ml}$ of acetic acid in EtOAc $(100 \mathrm{~mL})$. The residue was partitioned between water and EtOAc. The organic layer was washed with brine, dried over $\mathrm{Na}_{2} \mathrm{SO}_{4}$, and concentrated under reduced pressure. The residue was purified by column chromatography (2:1 to $\left.1: 2, \mathrm{CH}_{2} \mathrm{Cl}_{2} / \mathrm{EtOAc}\right)$ to afford 4 (7.0 g, 84\% yield) as a white foam. ${ }^{1} \mathrm{H}$ NMR $\left(500 \mathrm{MHz}, \mathrm{CDCl}_{3}\right): \delta 8.75$ (s, 1H, H-2), 8.57 (s, 1H, H8), 8.08-8.08 (m, 2H, ArH), 7.64-7.63 (m, 1H, ArH), 7.52-7.48 (m, 2H, ArH), 6.52 (s, 1H, H-1'), $5.78\left(\mathrm{~s}, 1 \mathrm{H}, \mathrm{H}-2^{\prime}\right), 4.79-4.71\left[\mathrm{~m}, 2 \mathrm{H}, \mathrm{CH}\left(\mathrm{CH}_{3}\right)_{2}\right], 4.53$ (d, J=10.6 Hz, H-4a'), 4.49 (d, J=4.0 Hz, $\left.1 \mathrm{H}, \mathrm{H}-3^{\prime}\right), 4.39$ (dd, $\left.J=10.6,4.2 \mathrm{~Hz}, 1 \mathrm{H}, \mathrm{H}-4 \mathrm{~b}^{\prime}\right), 3.98-3.89$ (m, 2H, PCH$), 1.36-1.29$ [m, 12H, $\left.\mathrm{CH}\left(\mathrm{CH}_{3}\right)_{2}\right] .{ }^{13} \mathrm{C} \mathrm{NMR}\left(125 \mathrm{MHz}, \mathrm{CDCl}_{3}\right): \delta 165.1(\mathrm{CO}), 152.1(\mathrm{C}-2), 151.4(\mathrm{C}-4), 151.1(\mathrm{C}-6)$, 144.1 (C-8), 134.1 (Ar-C), 131.7 (C-5), 129.9, 128.7, 128.4 (Ar-C), $88.3\left(\mathrm{C}-1^{\prime}\right), 83.69$ (d, ${ }^{3} J_{\mathrm{P}, \mathrm{C}}=$ $\left.\left.9.5 \mathrm{~Hz}, \mathrm{C}-3^{\prime}\right), 80.1\left(\mathrm{C}-2^{\prime}\right), 73.8\left(\mathrm{C}-4^{\prime}\right), 71.5\left[\mathrm{CH}_{(\mathrm{CH}}\right)_{2}\right], 64.8\left(\mathrm{~d},{ }^{1} J_{\mathrm{P}, \mathrm{C}}=168.8 \mathrm{~Hz}, \mathrm{PCH}_{2}\right), 24.0$ $\left[\mathrm{CH}\left(\mathrm{CH}_{3}\right)_{2}\right] .{ }^{31} \mathrm{P} \mathrm{NMR}\left(121 \mathrm{MHz}, \mathrm{CDCl}_{3}\right): \delta 17.5$. HRMS: $[\mathrm{M}+\mathrm{H}]^{+}$calcd for $\mathrm{C}_{23} \mathrm{H}_{29} \mathrm{ClN}_{4} \mathrm{O}_{7} \mathrm{P}$, 
539.1457; found, 539.1455.

1'a-(Hypoxantin-9-yl)-3'-O-diisopropylphosphonomethyl-L-threose (5). A solution of 4 (40 mg, $0.074 \mathrm{mmol}$ ), 2-mercaptoethanol (23 mg, $0.30 \mathrm{mmol})$ and NaOMe (16 mg, $0.30 \mathrm{mmol})$ in 1.5 $\mathrm{mL}$ of dry $\mathrm{MeOH}$ was heated at $66^{\circ} \mathrm{C}$ for $20 \mathrm{~h}$. The reaction mixture was cooled to $\mathrm{rt}$ and concentrated under reduced pressure. The residue was purified by column chromatography (20:1 to $\left.10: 1, \mathrm{CH}_{2} \mathrm{Cl}_{2} / \mathrm{MeOH}\right)$ to obtain 5 (24 mg, 78\%) as a colorless oil. ${ }^{1} \mathrm{H}$ NMR (600 MHz, MeOD): $\delta 8.18(\mathrm{~s}, 1 \mathrm{H}, \mathrm{H}-8), 8.08(\mathrm{~s}, 1 \mathrm{H}, \mathrm{H}-2), 6.05$ (d, J=1.4 Hz, 1H, H-1'), 4.70-4.62 [m, 2H, CH( $\left.\left.\mathrm{CH}_{3}\right)_{2}\right]$, 4.64 (s, 1H, H-2'), 4.41 (d, $J=10.4$ Hz, 1H, H-4a'), 4.28 (dd, $J=10.4,4.1$ Hz, H-4b'), 4.19-4.17 $\left(\mathrm{m}, 1 \mathrm{H}, \mathrm{H}-3\right.$ ') $, 3.95-3.84\left(\mathrm{~m}, 2 \mathrm{H}, \mathrm{PCH} \mathrm{H}_{2}\right), 1.33-1.26\left[\mathrm{~m}, 12 \mathrm{H}, \mathrm{CH}\left(\mathrm{CH}_{3}\right)_{2}\right] .{ }^{13} \mathrm{C} \mathrm{NMR}(150 \mathrm{MHz}$, MeOD): $\delta 158.9$ (C-6), 149.6 (C-4), 146.8 (C-2), 140.5 (C-8), 125.3 (C-5), 92.4 (C-1'), 87.5 (d, $\left.{ }^{3} J_{\mathrm{P}, \mathrm{C}}=12.1 \mathrm{~Hz}, \mathrm{C}-3^{\prime}\right), 80.1\left(\mathrm{C}-2^{\prime}\right), 74.0\left(\mathrm{C}-4^{\prime}\right), 73.3\left[\mathrm{CH}\left(\mathrm{CH}_{3}\right)_{2}\right], 64.9\left(\mathrm{~d},{ }^{1} J_{\mathrm{P}, \mathrm{C}}=168.9 \mathrm{~Hz}, \mathrm{PCH}_{2}\right)$, $24.3\left[\mathrm{CH}\left(\mathrm{CH}_{3}\right)_{2}\right] .{ }^{31} \mathrm{P}$ NMR (121 MHz, MeOD): $\delta$ 19.2. HRMS: $[\mathrm{M}+\mathrm{H}]^{+}$calcd for $\mathrm{C}_{16} \mathrm{H}_{26} \mathrm{~N}_{4} \mathrm{O}_{7} \mathrm{P}$, 417.1533; found, 417.1531.

1' $\alpha$-(Hypoxantin-9-yl)-2'-deoxy-3'-O-diisopropylphosphonomethyl-L-threose (6). Tо а solution of $5(0.27 \mathrm{~g}, 0.65 \mathrm{mmol})$ and DMAP (24 mg, $0.19 \mathrm{mmol})$ in anhydrous $\mathrm{CH}_{2} \mathrm{Cl}_{2}(13 \mathrm{~mL})$ was added 1,1'-thiocarbonyldiimidazole (TCDI) $(0.23 \mathrm{~g}, 1.30 \mathrm{mmol})$ at $\mathrm{rt}$. The reaction mixture was stirred at $\mathrm{rt}$ for overnight. The reaction mixture was washed with brine, dried over $\mathrm{Na}_{2} \mathrm{SO}_{4}$, and concentrated under reduced pressure. To the residue in toluene $(13 \mathrm{ml})$ was added azobisisobutyronitrile (AIBN) $(43 \mathrm{mg}, 0.26 \mathrm{mmol})$ and tributytin hydride $(0.70 \mathrm{ml}, 2.59 \mathrm{mmol})$. The reaction mixture was refluxed for $20 \mathrm{~min}$. The solvent was removed under reduced pressure and the residue was purified by column chromatography (20:1 to $\left.10: 1, \mathrm{CH}_{2} \mathrm{Cl}_{2} / \mathrm{MeOH}\right)$ to afford $6\left(0.23 \mathrm{~g}, 89 \%\right.$ yield) as a colorless oil. ${ }^{1} \mathrm{H} \mathrm{NMR}\left(300 \mathrm{MHz}, \mathrm{CDCl}_{3}\right): \delta 8.30(\mathrm{~s}, 1 \mathrm{H}, \mathrm{H}-8), 8.12(\mathrm{~s}$, $1 \mathrm{H}, \mathrm{H}-2), 6.42$ (dd, $\left.J=7.7,1.9 \mathrm{~Hz}, 1 \mathrm{H}, \mathrm{H}-1^{\prime}\right), 4.81-4.66\left[\mathrm{~m}, 2 \mathrm{H}, \mathrm{CH}\left(\mathrm{CH}_{3}\right)_{2}\right], 4.46-4.43(\mathrm{~m}, 1 \mathrm{H}$, H-3'), 4.35 (d, $J=10.5$ Hz, 1H, H-4a'), 4.05 (dd, $\left.J=10.5,4.1 \mathrm{~Hz}, \mathrm{H}-4 \mathrm{~b}^{\prime}\right), 3.82-3.69$ (m, 2H, PCH2), 2.74-2.55 (m, 2H, H-2'),1.34-1.29 [m, 12H, CH(CH3)2]. ${ }^{13} \mathrm{C}$ NMR (75 MHz, $\left.\mathrm{CDCl}_{3}\right): \delta 158.6(\mathrm{C}-$ 6), 148.5 (C-4), 145.2 (C-2), 139.0 (C-8), 124.4 (C-5), 83.6 (C-1'), 80.5 (d, $\left.{ }^{3} J_{\mathrm{P}, \mathrm{C}}=11.8 \mathrm{~Hz}, \mathrm{C}-3^{\prime}\right)$, $73.7\left(\mathrm{C}-4^{\prime}\right), 71.7\left[\mathrm{CH}\left(\mathrm{CH}_{3}\right)_{2}\right], 64.1\left(\mathrm{~d},{ }^{1} \mathrm{~J}_{\mathrm{P}, \mathrm{C}}=169.6 \mathrm{~Hz}, \mathrm{PCH} 2\right), 38.6\left(\mathrm{C}-2^{\prime}\right), 23.9\left[\mathrm{CH}\left(\mathrm{CH}_{3}\right)_{2}\right] .{ }^{31} \mathrm{P}$ NMR (121 MHz, $\left.\mathrm{CDCl}_{3}\right): \delta$ 18.8. HRMS: $[\mathrm{M}+\mathrm{H}]^{+}$calcd for $\mathrm{C}_{16} \mathrm{H}_{26} \mathrm{~N}_{4} \mathrm{O}_{6} \mathrm{P}, 401.1584$; found, 401.1585 .

1' $\alpha$-(Hypoxantin-9-yl)-2' -deoxy-3'-O-phosphonomethyl-L-threose (7). To a solution of 6 (0.23 $\mathrm{g}, 0.57 \mathrm{mmol})$ and 2,6-lutidine $(0.54 \mathrm{~mL}, 4.60 \mathrm{mmol})$ in dry $\mathrm{CH}_{3} \mathrm{CN}(12 \mathrm{~mL})$ was added 
bromotrimethylsilane $(0.61 \mathrm{~mL}, 4.60 \mathrm{mmol})$ at $0{ }^{\circ} \mathrm{C}$. The reaction mixture was stirred at $\mathrm{rt}$ for overnight and quenched with 1.0 M TEAB buffer $(2 \mathrm{~mL})$. The solvent was removed under reduced pressure. The residue was partitioned between water and EtOAc (1:1), the water layer was lyophilized and the residue was first purified by chromatography on a silica gel column (10:1:0 to 10:5:1, $\mathrm{CH}_{2} \mathrm{Cl}_{2} / \mathrm{MeOH} / 1 \mathrm{M}$ TEAB) to give the crude product. Further purification using preparative reverse phase $\mathrm{HPLC}$ with gradient $\mathrm{CH}_{3} \mathrm{CN}$ in $0.05 \mathrm{M} \mathrm{TEAB}$ solution from $2 \%$ to $30 \%$ gave 7 (96 mg, 40\%) as a white foam. ${ }^{1} \mathrm{H}$ NMR (300 MHz, $\left.\mathrm{D}_{2} \mathrm{O}\right): \delta 8.55$ (s, $\left.1 \mathrm{H}, \mathrm{H}-8\right), 8.19(\mathrm{~s}, 1 \mathrm{H}$, H-2), 6.42 (dd, $J=8.0,2.3 \mathrm{~Hz}, 1 \mathrm{H}, \mathrm{H}-1^{\prime}$ ), 4.55 (brs, 1H, H-3'), 4.36 (d, $J=10.0 \mathrm{~Hz}, 1 \mathrm{H}, \mathrm{H}-4 \mathrm{a}^{\prime}$ ), 4.09 (dd, $\left.J=10.0,4.2 \mathrm{~Hz}, \mathrm{H}-4 \mathrm{~b}^{\prime}\right), 3.55-3.51$ (m, 2H, PCH $), 2.85-2.65$ (m, 2H, H-2'). ${ }^{13} \mathrm{C}$ NMR (75 MHz, $\mathrm{D}_{2} \mathrm{O}$ ): $\delta 159.6$ (C-6), 149.1 (C-4), 146.8 (C-2), 141.6 (C-8), 123.9 (C-5), 84.4 (C-1'), $80.0\left(\mathrm{~d},{ }^{3} J_{\mathrm{P}, \mathrm{C}}=10.4 \mathrm{~Hz}, \mathrm{C}-3^{\prime}\right), 74.4\left(\mathrm{C}-4^{\prime}\right), 67.3\left(\mathrm{~d},{ }^{1} J_{\mathrm{P}, \mathrm{C}}=150.7 \mathrm{~Hz}, \mathrm{PCH}_{2}\right), 37.6\left(\mathrm{C}-2^{\prime}\right) .{ }^{31} \mathrm{P}$ NMR (121 MHz, $\mathrm{D}_{2} \mathrm{O}$ ): $\delta$ 13.4. HRMS: [M-H] ${ }^{-}$calcd for $\mathrm{C}_{10} \mathrm{H}_{12} \mathrm{~N}_{4} \mathrm{O}_{6} \mathrm{P}, 315.0500$; found, 315.0486 .

\section{1' $\alpha$-(Hypoxanthin-9-yl)-2'-deoxy-3'- $O$-[N, $N^{\prime}$-bis( $n$-propyl-L-}

phenylalaninate)]methylphosphonobisamidate]-L-threose (8). To a mixture of 7 (30 mg, 0.072 $\mathrm{mmol}, \mathrm{Et}_{3} \mathrm{~N}$ salt) and $(S)$-phenylalanine- $O-n$-Pr ester hydrochloride $(105 \mathrm{mg}, 0.43 \mathrm{mmol})$ in anhydrous pyridine $(2 \mathrm{~mL})$ was added $\mathrm{Et}_{3} \mathrm{~N}(0.1 \mathrm{~mL})$. The resultant mixture was stirred at $60{ }^{\circ} \mathrm{C}$ under argon. In a separate flask, 2,2'-dithiodipyridine $(111 \mathrm{mg}, 0.50 \mathrm{mmol})$ and $\mathrm{PPh}_{3}(132 \mathrm{mg}$, $0.50 \mathrm{mmol}$ ) were dissolved in anhydrous pyridine $(1 \mathrm{~mL})$ and stirred at $\mathrm{rt}$ for $15 \mathrm{~min}$ to give a light yellow solution, this reagent solution was then added to the solution of $\mathbf{7}$ in one portion. The reaction mixture was stirred at $60{ }^{\circ} \mathrm{C}$ for overnight under argon and then concentrated under reduced pressure. The resultant residue was first purified by chromatography on a silica gel column (20:1 to $10: 1, \mathrm{DCM} / \mathrm{MeOH}$ ) and then by preparative reverse phase HPLC (linear gradient, 3095\% $\mathrm{CH}_{3} \mathrm{CN}$ in water to give 8 as a white solid (30 mg, 60\%). ${ }^{1} \mathrm{H}$ NMR (300 MHz, acetone- $\left.d_{6}\right): \delta$ 8.26 (s, 1H, H-8), 8.06 (s, 1H, H-2), 7.33-7.15 (m, 10H, ArH), 6.36 (dd, $J=7.8,1.8$ Hz, 1H, H1'), 4.37-4,31 (m, 2H, H-4a' and H-3'), 4.30-4.19 (m, 1H, Phe-CH), 4.10-3.93 (m, 6H, H-4b', Phe- $\mathrm{CH}$ and $\left.\mathrm{OCH}_{2} \mathrm{CH}_{2} \mathrm{CH}_{3}\right), 3.82(\mathrm{t}, J=11.2 \mathrm{~Hz}, 1 \mathrm{H}, \mathrm{NH}), 3.56-3.31\left(\mathrm{~m}, 3 \mathrm{H}, \mathrm{PCH}_{2}\right.$ and $\left.\mathrm{NH}\right)$, 3.16-2.76 (m, 4H, Phe-CH $\mathrm{CH}_{2}$, 2.76-2.67 (m, 1H, H-2a'), 2.45 (d, J = 14.7 Hz, 1H, H-2b'), 1.68 $1.54\left(\mathrm{~m}, 4 \mathrm{H}, \mathrm{OCH}_{2} \mathrm{CH}_{2} \mathrm{CH}_{3}\right), 0.93-0.86\left(\mathrm{~m}, 6 \mathrm{H}, \mathrm{OCH}_{2} \mathrm{CH}_{2} \mathrm{CH}_{3}\right) .{ }^{13} \mathrm{C} \mathrm{NMR}$ (75 MHz, acetone- $\left.d_{6}\right)$ : 174.2, 173.5 (Phe-CO), 157.3 (C-6), 148.9 (C-4), 146.1 (C-2), 139.6 (C-8), 138.5, 138.1, 130.64, 130.61, 129.2, 129.0, 127.41, $127.35(\mathrm{Ar}-\mathrm{C}), 125.7(\mathrm{C}-5), 85.0\left(\mathrm{C}-1^{\prime}\right), 81.3\left(\mathrm{~d},{ }^{3} J_{\mathrm{P}, \mathrm{C}}=12.1 \mathrm{~Hz}, \mathrm{C}-\right.$ 3'), $74.3\left(\mathrm{C}-4^{\prime}\right), 67.1\left(\mathrm{OCH}_{2} \mathrm{CH}_{2} \mathrm{CH}_{3}\right), 66.8\left(\mathrm{~d},{ }^{1} J_{\mathrm{P}, \mathrm{C}}=136.3 \mathrm{~Hz}, \mathrm{PCH}_{2}\right), 55.4,54.8$ (Phe-CH), 41.2, 
41.1 (Phe- $\left.\mathrm{CH}_{2}\right), 39.6\left(\mathrm{C}-2^{\prime}\right)$, $22.6\left(\mathrm{OCH}_{2} \mathrm{CH}_{2} \mathrm{CH}_{3}\right), 10.7\left(\mathrm{OCH}_{2} \mathrm{CH}_{2} \mathrm{CH}_{3}\right) .{ }^{31} \mathrm{P}$ NMR (121 MHz, acetone- $d_{6}$ ): $\delta$ 19.7. HRMS: $[\mathrm{M}+\mathrm{H}]^{+}$calcd for $\mathrm{C}_{34} \mathrm{H}_{44} \mathrm{~N}_{6} \mathrm{O}_{8} \mathrm{P}, 695.2953$; found, 695.2966.

4-Benzoylamino-3-(2'-O-benzoyl-3'-O-tert-butyldimethylsilyl- $\alpha$-L-threofuranosyl)-7Hpyrrolo[2,3-d]pyrimidine (11). A solution of 1 (130 $\mathrm{mg}, 0.34 \mathrm{mmol})$ and $7 H$-pyrrolo[2,3d] pyrimidin-4-benzamide ( $90 \mathrm{mg}, 0.38 \mathrm{mmol})$ in $2 \mathrm{~mL}$ of dry toluene was treated with BSA $(0.18$ $\mathrm{mL}, 0.75 \mathrm{mmol})$. The reaction mixture was stirred at $\mathrm{rt}$ for $0.5 \mathrm{~h}$, and then TMSOTf $(0.10 \mathrm{~mL}, 0.51$ mmol) was added. The resulting reaction mixture was stirred at $95{ }^{\circ} \mathrm{C}$ for $1.5 \mathrm{~h}$. The reaction mixture was cooled to rt and poured into an ice-cold stirred mixture of sat. aq. $\mathrm{NaHCO}_{3}$ and AcOEt. The organic layer was separated and washed with brine, dried over $\mathrm{Na}_{2} \mathrm{SO}_{4}$, and concentrated under reduced pressure. The residue was purified by column chromatography $\left(5: 1 \mathrm{CH}_{2} \mathrm{Cl}_{2} / \mathrm{EtOAc}\right)$ to obtain 11 (120 mg, 63\% yield) as a white foam. ${ }^{1} \mathrm{H}$ NMR (500 MHz, $\left.\mathrm{CDCl}_{3}\right): \delta 10.85(\mathrm{~s}, 1 \mathrm{H}$, $\mathrm{NH}$ ), 8.80 (s, 1H, H-2), 8.35-8.34 (m, 4H, ArH), 7.87-7.31 (m, 6H, ArH), 7.22 (s, 1H, H-6), 7.06 (s, 1H, H-1') 7.04 (s, 1H, H-5), 5.90 (s, 1H, H-2'), 4.75-4.65 (m, 3H, H-3' and H-4'), 1.07 [s, 9H, $\left.\mathrm{C}\left(\mathrm{CH}_{3}\right)_{3}\right], 0.43$ (s, $\left.\left.3 \mathrm{H}, \mathrm{SiCH}\right)_{3}\right), 0.28$ (s, 3H, $\left.\mathrm{SiCH}_{3}\right) .{ }^{13} \mathrm{C} \mathrm{NMR}\left(125 \mathrm{MHz}, \mathrm{CDCl}_{3}\right): \delta 174.3(\mathrm{CO})$, 165.2 (CO), 152.0 (C-4), 147.3 (C-7a), 142.2 (C-2), 137.3, 133.6, 131.2, 129.9, 129.3, 129.0, 128.5, 127.7 (Ar-C), 120.8 (C-6), 107.0 (C-5), 105.3 (C-4a), 92.2 (C-1'), 82.7 (C-2'), 77.6 (C-4'), 74.6 $\left(\mathrm{C}-3^{\prime}\right), 25.5\left[\mathrm{C}\left(\mathrm{CH}_{3}\right)_{3}\right], 17.8\left[\mathrm{C}\left(\mathrm{CH}_{3}\right)_{3}\right],-4.9,-5.5\left(\mathrm{SiCH}_{3}\right)$. HRMS: $[\mathrm{M}+\mathrm{H}]^{+}$calcd for $\mathrm{C}_{30} \mathrm{H}_{35} \mathrm{~N}_{4} \mathrm{O}_{5} \mathrm{Si}$, 559.2371; found, 559.2388.

\section{4-Benzoylamino-3-(3'-O-tert-butyldimethylsilyl- $\alpha$-L-threofuranosyl)-7H-pyrrolo[2,3-}

d]pyrimidine (12). To a solution of $11(100 \mathrm{mg}, 0.18 \mathrm{mmol})$ in $3.6 \mathrm{~mL}$ of THF/MeOH/ $\mathrm{H}_{2} \mathrm{O}(5: 4: 1)$ was added $2 \mathrm{M}$ aq. $\mathrm{NaOH}(0.18 \mathrm{~mL}, 0.36 \mathrm{mmol})$ at $0{ }^{\circ} \mathrm{C}$. The reaction mixture was stirred at $0{ }^{\circ} \mathrm{C}$ for $4 \mathrm{~h}$. The reaction mixture was neutralized with acetic acid and the solvent was removed under reduced pressure. The residue was then portioned between water and ethyl acetate. The organic layer was washed with brine, dried over $\mathrm{Na}_{2} \mathrm{SO}_{4}$ and concentrated. The residue was purified by column chromatography (5:1 to 5:2, $\mathrm{CH}_{2} \mathrm{Cl}_{2} / \mathrm{EtOAc}$ ) to give $\mathbf{1 2}(64 \mathrm{mg}, 79 \%)$ as a white powder. ${ }^{1} \mathrm{H}$ NMR (600 MHz, CDCl $): \delta 10.58$ (s, 1H, NH), 8.44 (s, 1H, H-2), 8.20-8.17 (m, 2H, $\operatorname{Ar} H$ ), 7.51-7.48 (m, 1H, ArH), 7.45-7.41 (m, 2H, ArH), 6.93 (dd, $J=3.5,2.4$ Hz, 1H, H-6), 6.62 (dd, $J$ $=3.5,2.2 \mathrm{~Hz}, 1 \mathrm{H}, \mathrm{H}-5), 6.25$ (d, $J=1.0 \mathrm{~Hz}, 1 \mathrm{H}, \mathrm{H}-1^{\prime}$ ), 4.39 (brs, $1 \mathrm{H}, \mathrm{H}-2^{\prime}$ ), 4.37 (dd, $J=9.5,3.6$ $\left.\mathrm{Hz}, 1 \mathrm{H}, \mathrm{H}-4 \mathrm{a}^{\prime}\right), 4.33-4.31$ (m, 1H, H-3'), 4.24 (d, J = 9.5 Hz, 1H, H-4b'), 0.78 [s, 9H, C(CH3) ${ }_{3}$, 0.08 (s, 3H, $\left.\mathrm{SiCH}_{3}\right),-0.03$ (s, 3H, $\left.\mathrm{SiCH}_{3}\right) .{ }^{13} \mathrm{C} \mathrm{NMR}\left(150 \mathrm{MHz}, \mathrm{CDCl}_{3}\right): \delta 175.0(\mathrm{CO}), 151.7(\mathrm{C}-$ 4), 147.1 (C-7a), 141.4 (C-2), 136.8, 131.8, 129.4, 128.2 (Ar-C), 121.1 (C-6), 106.3 (C-5), 105.2 
(C-4a), $95.6\left(\mathrm{C}-1^{\prime}\right), 82.8\left(\mathrm{C}-2^{\prime}\right), 76.7\left(\mathrm{C}-4^{\prime}\right), 76.4\left(\mathrm{C}-3^{\prime}\right), 25.5\left[\mathrm{C}\left(\mathrm{CH}_{3}\right)_{3}\right], 17.8\left[\mathrm{C}\left(\mathrm{CH}_{3}\right)_{3}\right],-5.0,-$ $5.2\left(\mathrm{SiCH}_{3}\right)$. HRMS: $[\mathrm{M}+\mathrm{H}]^{+}$calcd for $\mathrm{C}_{23} \mathrm{H}_{31} \mathrm{~N}_{4} \mathrm{O}_{4} \mathrm{Si}, 455.2109$; found, 455.2100.

4-Chloro-5-iodo-7-(2'-O-benzoyl-3'-O-tert-butyldimethylsilyl- $\alpha$-L-threofuranosyl)-7Hpyrrolo[2,3- $d]$ pyrimidine (13). This compound was prepared as described for 2 . Obtained from sugar $1(0.25 \mathrm{~g}, 0.66 \mathrm{mmol})$ and 4-chloro-5-iodo-7H-pyrrolo[2,3-d]pyrimidine 6-chloropurine (202 $\mathrm{mg}, 0.72 \mathrm{mmol})$ as a white solid. Yield 52\% (0.20 g).

${ }^{1} \mathrm{H}$ NMR (600 MHz, $\mathrm{CDCl}_{3}$ ): $\delta 8.60$ (s, 1H, H-2), 8.09-8.06 (m, $\left.2 \mathrm{H}, \mathrm{ArH}\right), 8.00$ (s, 1H, H-6), 7.64-7.60 (m, 1H, ArH), 7.50-7.46 (m, 2H, ArH), 6.67 (d, $\left.J=0.7 \mathrm{~Hz}, 1 \mathrm{H}, \mathrm{H}-1^{\prime}\right), 5.43$ (d, $J=0.8$ Hz, 1H, H-2'), 4.51-4.49 (m, 1H, H-3'), 4.30 (dd, $\left.J=10.0,3.6 \mathrm{~Hz}, 1 \mathrm{H}, \mathrm{H}-4 \mathrm{a}^{\prime}\right), 4.24$ (d, $J=9.8 \mathrm{~Hz}$, 1H, H-4b'), 0.95 [s, 9H, C(CH3) 3 ], 0.19 (s, 3H, $\left.\mathrm{SiCH}_{3}\right), 0.14$ (s, 3H, $\left.\mathrm{SiCH}_{3}\right) .{ }^{13} \mathrm{C}$ NMR (150 MHz, $\mathrm{CDCl}_{3}$ ): $\delta 165.0(\mathrm{CO}), 152.5$ (C-4), 150.9 (C-2), 150.5 (C-7a), 133.8 (Ar-C), 133.3 (C-6), 129.9, 128.7, 128.6 (Ar-C), 117.2 (C-4a), 88.1 (C-1'), 83.1 (C-2'), 76.5 (C-4'), 75.2 (C-3'), 52.0 (C-5), $25.7\left[\mathrm{C}\left(\mathrm{CH}_{3}\right)_{3}\right], 18.0\left[\mathrm{C}\left(\mathrm{CH}_{3}\right)_{3}\right],-4.9,-5.2\left(\mathrm{SiCH}_{3}\right)$. HRMS: $[\mathrm{M}+\mathrm{H}]^{+}$calcd for $\mathrm{C}_{23} \mathrm{H}_{28} \mathrm{ClIN}_{3} \mathrm{O}_{4} \mathrm{Si}$, 600.0579; found, 600.0602 .

\section{4-Chloro-7-(3'-O-tert-butyldimethylsilyl- $\alpha$-L-threofuranosyl)-7H-pyrrolo[2,3- $d]$ pyrimidine}

(14). A solution of iodonucleoside $13(3.80 \mathrm{~g}, 6.33 \mathrm{mmol})$ in $40 \mathrm{~mL}$ of anhydrous THF was dropwise added $i \mathrm{PrMgCl} \cdot \mathrm{LiCl}(1.3 \mathrm{M}$ in $\mathrm{THF}, 6.1 \mathrm{~mL}, 7.92 \mathrm{mmol})$ at $-78{ }^{\circ} \mathrm{C}$ and the reaction mixture was stirred at the same temperature for $20 \mathrm{~min}$. The reaction was quenched by dropwise addition of isopropanol $(0.68 \mathrm{~mL}, 8.87 \mathrm{mmol})$. The reaction mixture was poured into an ice-cold mixture of AcOEt and sat. aq. $\mathrm{NH}_{4} \mathrm{Cl}$. The organic layer was separated and washed with brine, dried over $\mathrm{Na}_{2} \mathrm{SO}_{4}$, and concentrated under reduced pressure. To the residue, $100 \mathrm{~mL}$ of $7 \mathrm{~N} \mathrm{NH}_{3}$ in $\mathrm{MeOH}$ was added and the resultant mixture was stirred at $\mathrm{rt}$ for overnight. The volatiles were evaporated and the residue was purified by column chromatography (2:1 Hexane/EtOAc) to obtain 14 (2.13 g, 91\% yield) as a colorless oil. ${ }^{1} \mathrm{H}$ NMR (300 MHz, $\left.\mathrm{CDCl}_{3}\right): \delta 8.58(\mathrm{~s}, 1 \mathrm{H}, \mathrm{H}-2), 7.63$ (d, $J=3.7 \mathrm{~Hz}, 1 \mathrm{H}, \mathrm{H}-6$ ), 6.57 (d, $J=3.7 \mathrm{~Hz}, 1 \mathrm{H}, \mathrm{H}-5$ ), 6.25 (s, 1H, H-1'), 4.68 (brs, 1H, OH), 4.38-4.36 (m, 2H, H-2' and H-3'), 4.32 (dd, $\left.J=9.5,4.0 \mathrm{~Hz}, 1 \mathrm{H}, \mathrm{H}-4 \mathrm{a}^{\prime}\right), 4.16(\mathrm{~d}, J=9.5 \mathrm{~Hz}, 1 \mathrm{H}$, $\left.\mathrm{H}-4 \mathrm{~b}^{\prime}\right), 0.83$ [s, 9H, C(CH3) 3 ], 0.10 (s, 3H, $\left.\mathrm{SiCH}_{3}\right), 0.01$ (s, 3H, $\left.\mathrm{SiCH}_{3}\right) .{ }^{13} \mathrm{C} \mathrm{NMR}(75 \mathrm{MHz}$, $\mathrm{CDCl}_{3}$ ): $\delta 152.1$ (C-4), 150.2 (C-2), 150.0 (C-7a), 127.7 (C-6), 118.4 (C-4a), 99.4 (C-5), 91.6 (C1'), $82.4\left(\mathrm{C}-2^{\prime}\right), 76.8\left(\mathrm{C}-3^{\prime}\right), 75.8\left(\mathrm{C}-4^{\prime}\right), 25.6\left[\mathrm{C}\left(\mathrm{CH}_{3}\right)_{3}\right], 17.9\left[\mathrm{C}\left(\mathrm{CH}_{3}\right)_{3}\right],-4.9,-5.0\left(\mathrm{SiCH}_{3}\right)$. HRMS: [M+H] $]^{+}$calcd for $\mathrm{C}_{16} \mathrm{H}_{25} \mathrm{ClN}_{3} \mathrm{O}_{3} \mathrm{Si}, 370.1348$; found, 370.1349 .

\section{4-Chloro-7-(2'-deoxy-3'-O-tert-butyldimethylsilyl- $\alpha$-L-threofuranosyl)-7H-pyrrolo[2,3-}


d]pyrimidine (15). This compound was prepared as described for 6. Obtained from 14 (2.23 g, $6.03 \mathrm{mmol})$ as a colorless oil. Yield 80\% (1.70 g). ${ }^{1} \mathrm{H}$ NMR $\left(300 \mathrm{MHz}, \mathrm{CDCl}_{3}\right): \delta 8.59(\mathrm{~s}, 1 \mathrm{H}, \mathrm{H}-$ 2), 7.85 (d, $J=3.8 \mathrm{~Hz}, 1 \mathrm{H}, \mathrm{H}-6), 6.69$ (dd, $\left.J=8.2,2.2 \mathrm{~Hz}, 1 \mathrm{H}, \mathrm{H}-1^{\prime}\right), 6.56$ (d, $J=3.8 \mathrm{~Hz}, 1 \mathrm{H}, \mathrm{H}-$ 5), 4.61-4.56 (m, 1H, H-3'), 4.07-3.98 (m, 2H, H-4'), 2.72-2.62 (m, 1H, H-2a'), 2.27-2.21 (m, 1H, $\left.\mathrm{H}-2 b^{\prime}\right), 0.87$ [s, 9H, C(CH3) $], 0.08$ (s, 3H, SiCH $H_{3}, 0.03$ (s, 3H, SiCH3). ${ }^{13} \mathrm{C} \mathrm{NMR} \mathrm{(75} \mathrm{MHz,}$ $\left.\mathrm{CDCl}_{3}\right): \delta 151.7$ (C-4), 150.9 (C-7a), 150.5 (C-2), 127.8 (C-6), 117.9 (C-4a), 99.6 (C-5), 83.6 (C$\left.1^{\prime}\right), 77.0\left(\mathrm{C}-4^{\prime}\right), 71.3\left(\mathrm{C}-3^{\prime}\right), 41.6\left(\mathrm{C}-2^{\prime}\right), 25.6\left[\mathrm{C}\left(\mathrm{CH}_{3}\right)_{3}\right], 17.9\left[C\left(\mathrm{CH}_{3}\right)_{3}\right],-5.00,-5.03\left(\mathrm{SiCH}_{3}\right)$. HRMS: $[\mathrm{M}+\mathrm{H}]^{+}$calcd for $\mathrm{C}_{16} \mathrm{H}_{25} \mathrm{ClN}_{3} \mathrm{O}_{2} \mathrm{Si}$, 354.1399; found, 354.1396.

4-Chloro-7-(2'-deoxy- $\alpha$-L-threofuranosyl)-7H-pyrrolo[2,3- $d]$ pyrimidine (16). This compound was prepared as described for 3. Obtained from $15(1.70 \mathrm{~g}, 4.80 \mathrm{mmol})$ as a white solid. Yield 83\% (0.95 g). ${ }^{1} \mathrm{H}$ NMR (300 MHz, $\left.\mathrm{CDCl}_{3}\right): \delta 8.62$ (s, 1H, H-2), 7.59 (d, J=3.7 Hz, 1H, H-6), 6.61 (d, $J=3.7 \mathrm{~Hz}, 1 \mathrm{H}, \mathrm{H}-5), 6.25$ (dd, $\left.J=9.1,2.9 \mathrm{~Hz}, 1 \mathrm{H}, \mathrm{H}-1^{\prime}\right), 4.64-4.61$ (m, 1H, H-3'), 4.21-4.17 (m, 1H, H-4a'), 3.94 (dd, $J=9.9,3.8$ Hz, 1H, H-4b'), 2.87-2.77 (m, 1H, H-2a'), 2.55-2.48 (m, 1H, H2b'). ${ }^{13} \mathrm{C}$ NMR (75 MHz, $\left.\mathrm{CDCl}_{3}\right): \delta 152.5$ (C-4), 149.7 (C-2), 149.4 (C-7a), 129.7 (C-6), 119.2 (C4a), 99.7 (C-5), $86.3\left(\mathrm{C}-1^{\prime}\right), 76.9\left(\mathrm{C}-4^{\prime}\right), 70.6\left(\mathrm{C}-3^{\prime}\right), 40.5\left(\mathrm{C}-2^{\prime}\right)$. HRMS: $[\mathrm{M}+\mathrm{H}]^{+}$calcd for $\mathrm{C}_{10} \mathrm{H}_{11} \mathrm{ClN}_{3} \mathrm{O}_{2}, 240.0534$; found, 240.0532 .

\section{4-Chloro-7-(2'-deoxy-3'-O-diisopropylphosphonomethyl- $\alpha$-L-threofuranosyl)-7H-}

pyrrolo[2,3- $d]$ pyrimidine (17). This compound was prepared as described for 4 . Obtained from $16(0.45 \mathrm{~g}, 1.88 \mathrm{mmol})$ as a colorless oil. Yield 84\% (0.66 g). ${ }^{1} \mathrm{H}$ NMR (300 MHz, DMSO- $\left.d_{6}\right): \delta$ 8.64 (s, 1H, H-2), 7.93 (d, J=3.7 Hz, 1H, H-6), 6.68-6.62 (m, 2H, H-5 and H-1'), 4.71-4.55 [m, $\left.2 \mathrm{H}, \mathrm{CH}\left(\mathrm{CH}_{3}\right)_{2}\right], 4.42-4.38$ (m, 1H, H-3'), 4.24 (d, J=10.4 Hz, 1H, H-4a'), 3.94-3.78 (m, 3H, H$4 \mathrm{~b}^{\prime}$ and $\left.\mathrm{PCH}_{2}\right), 2.84-2.74\left(\mathrm{~m}, 1 \mathrm{H}, \mathrm{H}-2 \mathrm{a}^{\prime}\right), 2.35$ (d, $\left.J=15.1 \mathrm{~Hz}, 1 \mathrm{H}, \mathrm{H}-2 \mathrm{~b}^{\prime}\right), 1.28-1.23$ [m, 12H, $\left.\mathrm{CH}\left(\mathrm{CH}_{3}\right)_{2}\right] .{ }^{13} \mathrm{C}$ NMR (75 MHz, DMSO-d6): $\delta 150.7$ (C-4), 150.6 (C-7a), $150.5(\mathrm{C}-2), 128.8(\mathrm{C}-$ 6), 117.0 (C-4a), $99.4(\mathrm{C}-5), 82.9\left(\mathrm{C}-1^{\prime}\right), 80.3\left(\mathrm{~d},{ }^{3} J_{\mathrm{P}, \mathrm{C}}=13.5 \mathrm{~Hz}, \mathrm{C}-3{ }^{\prime}\right), 72.8\left(\mathrm{C}-4^{\prime}\right), 70.3,70.2$ $\left[\mathrm{CH}\left(\mathrm{CH}_{3}\right)_{2}\right], 63.3\left(\mathrm{~d},{ }^{1} \mathrm{~J}_{\mathrm{P}, \mathrm{C}}=166.2 \mathrm{~Hz}, \mathrm{PCH}\right), 37.8\left(\mathrm{C}-2^{\prime}\right), 23.8\left[\mathrm{CH}\left(\mathrm{CH}_{3}\right)_{2}\right] .{ }^{31} \mathrm{P} \mathrm{NMR}(121 \mathrm{MHz}$, DMSO- $d_{6}$ ): $\delta$ 19.3. HRMS: $[\mathrm{M}+\mathrm{H}]^{+}$calcd for $\mathrm{C}_{17} \mathrm{H}_{26} \mathrm{ClN}_{3} \mathrm{O}_{5} \mathrm{P}, 418.1293$; found, 418.1292 .

\section{4-Amino-7-(2'-deoxy-3'-O-diisopropylphosphonomethyl- $\alpha$-L-threofuranosyl)-7H-}

pyrrolo[2,3-d $]$ pyrimidine (18). A mixture of $17(0.60 \mathrm{~g}, 1.44 \mathrm{mmol})$ in $50 \mathrm{~mL}$ of $7 \mathrm{~N} \mathrm{NH}_{3}$ in $\mathrm{MeOH}$ was stirred in a pressure flask at $120^{\circ} \mathrm{C}$ for $16 \mathrm{~h}$. After cooling to $\mathrm{rt}$, the volatiles were evaporated under reduced pressure. The residue was purified by column chromatography (20:1 to 10:1, $\left.\mathrm{CH}_{2} \mathrm{Cl}_{2} / \mathrm{MeOH}\right)$ to afford $18(0.40 \mathrm{~g}, 70 \%$ yield $)$ as a white foam. ${ }^{1} \mathrm{H}$ NMR (600 $\mathrm{MHz}$, 
DMSO-d $\left.d_{6}\right): \delta 8.23$ (s, 1H, H-2), 7.46 (d, $\left.J=3.7 \mathrm{~Hz}, 1 \mathrm{H}, \mathrm{H}-6\right), 7.35$ (brs, 2H, NH$\left.H_{2}\right), 6.65$ (d, $J=$ $3.7 \mathrm{~Hz}, 1 \mathrm{H}, \mathrm{H}-5), 6.52\left(\mathrm{dd}, J=8.5,2.7 \mathrm{~Hz}, 1 \mathrm{H}, \mathrm{H}-1^{\prime}\right), 4.68-4.61\left[\mathrm{~m}, 2 \mathrm{H}, \mathrm{CH}\left(\mathrm{CH}_{3}\right)_{2}\right], 4.36-4.33$ (m, 1H, H-3'), 4.15 (d, $\left.J=10.3 \mathrm{~Hz}, 1 \mathrm{H}, \mathrm{H}-4 \mathrm{a}^{\prime}\right), 3.90-3.80$ (m, 3H, H-4b' and PCH $), 2.74-2.69$ $\left(\mathrm{m}, 1 \mathrm{H}, \mathrm{H}-2 \mathrm{a}^{\prime}\right), 2.22\left(\mathrm{~d}, J=14.9 \mathrm{~Hz}, 1 \mathrm{H}, \mathrm{H}-2 \mathrm{~b}^{\prime}\right), 1.29-1.26$ [m, 12H, $\left.\mathrm{CH}\left(\mathrm{CH}_{3}\right)_{2}\right] .{ }^{13} \mathrm{C} \mathrm{NMR}(150$ MHz, DMSO-d6): $\delta 156.3$ (C-4), 150.1 (C-2), 149.5 (C-7a), 122.5 (C-6), 102.2 (C-4a), 100.4 (C5), $82.0\left(\mathrm{C}-1^{\prime}\right), 80.5\left(\mathrm{~d},{ }^{3} J_{\mathrm{P}, \mathrm{C}}=14.0 \mathrm{~Hz}, \mathrm{C}-3^{\prime}\right), 72.2\left(\mathrm{C}-4^{\prime}\right), 70.3\left[\mathrm{CH}\left(\mathrm{CH}_{3}\right)_{2}\right], 63.2\left(\mathrm{~d},{ }^{1} J_{\mathrm{P}, \mathrm{C}}=166.3\right.$ $\left.\left.\mathrm{Hz}, \mathrm{PCH}_{2}\right), 37.7\left(\mathrm{C}-2^{\prime}\right), 23.8\left[\mathrm{CH}_{(} \mathrm{CH}_{3}\right)_{2}\right] .{ }^{31} \mathrm{P} \mathrm{NMR}\left(121 \mathrm{MHz}, \mathrm{CDCl}_{3}\right): \delta$ 19.1. HRMS: $[\mathrm{M}+\mathrm{H}]^{+}$ calcd for $\mathrm{C}_{17} \mathrm{H}_{28} \mathrm{~N}_{4} \mathrm{O}_{5} \mathrm{P}, 399.1792$; found, 399.1789.

(4R,1E)-4-Amino-7-(3-phosphonomethoxy-4-hydroxy-1-buten-1-yl)-7H-pyrrolo[2,3-

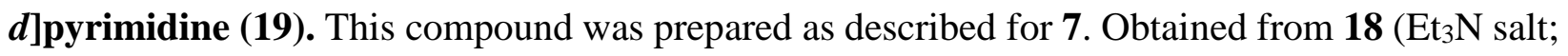
$200 \mathrm{mg}, 0.50 \mathrm{mmol})$ as a white foam. Yield 54\% (112 mg). ${ }^{1} \mathrm{H}$ NMR $\left(600 \mathrm{MHz}, \mathrm{D}_{2} \mathrm{O}\right): \delta 7.88(\mathrm{~s}$, 1H, H-2), 7.15 (d, J = 3.8 Hz, 1H, H-6), 7.09 (d, $\left.J=14.5 \mathrm{~Hz}, 1 \mathrm{H}, \mathrm{H}-1^{\prime}\right), 6.30$ (d, $J=3.7 \mathrm{~Hz}, 1 \mathrm{H}$, H-5), 5.77 (dd, $\left.J=14.4,8.0 \mathrm{~Hz}, 1 \mathrm{H}, \mathrm{H}-2^{\prime}\right), 4.21-4.17$ (m, 1H, H-3'), 3.83-3.63 (m, 3H, H-4' and $\left.\mathrm{PCH}_{2}\right) .{ }^{13} \mathrm{C}$ NMR (150 MHz, D $\left.2 \mathrm{O}\right): \delta 157.9$ (C-4), 151.7 (C-2), 149.5 (C-7a), 128.0 (C-1'), 124.6 (C-6), 115.8 (C-2'), 105.4 (C-4a), $104.4(\mathrm{C}-5), 83.9$ (d, $\left.{ }^{3} J_{\mathrm{P}, \mathrm{C}}=12.1 \mathrm{~Hz}, \mathrm{C}-3^{\prime}\right), 68.1\left(\mathrm{~d},{ }^{2} J_{\mathrm{P}, \mathrm{C}}=156.3\right.$ $\left.\mathrm{Hz}, \mathrm{PCH}_{2}\right), 66.8\left(\mathrm{C}-4{ }^{\prime}\right) .{ }^{31} \mathrm{P}$ NMR (121 MHz, $\left.\mathrm{D}_{2} \mathrm{O}\right): \delta 15.8$. HRMS: [M-H] ${ }^{-}$calcd for $\mathrm{C}_{11} \mathrm{H}_{14} \mathrm{~N}_{4} \mathrm{O}_{5} \mathrm{P}$, 313.0707; found, 313.0710.

Propyl ((5R)-5-((E)-2-(4-amino-7H-pyrrolo[2,3- $d]$ pyrimidin-7-yl)vinyl)-2-oxido-1,4,2dioxaphosphinan-2-yl)-L-phenylalaninate (20a and 20b). This compound was prepared as described for 8. Obtained from $19(28 \mathrm{mg}, 0.067 \mathrm{mmol})$ as a white solid and a mixture of diastereoisomers with a ratio of ca. 2:1 (fast elute/slow elute). Yield 24\% (8 mg, 20a) and 12\% (4 $\mathrm{mg}, \mathbf{2 0 b})$. The two isomers showed similar NMR characteristics. Major isomer 20a: ${ }^{1} \mathrm{H}$ NMR (600 MHz, MeOD): $\delta 8.14$ (s, 1H, H-2), 7.58 (dd, $\left.J=14.6,1.1 \mathrm{~Hz}, 1 \mathrm{H}, \mathrm{H}-1^{\prime}\right), 7.43$ (d, $J=3.8 \mathrm{~Hz}, 1 \mathrm{H}$, H-6), 7.31-7.20 (m, 5H, ArH), 6.71 (d, $J=3.7 \mathrm{~Hz}, 1 \mathrm{H}, \mathrm{H}-5), 5.98$ (dd, $J=14.5,6.0 \mathrm{~Hz}, 1 \mathrm{H}, \mathrm{H}-$ 2'), 4.44-4.40 (m, 1H, H-3'), 4.37-4.30 (m, 2H, H-4'), 4.24-4.20 (m, 1H, Phe-CH), 4.04 (t, J=6.6 $\left.\mathrm{Hz}, 2 \mathrm{H}, \mathrm{OCH}_{2} \mathrm{CH}_{2} \mathrm{CH}_{3}\right), 3.77-3.71\left(\mathrm{~m}, 2 \mathrm{H}, \mathrm{PCH}_{2}\right), 3.18-3.14(\mathrm{~m}, 1 \mathrm{H}$, Phe-CH$), 2.94$ (dd, $J=$ 13.6, $8.8 \mathrm{~Hz}, 1 \mathrm{H}$, Phe- $\left.\mathrm{CH}_{2}\right), 1.63-1.58\left(\mathrm{~m}, 2 \mathrm{H}, \mathrm{OCH}_{2} \mathrm{CH}_{2} \mathrm{CH}_{3}\right), 0.88(\mathrm{t}, J=7.4 \mathrm{~Hz}, 3 \mathrm{H}$, $\left.\mathrm{OCH}_{2} \mathrm{CH}_{2} \mathrm{CH}_{3}\right) .{ }^{13} \mathrm{C}$ NMR (150 MHz, MeOD): $\delta 174.4$ (CO), 159.1 (C-4), 153.2 (C-2), $150.6(\mathrm{C}-$ 7a), 138.5, 130.6, 129.5, 127.9 (Ar-C), 127.3 (C-1'), 121.8 (C-6), 110.0 (C-2'), 104.8 (C-4a), 103.0 $(\mathrm{C}-5), 75.4\left(\mathrm{~d},{ }^{3} J_{\mathrm{P}, \mathrm{C}}=4.6 \mathrm{~Hz}, \mathrm{C}-3^{\prime}\right), 73.6\left(\mathrm{~d},{ }^{2} J_{\mathrm{P}, \mathrm{C}}=7.8 \mathrm{~Hz}, \mathrm{C}-4^{\prime}\right), 68.0\left(\mathrm{OCH}_{2} \mathrm{CH}_{2} \mathrm{CH}_{3}\right), 65.3(\mathrm{~d}$, $\left.{ }^{1} J_{\mathrm{P}, \mathrm{C}}=134.1 \mathrm{~Hz}, \mathrm{PCH}\right), 56.2(\mathrm{Phe}-\mathrm{CH}), 41.2\left(\mathrm{Phe}-\mathrm{CH}_{2}\right), 23.0 \quad\left(\mathrm{OCH}_{2} \mathrm{CH}_{2} \mathrm{CH}_{3}\right), 10.7$ 
$\left(\mathrm{OCH}_{2} \mathrm{CH}_{2} \mathrm{CH}_{3}\right) .{ }^{31} \mathrm{P}$ NMR (121 MHz, MeOD): $\delta$ 16.8. HRMS: $[\mathrm{M}+\mathrm{H}]^{+}$calcd for $\mathrm{C}_{23} \mathrm{H}_{29} \mathrm{~N}_{5} \mathrm{O}_{5} \mathrm{P}$, 486.1901; found, 486.1904.

$1^{\prime} \alpha$-(2,6-diamino-purin-9-yl)-2'-deoxy-3'- $O$-diisopropylphosphonomethyl-L-threose (22a). A solution of 21 (170 mg, $0.39 \mathrm{mmol})$ in $7 \mathrm{~N} \mathrm{NH}_{3}$ in $\mathrm{MeOH}(30 \mathrm{~mL})$ was placed in a reaction bomb and heated to $100{ }^{\circ} \mathrm{C}$ for $4 \mathrm{~h}$. The reaction mixture was cooled to $\mathrm{rt}$ and concentrated under reduced pressure. The residue was purified by column chromatography on silica gel (20:1 to 10:1, $\left.\mathrm{CH}_{2} \mathrm{Cl}_{2} / \mathrm{MeOH}\right)$ to give 22a $(113 \mathrm{mg}, 70 \%)$ as a white foam. ${ }^{1} \mathrm{H}$ NMR (600 MHz, DMSO- $\left.d_{6}\right): \delta$ 7.86 (s, 1H, H-8), 6.68 (brs, 2H, NH2), 6.12 (dd, $\left.J=8.4,2.4 \mathrm{~Hz}, 1 \mathrm{H}, \mathrm{H}-1^{\prime}\right), 5.79$ (d, $J=6.3 \mathrm{~Hz}$, $\left.2 \mathrm{H}, \mathrm{NH} \mathrm{H}_{2}\right), 4.66-4.58\left[\mathrm{~m}, 2 \mathrm{H}, \mathrm{CH}\left(\mathrm{CH}_{3}\right)_{2}\right], 4.37-4.33$ (m, 1H, H-3'), $4.16(\mathrm{~d}, J=10.2 \mathrm{~Hz}, 1 \mathrm{H}, \mathrm{H}-$ $\left.4 \mathrm{a}^{\prime}\right), 3.90-3.81\left(\mathrm{~m}, 3 \mathrm{H}, \mathrm{H}-4 \mathrm{~b}^{\prime}\right.$ and $\left.\mathrm{PCH}_{2}\right), 2.70-2.65\left(\mathrm{~m}, 1 \mathrm{H}, \mathrm{H}-2 \mathrm{a}^{\prime}\right), 2.34\left(\mathrm{~d}, J=14.8 \mathrm{~Hz}, \mathrm{H}-2 \mathrm{~b}^{\prime}\right)$, 1.27-1.24 [m, 12H, CH(CH3) $)_{2}$. ${ }^{13} \mathrm{C}$ NMR (150 MHz, DMSO-d $\left.d_{6}\right): \delta 160.4$ (C-2), 156.1 (C-6), $151.7(\mathrm{C}-4), 135.6(\mathrm{C}-8), 112.9(\mathrm{C}-5), 81.7\left(\mathrm{C}-1^{\prime}\right), 80.3\left(\mathrm{~d},{ }^{3} J_{\mathrm{P}, \mathrm{C}}=14.1 \mathrm{~Hz}, \mathrm{C}-3^{\prime}\right), 72.4\left(\mathrm{C}-4^{\prime}\right), 70.4$ $\left[\mathrm{CH}\left(\mathrm{CH}_{3}\right)_{2}\right], 63.2\left(\mathrm{~d},{ }^{1} \mathrm{~J}_{\mathrm{P}, \mathrm{C}}=165.8 \mathrm{~Hz}, \mathrm{PCH}\right), 37.6\left(\mathrm{C}-2^{\prime}\right), 23.8\left[\mathrm{CH}\left(\mathrm{CH}_{3}\right)_{2}\right] .{ }^{31} \mathrm{P} \mathrm{NMR}(121 \mathrm{MHz}$, DMSO-d6): $\delta$ 19.2. HRMS: [M+H] $]^{+}$calcd for $\mathrm{C}_{16} \mathrm{H}_{28} \mathrm{~N}_{6} \mathrm{O}_{5} \mathrm{P}, 415.1853$; found, 415.1853.

1' $\alpha$-(2-amino-6-cyclopropylamino-purin-9-yl)-2'-deoxy-3'-O-diisopropylphosphonomethylL-threose (22b). A mixture of 21 (200 mg, $0.46 \mathrm{mmol}$ ) and cyclopropylamine ( $80 \mathrm{mg}, 1.40 \mathrm{mmol}$ ) in $\mathrm{CH}_{3} \mathrm{CN}$ ( $4 \mathrm{~mL}$ ) was placed in a reaction bomb and heated to $100^{\circ} \mathrm{C}$ for $4 \mathrm{~h}$. The reaction mixture was cooled to $\mathrm{rt}$ and concentrated. The residue was purified by column chromatography (40:1 to 20:1, $\left.\mathrm{CH}_{2} \mathrm{Cl}_{2} / \mathrm{MeOH}\right)$ to give $\mathbf{2 2 b}(190 \mathrm{mg}, 91 \%)$ as white foam. ${ }^{1} \mathrm{H}$ NMR (300 MHz, $\left.\mathrm{CDCl}_{3}\right): \delta$ 7.91 (s, 1H, H-8), 6.27 (dd, $J=7.6,2.1 \mathrm{~Hz}, 1 \mathrm{H}, \mathrm{H}-1^{\prime}$ ), 5.77 (brs, 1H, NH), 4.88 (brs, 2H, NH2), 4.69-4.82 [m, 2H, CH(CH 3$\left.)_{2}\right], 4.46$ (brs, 1H, H-3'), 4.27 (d, J = $\left.10.4 \mathrm{~Hz}, 1 \mathrm{H}, \mathrm{H}-4 \mathrm{a}^{\prime}\right), 4.00$ (dd, $J$ $\left.=10.4,4.3 \mathrm{~Hz}, 1 \mathrm{H}, \mathrm{H}-4 \mathrm{~b}^{\prime}\right), 3.74(\mathrm{~d}, J=8.9 \mathrm{~Hz}, 2 \mathrm{H}, \mathrm{PCH}), 2.99$ [brs, $1 \mathrm{H}, \mathrm{CH}\left(\mathrm{CH}_{2}\right)_{2}$ ], 2.68-2.50 (m, 2H, H-2), 1.30-1.35 [m, 12H, CH( $\left.\left.\mathrm{CH}_{3}\right)_{2}\right], 0.80-0.87$ [m, 2H, $\left.\mathrm{CH}\left(\mathrm{CH}_{2}\right)_{2}\right], 0.57-0.62$ [m, 2H, $\left.\mathrm{CH}\left(\mathrm{CH}_{2}\right)_{2}\right] .{ }^{13} \mathrm{C}$ NMR $\left(75 \mathrm{MHz}, \mathrm{CDCl}_{3}\right): \delta 160.0$ (C-2), $156.2(\mathrm{C}-6), 151.0(\mathrm{C}-4), 136.3(\mathrm{C}-8)$,

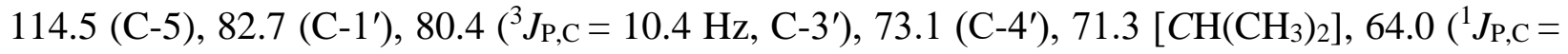
$168.3 \mathrm{~Hz}, \mathrm{PCH} 2), 38.1\left(\mathrm{C}-2^{\prime}\right), 24.0\left[\mathrm{CH}\left(\mathrm{CH}_{3}\right)_{2}\right], 23.6\left[\mathrm{CH}\left(\mathrm{CH}_{2}\right)_{2}\right], 7.4\left[\mathrm{CH}\left(\mathrm{CH}_{2}\right)_{2}\right] .{ }^{31} \mathrm{P} \mathrm{NMR}(121$ $\mathrm{MHz}, \mathrm{CDCl}_{3}$ ): $\delta$ 18.3. HRMS: $[\mathrm{M}+\mathrm{H}]^{+}$calcd for $\mathrm{C}_{19} \mathrm{H}_{32} \mathrm{~N}_{6} \mathrm{O}_{5} \mathrm{P}, 455.2166$; found, 455.2165.

1' $\alpha$-(2,6-diamino-purin-9-yl)-2'-deoxy-3'-O-phosphonomethyl-L-threose $\quad$ (23a). This compound was prepared as described for compound 7. Obtained from 22a (113 mg, $0.27 \mathrm{mmol})$ as a white foam. Yield 60\% (70 mg). ${ }^{1} \mathrm{H}$ NMR $\left(300 \mathrm{MHz}, \mathrm{D}_{2} \mathrm{O}\right): \delta 8.18(\mathrm{~s}, 1 \mathrm{H}, \mathrm{H}-8), 6.11$ (dd, $J$ $\left.=8.1,1.8 \mathrm{~Hz}, 1 \mathrm{H}, \mathrm{H}-1^{\prime}\right), 4.42$ (brs, 1H, H-3'), 4.20 (d, J=10.2 Hz, 1H, H-4a'), 3.94 (dd, J = 10.2, 
4.1 Hz, 1H, H-4b'), 4.20 (d, $\left.J=8.8 \mathrm{~Hz}, 2 \mathrm{H}, \mathrm{PCH}_{2}\right) .2 .48-2.60$ (m, 2H, H-2'). ${ }^{13} \mathrm{C}$ NMR (75 MHz, $\left.\mathrm{D}_{2} \mathrm{O}\right): \delta 159.8(\mathrm{C}-2), 155.8(\mathrm{C}-6), 150.6(\mathrm{C}-4), 138.6(\mathrm{C}-8), 112.6(\mathrm{C}-5), 82.5\left(\mathrm{C}-1^{\prime}\right), 79.1\left(\mathrm{~d},{ }^{3} J_{\mathrm{P}, \mathrm{C}}\right.$ $\left.=10.5 \mathrm{~Hz}, \mathrm{C}-3^{\prime}\right), 73.0\left(\mathrm{C}-4^{\prime}\right), 66.7\left(\mathrm{~d},{ }^{1} \mathrm{~J}_{\mathrm{P}, \mathrm{C}}=150.5 \mathrm{~Hz}, \mathrm{PCH}_{2}\right), 36.5\left(\mathrm{C}-2^{\prime}\right) .{ }^{31} \mathrm{P} \mathrm{NMR}(121 \mathrm{MHz}$, $\left.\mathrm{D}_{2} \mathrm{O}\right): \delta$ 13.1. HRMS: [M-H] ${ }^{-}$calcd for $\mathrm{C}_{10} \mathrm{H}_{14} \mathrm{~N}_{6} \mathrm{O}_{5} \mathrm{P}, 329.0769$; found, 329.0769.

\section{1' $\alpha$-(2-amino-6-cyclopropylamino-purin-9-yl)-2'-deoxy-3'-O-phosphonomethyl-L-threose}

(23b). This compound was prepared as described for 7. Obtained from 22b (170 mg, $0.37 \mathrm{mmol})$ as a white foam. Yield 62\% (109 mg). ${ }^{1} \mathrm{H}$ NMR (300 MHz, D $\left.\mathrm{D}_{2} \mathrm{O}\right): \delta 8.04$ (s, 1H, H-8), 5.99 (d, $J$ $\left.=5.9 \mathrm{~Hz}, 1 \mathrm{H}, \mathrm{H}-1^{\prime}\right), 4.35$ (brs, $\left.1 \mathrm{H}, \mathrm{H}-3^{\prime}\right), 4.10$ (d, $\left.J=10.2 \mathrm{~Hz}, 1 \mathrm{H}, \mathrm{H}-4 \mathrm{a}^{\prime}\right), 3.86$ (dd, $J=10.2,4.1$ $\left.\mathrm{Hz}, 1 \mathrm{H}, \mathrm{H}-4 \mathrm{~b}^{\prime}\right), 3.35\left(\mathrm{~d}, J=8.9 \mathrm{~Hz}, 2 \mathrm{H}, \mathrm{PCH}_{2}\right), 2.62-2.54$ [m, 2H, $\mathrm{CH}\left(\mathrm{CH}_{2}\right)_{2}$ and $\left.\mathrm{H}-2 \mathrm{a}^{\prime}\right], 2.40(\mathrm{~d}$, $\left.J=14.8 \mathrm{~Hz}, \mathrm{H}-2 \mathrm{~b}^{\prime}\right), 0.68\left[\mathrm{~d}, J=6.8 \mathrm{~Hz}, 2 \mathrm{H}, \mathrm{CH}\left(\mathrm{CH}_{2}\right)_{2}\right], 0.44$ [brs, $\left.2 \mathrm{H}, \mathrm{CH}\left(\mathrm{CH}_{2}\right)_{2}\right] .{ }^{13} \mathrm{C} \mathrm{NMR}(75$ MHz, $\left.\mathrm{D}_{2} \mathrm{O}\right): \delta 159.7$ (C-2), 155.7 (C-6), 149.6 (C-4), 137.7 (C-8), 112.6 (C-5), 82.3 (C-1'), 79.03 $\left(\mathrm{d},{ }^{3} J_{\mathrm{P}, \mathrm{C}}=10.3 \mathrm{~Hz}, \mathrm{C}-3^{\prime}\right), 72.9\left(\mathrm{C}-4^{\prime}\right), 66.7\left(\mathrm{~d},{ }^{1} J_{\mathrm{P}, \mathrm{C}}=150.0 \mathrm{~Hz}, \mathrm{PCH}_{2}\right), 36.5\left(\mathrm{C}-2^{\prime}\right), 22.9$ $\left[\mathrm{CH}\left(\mathrm{CH}_{2}\right)_{2}\right], 6.4\left[\mathrm{CH}\left(\mathrm{CH}_{2}\right)_{2}\right] .{ }^{31} \mathrm{P}$ NMR $\left(121 \mathrm{MHz}, \mathrm{D}_{2} \mathrm{O}\right): \delta$ 13.0. HRMS: [M-H] calcd for $\mathrm{C}_{13} \mathrm{H}_{18} \mathrm{~N}_{6} \mathrm{O}_{5} \mathrm{P}, 369.1082$; found, 369.1071.

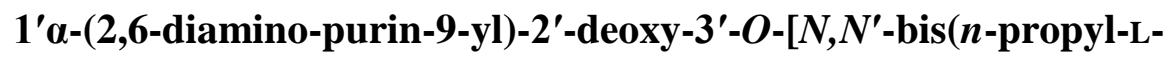

phenylalaninate)]methylphosphonobisamidate]-L-threose (24a). This compound was prepared as described for 8. Obtained from 23a (23 mg, $0.055 \mathrm{mmol}, \mathrm{Et}_{3} \mathrm{~N}$ salt) as a white foam. Yield 53\% (20 mg). ${ }^{1} \mathrm{H}$ NMR (300 MHz, DMSO-d6): $\delta 7.89$ (s, 1H, H-8), 7.29-7.12 (m, 10H, ArH), 6.66 (brs, 2H, $\left.\mathrm{NH}_{2}\right), 6.09$ (dd, $\left.J=7.9,2.7 \mathrm{~Hz}, 1 \mathrm{H}, \mathrm{H}-1^{\prime}\right), 5.81$ (brs, 2H, $\left.\mathrm{NH}_{2}\right), 4.55$ (t, $J=10.9 \mathrm{~Hz}, 1 \mathrm{H}, \mathrm{NH}$ ), 4.24-4.16 (m, 2H, NH and H-3'), 4.08-3.77 (m, 8H, H-4', Phe-CH and $\mathrm{OCH}_{2} \mathrm{CH}_{2} \mathrm{CH}_{3}$ ), 3.37-3.19 $\left(\mathrm{m}, 2 \mathrm{H}, \mathrm{PCH}_{2}\right), 3.98-2.76\left(\mathrm{~m}, 4 \mathrm{H}, \mathrm{Phe}-\mathrm{CH}_{2}\right), 2.65-2.56\left(\mathrm{~m}, 1 \mathrm{H}, \mathrm{H}-2 \mathrm{a}^{\prime}\right), 2.21(\mathrm{~d}, J=13.8 \mathrm{~Hz}, \mathrm{H}-$ $\left.2 b^{\prime}\right), 1.58-1.40\left(\mathrm{~m}, 4 \mathrm{H}, \mathrm{OCH}_{2} \mathrm{CH}_{2} \mathrm{CH}_{3}\right), 0.84-0.75\left(\mathrm{~m}, 6 \mathrm{H}, \mathrm{OCH}_{2} \mathrm{CH}_{2} \mathrm{CH}_{3}\right) .{ }^{13} \mathrm{C} \mathrm{NMR}(75 \mathrm{MHz}$, DMSO-d6): 173.0, 172.9 (Phe-CO), 160.4 (C-2), 156.2 (C-6), 151.7 (C-4), 137.3, 137.2 (Ar-C), 135.9 (C-8), 129.5, 128.2, $126.6(\mathrm{Ar}-C), 113.0(\mathrm{C}-5), 81.9\left(\mathrm{C}-1^{\prime}\right), 79.9\left(\mathrm{~d},{ }^{3} J_{\mathrm{P}, \mathrm{C}}=12.2 \mathrm{~Hz}, \mathrm{C}-3^{\prime}\right)$, $72.4\left(\mathrm{C}-4^{\prime}\right), 66.02,65.96\left(\mathrm{OCH}_{2} \mathrm{CH}_{2} \mathrm{CH}_{3}\right), 65.8\left(\mathrm{~d},{ }^{1} J_{\mathrm{P}, \mathrm{C}}=134.9 \mathrm{~Hz}, \mathrm{PCH}_{2}\right)$, 54.2, $54.1(\mathrm{Phe}-\mathrm{CH})$, 39.7 (Phe- $\mathrm{CH}_{2}$, overlap with DMSO- $\left.d_{6}\right), 37.5\left(\mathrm{C}-2^{\prime}\right), 21.53,21.48\left(\mathrm{OCH}_{2} \mathrm{CH}_{2} \mathrm{CH}_{3}\right), 10.33,10.29$ $\left(\mathrm{OCH}_{2} \mathrm{CH}_{2} \mathrm{CH}_{3}\right)$. ${ }^{31} \mathrm{P}$ NMR (121 MHz, DMSO-d $): \delta$ 20.3. HRMS: $[\mathrm{M}+\mathrm{H}]^{+}$calcd for $\mathrm{C}_{34} \mathrm{H}_{46} \mathrm{~N}_{8} \mathrm{O}_{7} \mathrm{P}, 709.3221$; found, 709.3244.

1' $\alpha$-(2-amino-6-cyclopropylamino-purin-9-yl)-2' -deoxy-3'- $O$-[ $N, N^{\prime}$-bis $(n$-propyl-L-

phenylalaninate)]methylphosphonobisamidate]-L-threose (24b). This compound was prepared as described for $\mathbf{8}$. Obtained from $\mathbf{2 3 b}(23 \mathrm{mg}, 0.049 \mathrm{mmol})$ as a white solid. Yield $67 \%$ (24 mg). 
${ }^{1} \mathrm{H}$ NMR (300 MHz, DMSO-d $\left.d_{6}\right): \delta 7.91(\mathrm{~s}, 1 \mathrm{H}, \mathrm{H}-8), 7.28-7.11(\mathrm{~m}, 10 \mathrm{H}, \mathrm{ArH}), 6.10$ (dd, $J=7.9$, $\left.2.5 \mathrm{~Hz}, 1 \mathrm{H}, \mathrm{H}-1^{\prime}\right), 5.92$ (brs, 2H, NH2), 4.55 (t, $\left.J=11.3 \mathrm{~Hz}, 1 \mathrm{H}, \mathrm{NH}\right), 4.23-4.16$ (m, 2H, NH and H-3'), 4.07-3.77 (m, 8H, H-4', Phe-CH and $\mathrm{OCH}_{2} \mathrm{CH}_{2} \mathrm{CH}_{3}$ ), 3.37-3.16 (m, 2H, PCH $)$, 3.05 [brs, $\left.1 \mathrm{H}, \mathrm{CH}\left(\mathrm{CH}_{2}\right)_{2}\right], 2.93-2.75$ (m, 4H, Phe-CH$), 2.66-2.56\left(\mathrm{~m}, 1 \mathrm{H}, \mathrm{H}-2 \mathrm{a}^{\prime}\right), 2.21(\mathrm{~d}, J=14.1 \mathrm{~Hz}, 1 \mathrm{H}$, $\left.\mathrm{H}-2 \mathrm{~b}^{\prime}\right), 1.57-1.39\left(\mathrm{~m}, 4 \mathrm{H}, \mathrm{OCH}_{2} \mathrm{CH}_{2} \mathrm{CH}_{3}\right), 0.83-0.73$ (m, 6H, $\left.\mathrm{OCH}_{2} \mathrm{CH}_{2} \mathrm{CH}_{3}\right), 0.66-0.53$ [m, 4H, $\left.\mathrm{CH}\left(\mathrm{CH}_{2}\right)_{2}\right] .{ }^{13} \mathrm{C}$ NMR (75 MHz, DMSO-d6): 173.0, 172.9 (Phe-CO), 160.0 (C-2), 155.8 (C-6), 151.4 (C-4), 137.3, 137.2 (Ar-C), 135.8 (C-8), 129.5, 128.2, 126.6 (Ar-C), 113.2 (C-5), 81.9 (C$\left.1^{\prime}\right), 80.0\left(\mathrm{~d},{ }^{3} J_{\mathrm{P}, \mathrm{C}}=11.7 \mathrm{~Hz}, \mathrm{C}-3^{\prime}\right), 72.4\left(\mathrm{C}-4^{\prime}\right), 66.0,65.9\left(\mathrm{OCH}_{2} \mathrm{CH}_{2} \mathrm{CH}_{3}\right), 65.8\left(\mathrm{~d},{ }^{1} J_{\mathrm{P}, \mathrm{C}}=135.9\right.$ $\mathrm{Hz}, \mathrm{PCH}_{2}$ ), 54.2, 54.0 (Phe- $\left.\mathrm{CH}\right), 39.7$ (Phe- $\mathrm{CH}_{2}$, overlap with DMSO-d $\left.d_{6}\right), 37.6\left(\mathrm{C}-2^{\prime}\right), 24.2$ [CH( $\left.\left(\mathrm{CH}_{2}\right)_{2}\right], 21.53,21.47\left(\mathrm{OCH}_{2} \mathrm{CH}_{2} \mathrm{CH}_{3}\right), 10.32,10.27\left(\mathrm{OCH}_{2} \mathrm{CH}_{2} \mathrm{CH}_{3}\right), 6.6\left[\mathrm{CH}\left(\mathrm{CH}_{2}\right)_{2}\right] .{ }^{31} \mathrm{P}$ NMR (121 MHz, DMSO-d $): \delta 20.3$. HRMS: $[\mathrm{M}+\mathrm{H}]^{+}$calcd for $\mathrm{C}_{37} \mathrm{H}_{50} \mathrm{~N}_{8} \mathrm{O} 7 \mathrm{P}, 749.3534$; found, 749.3547 .

$1^{\prime} \alpha$-(5-fluorouracil-1-yl)-2' -O-benzoyl-3'-O-tert-butyldimethylsilyl-L-threose (25). A solution of $1(0.20 \mathrm{~g}, 0.53 \mathrm{mmol})$ and 5-fluorouracil $(68 \mathrm{mg}, 0.53 \mathrm{mmol})$ in $2 \mathrm{~mL}$ of dry acetonitrile was treated with BSA $(0.26 \mathrm{~mL}, 1.05 \mathrm{mmol})$ and stirred at $60{ }^{\circ} \mathrm{C}$ for $1 \mathrm{~h}$. TMSOTf $(0.28 \mathrm{~mL}, 1.58$ mmol) was then added and the heating was continued for another $1 \mathrm{~h}$. The reaction mixture was cooled to rt and poured into an ice-cold stirred mixture of sat. aq. $\mathrm{NaHCO}_{3}$ and $\mathrm{AcOEt}$. The organic layer was separated and washed with brine, dried over $\mathrm{Na}_{2} \mathrm{SO}_{4}$, and concentrated. The residue was purified by column chromatography (3:1 to $2: 1$, hexane/EtOAc) to obtain $25(0.21 \mathrm{~g}, 88 \%$ yield $)$ as a white foam. ${ }^{1} \mathrm{H}$ NMR $\left(500 \mathrm{MHz}, \mathrm{CDCl}_{3}\right): \delta 9.39$ (brs, $\left.1 \mathrm{H}, \mathrm{NH}\right), 8.10-8.08(\mathrm{~m}, 2 \mathrm{H}, \mathrm{ArH}), 7.91$ (d, $J=6.4 \mathrm{~Hz}, 1 \mathrm{H}, \mathrm{H}-6), 7.66-7.63(\mathrm{~m}, 1 \mathrm{H}, \operatorname{ArH}), 7.53-7.49$ (m, 2H, ArH), 6.17 (s, 1H, H-1'), $5.28\left(\mathrm{~d}, J=0.8 \mathrm{~Hz}, 1 \mathrm{H}, \mathrm{H}-2^{\prime}\right), 4.42\left(\mathrm{~d}, J=2.9 \mathrm{~Hz}, 1 \mathrm{H}, \mathrm{H}-3^{\prime}\right), 4.28\left(\mathrm{~d}, J=9.8 \mathrm{~Hz}, 1 \mathrm{H}, \mathrm{H}-4 \mathrm{a}^{\prime}\right), 4.24$ $\left(\mathrm{dd}, J=9.8,2.9 \mathrm{~Hz}, 1 \mathrm{H}, \mathrm{H}-4 \mathrm{~b}^{\prime}\right), 0.96$ [s, 9H, C(CH3) 3 ], 0.22 (s, 3H, SiCH $\mathrm{CH}_{3}, 0.21$ (s, 3H, $\left.\mathrm{SiCH}_{3}\right)$. ${ }^{13} \mathrm{C} \mathrm{NMR}\left(125 \mathrm{MHz}, \mathrm{CDCl}_{3}\right): \delta 164.9(\mathrm{PhCO}), 156.9\left(\mathrm{~d},{ }^{2} J_{\mathrm{F}, \mathrm{C}}=26.9 \mathrm{~Hz}, \mathrm{C}-4\right), 148.7(\mathrm{C}-2), 140.1$ $\left(\mathrm{d},{ }^{1} J_{\mathrm{F}, \mathrm{C}}=236.7 \mathrm{~Hz}, \mathrm{C}-5\right), 133.8,129.9,128.7,128.6(\mathrm{Ar}-C), 125.3\left(\mathrm{~d},{ }^{2} J_{\mathrm{F}, \mathrm{C}}=34.8 \mathrm{~Hz}, \mathrm{C}-6\right), 89.8$ $\left(\mathrm{C}-1^{\prime}\right), 82.4\left(\mathrm{C}-2^{\prime}\right), 76.8\left(\mathrm{C}-4^{\prime}\right), 74.4\left(\mathrm{C}-3^{\prime}\right), 25.5\left[\mathrm{C}\left(\mathrm{CH}_{3}\right)_{3}\right], 17.9\left[C\left(\mathrm{CH}_{3}\right)_{3}\right],-4.9,-5.3\left(\mathrm{SiCH}_{3}\right)$. HRMS: $[\mathrm{M}+\mathrm{H}]^{+}$calcd for $\mathrm{C}_{21} \mathrm{H}_{28} \mathrm{FN}_{2} \mathrm{O}_{6} \mathrm{Si}$, 451.1695; found, 451.1695.

$\mathbf{1}^{\prime} \boldsymbol{\alpha}$-(5-fluorouracil-1-yl)-2'-O -benzoyl-L-threose (26). This compound was prepared as described for 3. Obtained from compound 25 (5.90 g, $13.1 \mathrm{mmol})$ as a white solid. Yield 90\% (3.96 g). ${ }^{1} \mathrm{H}$ NMR (300 MHz, DMSO-d6): $\delta 11.9$ (brs, $1 \mathrm{H}, \mathrm{NH}$ ), 8.06-8.00 (m, 3H, ArH and H-6), 7.73-7.68 (m, 1H, ArH), 7.59-7.54 (m, 2H, ArH), 5.98 (s, 2H, H-1' and OH), 5.33 (s, 1H, H-2'), 
$4.38-4.37$ (m, 1H, H-3'), 4.25 (d, $\left.J=9.8 \mathrm{~Hz}, 1 \mathrm{H}, \mathrm{H}-4 \mathrm{a}^{\prime}\right), 4.24\left(\mathrm{dd}, J=9.8,3.7 \mathrm{~Hz}, 1 \mathrm{H}, \mathrm{H}-4 \mathrm{~b}^{\prime}\right) .{ }^{13} \mathrm{C}$ NMR (75 MHz, DMSO- $\left.d_{6}\right): \delta 164.6(\mathrm{PhCO}), 157.1$ (d, $\left.{ }^{2} J_{\mathrm{F}, \mathrm{C}}=26.1 \mathrm{~Hz}, \mathrm{C}-4\right), 148.9(\mathrm{C}-2), 139.7$ $\left(\mathrm{d},{ }^{1} J_{\mathrm{F}, \mathrm{C}}=231.0 \mathrm{~Hz}, \mathrm{C}-5\right), 133.9,129.5,128.9,128.8(\mathrm{Ar}-C), 125.4\left(\mathrm{~d},{ }^{2} J_{\mathrm{F}, \mathrm{C}}=35.0 \mathrm{~Hz}, \mathrm{C}-6\right), 89.2$ $\left(\mathrm{C}-1^{\prime}\right), 81.7$ (C-2'), 75.4 (C-4'), 72.7 (C-3'). HRMS: [M+H] $]^{+}$calcd for $\mathrm{C}_{15} \mathrm{H}_{14} \mathrm{FN}_{2} \mathrm{O}_{6}, 337.0830$; found, 337.0824 .

\section{$1^{\prime} \alpha$-(5-fluorouracil-1-yl)-2'-O-benzoyl-3'-O-diisopropylphosphonomethyl-L-threose}

(27).

This compound was prepared as described for 4. Obtained from 26 (0.27 g, $0.80 \mathrm{mmol})$, diisopropylphosphonomethyl trifluoromethanesulfonate $(0.31 \mathrm{~g}, 0.96 \mathrm{mmol})$ and $\mathrm{NaH}(60 \%$ in oil, $96 \mathrm{mg}, 2.40 \mathrm{mmol})$ as a white foam. Yield 52\% (0.22 g). ${ }^{1} \mathrm{H}$ NMR $\left(300 \mathrm{MHz}, \mathrm{CDCl}_{3}\right): \delta 9.35(\mathrm{~d}$, $J=4.2 \mathrm{~Hz}, 1 \mathrm{H}, \mathrm{NH}), 8.03(\mathrm{~d}, J=7.5 \mathrm{~Hz}, 2 \mathrm{H}, \operatorname{Ar} H), 7.72(\mathrm{~d}, J=6.3 \mathrm{~Hz}, 1 \mathrm{H}, \mathrm{H}-6), 7.61(\mathrm{t}, J=7.5$ Hz, 1H, ArH), 7.46 (t, J=7.5 Hz, 2H, Ar-H), 6.20 (s, 1H, H-1'), 5.43 (s, 1H, H-2'), 4.82-4.72 [m, $\left.2 \mathrm{H}, \mathrm{CH}\left(\mathrm{CH}_{3}\right)_{2}\right], 4.44\left(\mathrm{~d}, J=10.8 \mathrm{~Hz}, 1 \mathrm{H}, \mathrm{H}-4 \mathrm{a}^{\prime}\right), 4.26$ (d, $\left.J=3.4 \mathrm{~Hz}, 1 \mathrm{H}, \mathrm{H}-3^{\prime}\right), 4.16$ (dd, $J=10.8$, $\left.3.7 \mathrm{~Hz}, 1 \mathrm{H}, \mathrm{H}-4 \mathrm{~b}^{\prime}\right), 4.06-3.88\left(\mathrm{~m}, 2 \mathrm{H}, \mathrm{PCH}_{2}\right), 1.35-1.32\left[\mathrm{~m}, 12 \mathrm{H}, \mathrm{CH}\left(\mathrm{CH}_{3}\right)_{2}\right] .{ }^{13} \mathrm{C} \mathrm{NMR}(75 \mathrm{MHz}$, $\left.\mathrm{CDCl}_{3}\right): \delta 165.1(\mathrm{PhCO}), 156.8\left(\mathrm{~d},{ }^{2} J_{\mathrm{F}, \mathrm{C}}=27.3 \mathrm{~Hz}, \mathrm{C}-4\right), 148.7(\mathrm{C}-2), 140.4\left(\mathrm{~d},{ }^{1} J_{\mathrm{F}, \mathrm{C}}=236.4 \mathrm{~Hz}\right.$, C-5), 133.9, 129.9, 128.6, $128.5(\mathrm{Ar}-C), 124.6\left(\mathrm{~d},{ }^{2} J_{\mathrm{F}, \mathrm{C}}=34.9 \mathrm{~Hz}, \mathrm{C}-6\right), 89.7\left(\mathrm{C}-1^{\prime}\right), 83.4\left(\mathrm{~d},{ }^{3} J_{\mathrm{P}, \mathrm{C}}\right.$ $\left.=10.3 \mathrm{~Hz}, \mathrm{C}-3^{\prime}\right), 79.9\left(\mathrm{C}-2^{\prime}\right), 73.5\left(\mathrm{C}-4^{\prime}\right), 71.6\left[C \mathrm{H}\left(\mathrm{CH}_{3}\right)_{2}\right], 64.7\left(\mathrm{~d},{ }^{1} J_{\mathrm{P}, \mathrm{C}}=168.6 \mathrm{~Hz}, \mathrm{PCH}_{2}\right), 23.9$ $\left[\mathrm{CH}\left(\mathrm{CH}_{3}\right)_{2}\right] .{ }^{31} \mathrm{P}$ NMR $\left(121 \mathrm{MHz}, \mathrm{CDCl}_{3}\right): \delta$ 17.7. HRMS: $[\mathrm{M}+\mathrm{H}]^{+}$calcd for $\mathrm{C}_{22} \mathrm{H}_{29} \mathrm{FN}_{2} \mathrm{O}_{9} \mathrm{P}$, 515.1589; found, 515.1583.

$1^{\prime} \alpha$-(5-fluorouracil-1-yl)-3'-O-diisopropylphosphonomethyl-L-threose (28). A solution of 27 $(2.00 \mathrm{~g}, 3.89 \mathrm{mmol})$ in $2 \mathrm{M}$ ammonia in $\mathrm{MeOH}(65 \mathrm{~mL})$ was stirred at $\mathrm{rt}$ for overnight. The reaction mixture was concentrated under reduced pressure and the residue was purified by column chromatography (30:1 to 20:1, $\mathrm{CH}_{2} \mathrm{Cl}_{2} / \mathrm{MeOH}$ ) to give compound 28 (1.50 g, 94\% yield) as a white foam. ${ }^{1} \mathrm{H}$ NMR (300 MHz, $\mathrm{CDCl}_{3}$ ): $\delta 10.84$ (brs, $1 \mathrm{H}, \mathrm{NH}$ ), 7.62 (d, J=6.3 Hz, 1H, H-6), 5.80 (s, 1H, H-1'), 5.42 (brs, 1H, OH), 4.78-4.67 [m, 2H, CH(CH$\left.)_{2}\right], 4,45$ (s, 1H, H-2'), 4.33 (d, J = 10.3 $\left.\mathrm{Hz}, 1 \mathrm{H}, \mathrm{H}-4 \mathrm{a}^{\prime}\right), 4.26$ (dd, $\left.J=10.3,3.2 \mathrm{~Hz}, 1 \mathrm{H}, \mathrm{H}-4 \mathrm{~b}^{\prime}\right), 4.13\left(\mathrm{~d}, J=2.8 \mathrm{~Hz}, 1 \mathrm{H}, \mathrm{H}-3^{\prime}\right), 3.81$ (d, $J=$ $\left.9.1 \mathrm{~Hz}, 2 \mathrm{H}, \mathrm{PCH}_{2}\right), 1.33-1.28\left[\mathrm{~m}, 12 \mathrm{H}, \mathrm{CH}\left(\mathrm{CH}_{3}\right)_{2}\right] .{ }^{13} \mathrm{C} \mathrm{NMR}\left(75 \mathrm{MHz}, \mathrm{CDCl}_{3}\right): \delta 157.6\left(\mathrm{~d},{ }^{2} \mathrm{~J}_{\mathrm{F}, \mathrm{C}}\right.$ $=27.3 \mathrm{~Hz}, \mathrm{C}-4), 149.5(\mathrm{C}-2), 140.2\left(\mathrm{~d},{ }^{1} J_{\mathrm{F}, \mathrm{C}}=233.9 \mathrm{~Hz}, \mathrm{C}-5\right), 124.9\left(\mathrm{~d},{ }^{2} J_{\mathrm{F}, \mathrm{C}}=34.5 \mathrm{~Hz}, \mathrm{C}-6\right), 93.0$ $\left(\mathrm{C}-1^{\prime}\right), 85.1\left(\mathrm{~d},{ }^{3} J_{\mathrm{P}, \mathrm{C}}=10.3 \mathrm{~Hz}, \mathrm{C}-3^{\prime}\right), 78.1\left(\mathrm{C}-2^{\prime}\right), 74.1\left(\mathrm{C}-4^{\prime}\right), 71.6\left[\mathrm{CH}\left(\mathrm{CH}_{3}\right)_{2}\right], 64.2\left(\mathrm{~d},{ }^{1} J_{\mathrm{P}, \mathrm{C}}=\right.$ 168.2 Hz, $\mathrm{PCH}$ ), $23.9\left[\mathrm{CH}\left(\mathrm{CH}_{3}\right)_{2}\right] .{ }^{31} \mathrm{P} \mathrm{NMR}\left(121 \mathrm{MHz}, \mathrm{CDCl}_{3}\right): \delta$ 18.3. HRMS: $[\mathrm{M}+\mathrm{H}]^{+}$calcd for $\mathrm{C}_{15} \mathrm{H}_{25} \mathrm{FN}_{2} \mathrm{O}_{8} \mathrm{P}, 411.1327$; found, 411.1334 . 
1' $\alpha$-(5-fluorouracil-1-yl)-2'-deoxy-3'-O-diisopropylphosphonomethyl-L-threose (29). This compound was prepared as described for $\mathbf{6}$. Obtained from $28(0.31 \mathrm{~g}, 0.76 \mathrm{mmol})$ as a white foam. Yield 92\% (275 mg). ${ }^{1} \mathrm{H}$ NMR (300 MHz, $\mathrm{CDCl}_{3}$ ): $\delta 10.37$ (brs, $\left.1 \mathrm{H}, \mathrm{NH}\right), 7.81$ (d, J=6.3 Hz, 1H, H-6), 6.22 (d, J=7.6 Hz, 1H, H-1'), 4.83-4.71 [m, 2H, CH(CH$\left.)_{2}\right], 4.38$ (d, J = $10.5 \mathrm{~Hz}, 1 \mathrm{H}, \mathrm{H}-$ $4 \mathrm{a}^{\prime}$ ), 4.33 (brs, 1H, H-3'), 3.86 (dd, $\left.J=10.5,2.8 \mathrm{~Hz}, 1 \mathrm{H}, \mathrm{H}-4 \mathrm{~b}^{\prime}\right), 3.75$ (d, $J=9.1 \mathrm{~Hz}, 2 \mathrm{H}, \mathrm{PCH}_{2}$ ), 2.59-2.49 (m, 1H, H-2a'), 2.23 (d, $\left.J=15.3 \mathrm{~Hz}, 1 \mathrm{H}, \mathrm{H}-2 \mathrm{~b}^{\prime}\right), 1.34-1.31$ [m, $\left.12 \mathrm{H}, \mathrm{CH}\left(\mathrm{CH}_{3}\right)_{2}\right] .{ }^{13} \mathrm{C}$ $\operatorname{NMR}\left(75 \mathrm{MHz}, \mathrm{CDCl}_{3}\right): \delta 157.2\left(\mathrm{~d},{ }^{2} J_{\mathrm{F}, \mathrm{C}}=26.4 \mathrm{~Hz}, \mathrm{C}-4\right), 149.2(\mathrm{C}-2), 140.1\left(\mathrm{~d},{ }^{1} J_{\mathrm{F}, \mathrm{C}}=235.8 \mathrm{~Hz}\right.$, C-5), $124.8\left(\mathrm{~d},{ }^{2} J_{\mathrm{F}, \mathrm{C}}=34.4 \mathrm{~Hz}, \mathrm{C}-6\right), 85.5\left(\mathrm{C}-1^{\prime}\right), 80.0\left(\mathrm{~d},{ }^{3} J_{\mathrm{P}, \mathrm{C}}=11.0 \mathrm{~Hz}, \mathrm{C}-3^{\prime}\right), 73.8\left(\mathrm{C}-4^{\prime}\right), 71.3$ $\left[\mathrm{CH}\left(\mathrm{CH}_{3}\right)_{2}\right], 63.8\left(\mathrm{~d},{ }^{1} \mathrm{~J}_{\mathrm{P}, \mathrm{C}}=169.3 \mathrm{~Hz}, \mathrm{PCH}_{2}\right), 38.2\left(\mathrm{C}-2^{\prime}\right), 23.8\left[\mathrm{CH}\left(\mathrm{CH}_{3}\right)_{2}\right] .{ }^{31} \mathrm{P} \mathrm{NMR}(121 \mathrm{MHz}$, $\left.\mathrm{CDCl}_{3}\right): \delta$ 18.2. HRMS: $[\mathrm{M}+\mathrm{H}]^{+}$calcd for $\mathrm{C}_{15} \mathrm{H}_{25} \mathrm{FN}_{2} \mathrm{O}_{7} \mathrm{P}, 395.1378$; found, 395.1390.

1' $\boldsymbol{\alpha}$-(5-fluorouracil-1-yl)-3'-O-phosphonomethyl-L-threose (31). This compound was prepared as described for 7. Obtained from $28(0.46 \mathrm{~g}, 1.12 \mathrm{mmol})$ and bromotrimethylsilane $(1.18 \mathrm{~mL}$, $8.97 \mathrm{mmol})$ as a white foam. Yield 68\% (0.33 g, Et 3 N salt). ${ }^{1} \mathrm{H}$ NMR $\left(300 \mathrm{MHz}, \mathrm{D}_{2} \mathrm{O}\right): \delta 7.79(\mathrm{~d}$, $J=6.3 \mathrm{~Hz}, 1 \mathrm{H}, \mathrm{H}-6), 5.76$ (s, 1H, H-1'), 4.34 (s, 1H, H-2'), 4.28 (d, J=9.2 Hz, 1H, H-4a'), 4.14$4.10\left(\mathrm{~m}, 2 \mathrm{H}, \mathrm{H}-3^{\prime}\right.$ and H-4b'), $3.44\left(\mathrm{~d}, J=8.5 \mathrm{~Hz}, 2 \mathrm{H}, \mathrm{PCH}_{2}\right) .{ }^{13} \mathrm{C} \mathrm{NMR}\left(75 \mathrm{MHz}, \mathrm{D}_{2} \mathrm{O}\right): \delta 164.8$ $\left(\mathrm{d},{ }^{2} J_{\mathrm{F}, \mathrm{C}}=20.0 \mathrm{~Hz}, \mathrm{C}-4\right), 154.5(\mathrm{C}-2), 141.1\left(\mathrm{~d},{ }^{1} J_{\mathrm{F}, \mathrm{C}}=236.2 \mathrm{~Hz}, \mathrm{C}-5\right), 125.1\left(\mathrm{~d},{ }^{2} J_{\mathrm{F}, \mathrm{C}}=35.3 \mathrm{~Hz}\right.$, C-6), $91.3\left(\mathrm{C}-1^{\prime}\right), 83.9\left(\mathrm{~d},{ }^{3} J_{\mathrm{P}, \mathrm{C}}=8.4 \mathrm{~Hz}, \mathrm{C}-3^{\prime}\right), 77.5\left(\mathrm{C}-2^{\prime}\right), 72.4\left(\mathrm{C}-4^{\prime}\right), 66.5\left(\mathrm{~d},{ }^{1} J_{\mathrm{P}, \mathrm{C}}=150.3 \mathrm{~Hz}\right.$, $\left.\mathrm{PCH}_{2}\right) .{ }^{31} \mathrm{P}$ NMR $\left(121 \mathrm{MHz}, \mathrm{D}_{2} \mathrm{O}\right): \delta$ 13.2. HRMS: [M-H] $]^{-}$calcd for $\mathrm{C}_{9} \mathrm{H}_{11} \mathrm{FN}_{2} \mathrm{O}_{8} \mathrm{P}, 325.0242$; found, 325.0247 .

\section{$1^{\prime} \alpha-(5-f l u o r o u r a c i l-1-y l)-3 '-O-\left[N, N^{\prime}\right.$-bis(n-propyl-L-}

phenylalaninate)]methylphosphonobisamidate]-L-threose (32).

This compound was prepared as described for $\mathbf{8}$. Obtained from 31 (70 $\mathrm{mg}, 0.16 \mathrm{mmol}$ ) as a white foam. Yield (39\%, $45 \mathrm{mg})$ and major isomer of $33(15 \%, 12 \mathrm{mg})$. Or obtained from 35 (185 mg, $0.34 \mathrm{mmol})$. Yield (69\% for two steps, $165 \mathrm{mg}) .{ }^{1} \mathrm{H}$ NMR (500 MHz, DMSO- $\left.d_{6}\right): \delta 11.85$ (s, $1 \mathrm{H}$, $\mathrm{NH}), 7.82(\mathrm{~d}, J=6.8 \mathrm{~Hz}, 1 \mathrm{H}, \mathrm{H}-6), 7.26-7.11(\mathrm{~m}, 10 \mathrm{H}, \mathrm{Ar}-H), 5.96(\mathrm{~s}, 1 \mathrm{H}, \mathrm{OH}), 5.62(\mathrm{~s}, 1 \mathrm{H}, \mathrm{H}-$ 1'), 4.49 (t, $J=11.5 \mathrm{~Hz}, 1 \mathrm{H}, \mathrm{NH}), 4.26-4.21(\mathrm{~m}, 2 \mathrm{H}, \mathrm{NH}$ and H-4a'), 4.05 (s, 1H, H-2'), 3.99-3.85 (m, 7H, H-4b', Phe-CH and $\mathrm{OCH}_{2} \mathrm{CH}_{2} \mathrm{CH}_{3}$ ), 3.82 (s, 1H, H-3'), 3.35-3.19 (m, 2H, PCH2), 2.902.74 (m, 4H, Phe- $\left.\mathrm{CH}_{2}\right), 1.52-1.43$ (m, 4H, $\left.\mathrm{OCH}_{2} \mathrm{CH}_{2} \mathrm{CH}_{3}\right), 0.83-0.75$ (m, 6H, $\left.\mathrm{OCH}_{2} \mathrm{CH}_{2} \mathrm{CH}_{3}\right)$. ${ }^{13} \mathrm{C}$ NMR (125 MHz, DMSO-d $)$ : 173.0, 172.8 (Phe-CO), 157.2 (d, $\left.{ }^{2} J_{\mathrm{F}, \mathrm{C}}=26.1 \mathrm{~Hz}, \mathrm{C}-4\right), 149.1$ $(\mathrm{C}-2), 139.6\left(\mathrm{~d},{ }^{1} J_{\mathrm{F}, \mathrm{C}}=230.3 \mathrm{~Hz}, \mathrm{C}-5\right), 137.19,137.15,129.5,129.4,128.2,126.59,126.57$ (ArC), $125.5\left(\mathrm{~d},{ }^{2} J_{\mathrm{F}, \mathrm{C}}=34.7 \mathrm{~Hz}, \mathrm{C}-6\right), 91.9\left(\mathrm{C}-1^{\prime}\right), 84.8\left(\mathrm{~d},{ }^{3} J_{\mathrm{P}, \mathrm{C}}=10.7 \mathrm{~Hz}, \mathrm{C}-3^{\prime}\right), 77.7\left(\mathrm{C}-2^{\prime}\right), 72.3(\mathrm{C}-$ 
4'), 66.0, $65.9\left(\mathrm{OCH}_{2} \mathrm{CH}_{2} \mathrm{CH}_{3}\right), 65.8\left(\mathrm{~d},{ }^{1} \mathrm{~J}_{\mathrm{P}, \mathrm{C}}=135.3 \mathrm{~Hz}, \mathrm{PCH}\right)$, 54.2, 53.9 (Phe- $\left.\mathrm{CH}\right), 39.6$ (Phe$\mathrm{CH}_{2}$, overlap with DMSO- $\left.d_{6}\right), 21.5$, $21.4\left(\mathrm{OCH}_{2} \mathrm{CH}_{2} \mathrm{CH}_{3}\right), 10.3,10.2\left(\mathrm{OCH}_{2} \mathrm{CH}_{2} \mathrm{CH}_{3}\right) .{ }^{31} \mathrm{P} \mathrm{NMR}$ (121 MHz, DMSO- $d_{6}$ ): $\delta$ 20.0. HRMS: $[\mathrm{M}+\mathrm{H}]^{+}$calcd for $\mathrm{C}_{33} \mathrm{H}_{43} \mathrm{FN}_{4} \mathrm{O}_{10} \mathrm{P}, 705.2695$; found, 705.2671 .

\section{1' $\alpha$-(5-fluorouracil-1-yl)-3'-O-methyl-2'-O-[N-n-propyl-L-phenylalaninate-}

cyclophosphonamidate]-L-threose (33). ${ }^{1} \mathrm{H}$ NMR (500 MHz, DMSO- $d_{6}$ ): $\delta 11.96$ (brs, $1 \mathrm{H}, \mathrm{N} H$ ), $8.42(\mathrm{~d}, J=7.1 \mathrm{~Hz}, 1 \mathrm{H}, \mathrm{H}-6), 7.31-7.20$ (m, 5H, ArH), 6.00-5.93 (m, 2H, H-1' and $\mathrm{NH}$ ), 4.994.96 (m, 1H, H-2'), 4.23-4.18 (m, 1H, H-3'), 4.15-4.07 (m, 1H, Phe-CH), 4.06-3.97 (m, 4H, H-4' and $\left.\mathrm{OCH}_{2} \mathrm{CH}_{2} \mathrm{CH}_{3}\right), 3.51-3.21\left(\mathrm{~m}, 2 \mathrm{H}, \mathrm{PCH}_{2}\right), 3.07-2.69\left(\mathrm{~m}, 2 \mathrm{H}, \mathrm{Phe}-\mathrm{CH}_{2}\right), 1.58-1.51(\mathrm{~m}, 2 \mathrm{H}$, $\left.\mathrm{OCH}_{2} \mathrm{CH}_{2} \mathrm{CH}_{3}\right), 0.84\left(\mathrm{t}, J=7.4 \mathrm{~Hz}, 3 \mathrm{H}, \mathrm{OCH}_{2} \mathrm{CH}_{2} \mathrm{CH}_{3}\right) .{ }^{13} \mathrm{C}$ NMR (125 MHz, DMSO- $\left.d_{6}\right): 172.4$ $\left(\mathrm{d},{ }^{3} J_{\mathrm{P}, \mathrm{C}}=3.1 \mathrm{~Hz}\right.$, Phe-CO), $156.9\left(\mathrm{~d},{ }^{2} J_{\mathrm{F}, \mathrm{C}}=26.5 \mathrm{~Hz}, \mathrm{C}-4\right), 149.5(\mathrm{C}-2), 140.7\left(\mathrm{~d},{ }^{1} J_{\mathrm{F}, \mathrm{C}}=232.8 \mathrm{~Hz}\right.$, C-5), 137.2, 129.6, 128.3, $126.7(\mathrm{Ar}-\mathrm{C}), 124.9\left(\mathrm{~d},{ }^{2} J_{\mathrm{F}, \mathrm{C}}=34.6 \mathrm{~Hz}, \mathrm{C}-6\right), 82.1\left(\mathrm{~d},{ }^{3} J_{\mathrm{P}, \mathrm{C}}=8.1 \mathrm{~Hz}, \mathrm{C}-\right.$ $\left.1^{\prime}\right), 77.9\left(\mathrm{~d},{ }^{2} J_{\mathrm{P}, \mathrm{C}}=3.4 \mathrm{~Hz}, \mathrm{C}-2^{\prime}\right), 75.8\left(\mathrm{~d},{ }^{3} J_{\mathrm{P}, \mathrm{C}}=5.4 \mathrm{~Hz}, \mathrm{C}-3^{\prime}\right), 66.3\left(\mathrm{OCH}_{2} \mathrm{CH}_{2} \mathrm{CH}_{3}\right), 65.5\left(\mathrm{C}-4^{\prime}\right)$, $65.4\left(\mathrm{~d},{ }^{1} J_{\mathrm{P}, \mathrm{C}}=132.1 \mathrm{~Hz}, \mathrm{PCH}\right.$ ), $54.5(\mathrm{Phe}-\mathrm{CH}), 39.6$ (Phe- $\mathrm{CH}_{2}$, overlap with DMSO- $\left.d_{6}\right), 21.5$ $\left(\mathrm{OCH}_{2} \mathrm{CH}_{2} \mathrm{CH}_{3}\right), 10.2\left(\mathrm{OCH}_{2} \mathrm{CH}_{2} \mathrm{CH}_{3}\right) .{ }^{31} \mathrm{P} \mathrm{NMR}\left(121 \mathrm{MHz}, \mathrm{DMSO}-d_{6}\right): \delta$ 18.1. HRMS: [M+H] ${ }^{+}$ calcd for $\mathrm{C}_{21} \mathrm{H}_{26} \mathrm{FN}_{3} \mathrm{O}_{8} \mathrm{P}, 498.1436$; found, 498.1441.

\section{1'a-(5-fluorouracil-1-yl)-2'-O-tert-butyldimethylsilyl-3'-O-diisopropylphosphonomethyl-L-}

threose (34). To a stirred solution of $28(0.22 \mathrm{~g}, 0.54 \mathrm{mmol})$ and imidazole $(110 \mathrm{mg}, 1.61 \mathrm{mmol})$ in $5 \mathrm{~mL}$ of anhydrous DMF was added TBSCl $(242 \mathrm{mg}, 0.80 \mathrm{mmol})$ at $0{ }^{\circ} \mathrm{C}$. The solution was stirred at $\mathrm{rt}$ overnight. The reaction mixture was diluted with ethyl acetate and washed with $1 \mathrm{M}$ $\mathrm{HCl}$ solution and brine. The organic layer was separated, dried over $\mathrm{Na}_{2} \mathrm{SO}_{4}$ and concentrated. The residue was purified by column chromatography (60:1 to 30:1, DCM/MeOH) to give $\mathbf{3 4}(0.25 \mathrm{~g}$, $89 \%$ ) as a colorless oil. ${ }^{1} \mathrm{H}$ NMR (300 MHz, $\left.\mathrm{CDCl}_{3}\right): \delta 10.84(\mathrm{~d}, J=4.2 \mathrm{~Hz}, 1 \mathrm{H}, \mathrm{NH}), 7.57(\mathrm{~d}, J$ $=6.5 \mathrm{~Hz}, 1 \mathrm{H}, \mathrm{H}-6), 5.67\left(\mathrm{~s}, 1 \mathrm{H}, \mathrm{H}-1^{\prime}\right), 4.79-4.62\left[\mathrm{~m}, 2 \mathrm{H}, \mathrm{CH}\left(\mathrm{CH}_{3}\right)_{2}\right], 4.33(\mathrm{~d}, J=10.3 \mathrm{~Hz}, 1 \mathrm{H}$, H-4a'), 4,27 (s, 1H, H-2'), 4.15 (dd, $J=10.3,3.1 \mathrm{~Hz}, 1 \mathrm{H}, \mathrm{H}-4 \mathrm{~b}^{\prime}$ ), 3.90 (d, $J=3.0 \mathrm{~Hz}, 1 \mathrm{H}, \mathrm{H}-3^{\prime}$ ), $3.69(\mathrm{~d}, J=9.1 \mathrm{~Hz}, 2 \mathrm{H}, \mathrm{PCH}), 1.31-1.25\left[\mathrm{~m}, 12 \mathrm{H}, \mathrm{CH}\left(\mathrm{CH}_{3}\right)_{2}\right], 0.86$ [s, 9H, $\left.\mathrm{C}\left(\mathrm{CH}_{3}\right)_{3}\right], 0.17$ (s, $\left.3 \mathrm{H}, \mathrm{SiCH}_{3}\right), 0.12\left(\mathrm{~s}, 3 \mathrm{H}, \mathrm{SiCH}_{3}\right) .{ }^{13} \mathrm{C} \mathrm{NMR}\left(75 \mathrm{MHz}, \mathrm{CDCl}_{3}\right): \delta 157.3\left(\mathrm{~d},{ }^{2} J_{\mathrm{F}, \mathrm{C}}=26.5 \mathrm{~Hz}, \mathrm{C}-4\right)$, $149.0(\mathrm{C}-2), 139.8\left(\mathrm{~d},{ }^{1} J_{\mathrm{F}, \mathrm{C}}=235.1 \mathrm{~Hz}, \mathrm{C}-5\right), 124.9\left(\mathrm{~d},{ }^{2} J_{\mathrm{F}, \mathrm{C}}=35.2 \mathrm{~Hz}, \mathrm{C}-6\right), 92.8\left(\mathrm{C}-1^{\prime}\right), 85.7(\mathrm{~d}$,

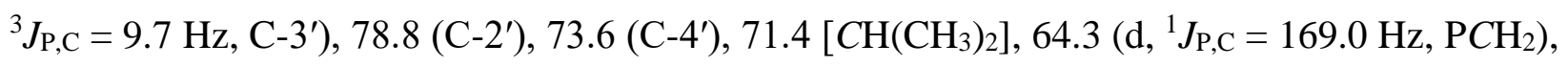
$25.5\left[\mathrm{C}\left(\mathrm{CH}_{3}\right)_{3}\right], 23.8\left[\mathrm{CH}\left(\mathrm{CH}_{3}\right)_{2}\right], 17.8\left[\mathrm{C}\left(\mathrm{CH}_{3}\right)_{3}\right],-4.8,-5.3\left(\mathrm{SiCH}_{3}\right) .{ }^{31} \mathrm{P}$ NMR (121 MHz, $\left.\mathrm{CDCl}_{3}\right): \delta$ 18.4. HRMS: $[\mathrm{M}+\mathrm{H}]^{+}$calcd for $\mathrm{C}_{21} \mathrm{H}_{39} \mathrm{FN}_{2} \mathrm{O}_{8} \mathrm{PSi}$, 525.2192; found, 525.2201. 
1'a-(5-fluorouracil-1-yl)-2'-O-tert-butyldimethylsilyl-3'-O-phosphonomethyl-L-threose (35).

This compound was prepared as described for 7, obtained form 34 (230 mg, $0.44 \mathrm{mmol})$ as a white foam. Yield 67\% (160 mg, Et $3 \mathrm{~N}$ salt). ${ }^{1} \mathrm{H}$ NMR (300 MHz, $\left.\mathrm{D}_{2} \mathrm{O}\right): \delta 7.87$ (d, J=6.6 Hz, 1H, H-6), 5.70 (s, 1H, H-1'), 4.42 (s, 1H, H-2'), 4.38 (d, J=10.7 Hz, 1H, H-4a'), 4.17 (dd, J=10.7, $3.5 \mathrm{~Hz}$, $1 \mathrm{H}, \mathrm{H}^{-4 \mathrm{~b}^{\prime}}$ ), 4.01 (d, $\left.J=3.1 \mathrm{~Hz}, 1 \mathrm{H}, \mathrm{H}-3^{\prime}\right), 3.52$ (d, $J=9.6 \mathrm{~Hz}, 2 \mathrm{H}, \mathrm{PCH}$ ), 0.83 [s, 9H, C(CH3) ${ }_{3}$, 0.13 (s, 3H, $\left.\mathrm{SiCH}_{3}\right), 0.11\left(\mathrm{~s}, 3 \mathrm{H}, \mathrm{SiCH}_{3}\right) .{ }^{13} \mathrm{C} \mathrm{NMR}\left(75 \mathrm{MHz}, \mathrm{D}_{2} \mathrm{O}\right): \delta 160.0\left(\mathrm{~d},{ }^{2} \mathrm{~J}_{\mathrm{F}, \mathrm{C}}=25.1 \mathrm{~Hz}\right.$, C-4), $150.1(\mathrm{C}-2), 140.0\left(\mathrm{~d},{ }^{1} J_{\mathrm{F}, \mathrm{C}}=231.1 \mathrm{~Hz}, \mathrm{C}-5\right), 126.3\left(\mathrm{~d},{ }^{2} J_{\mathrm{F}, \mathrm{C}}=35.1 \mathrm{~Hz}, \mathrm{C}-6\right), 92.4\left(\mathrm{C}-1^{\prime}\right)$, $84.6\left(\mathrm{~d},{ }^{3} J_{\mathrm{P}, \mathrm{C}}=11.9 \mathrm{~Hz}, \mathrm{C}-3^{\prime}\right), 78.2\left(\mathrm{C}-2^{\prime}\right), 73.6\left(\mathrm{C}-4^{\prime}\right), 65.4\left(\mathrm{~d},{ }^{1} J_{\mathrm{P}, \mathrm{C}}=156.3 \mathrm{~Hz}, \mathrm{PCH}_{2}\right), 24.7$

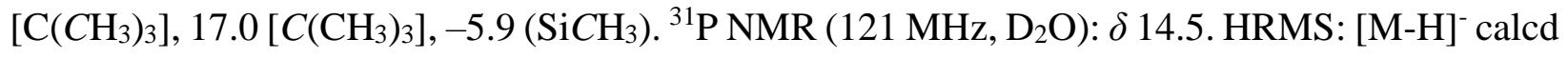
for $\mathrm{C}_{15} \mathrm{H}_{25} \mathrm{FN}_{2} \mathrm{O}_{8} \mathrm{PSi}$, 439.1107; found, 439.1114 .

\section{1'a-(5-fluorouracil-1-yl)-2'-deoxy-3'-O-[ $N, N^{\prime}$-bis(n-propyl-L-}

phenylalaninate)]methylphosphonobisamidate]-L-threose (36). This compound was prepared as described for 6. Obtained from $32(100 \mathrm{mg}, 0.14 \mathrm{mmol})$ as a white foam. Yield 90\% (88 $\mathrm{mg})$. ${ }^{1} \mathrm{H}$ NMR (500 MHz, acetone- $\left.d_{6}\right): \delta 10.62$ (brs, $\left.1 \mathrm{H}, \mathrm{NH}\right), 7.94$ (d, $\left.J=7.0 \mathrm{~Hz}, 1 \mathrm{H}, \mathrm{H}-6\right), 7.31-7.19$ (m, 10H, ArH), 6.11-6.08 (m, 1H, H-1'), 4.33 (dd, J=10.4, 1.5 Hz, 1H, H-4a'), 4.29-4.22 (m, 2H, H-3' and Phe-CH), 4.11-4.98 (m, 5H, Phe-CH and $\left.\mathrm{OCH}_{2} \mathrm{CH}_{2} \mathrm{CH}_{3}\right), 3.83-3.72\left(\mathrm{~m}, 2 \mathrm{H}, \mathrm{H}-4 \mathrm{~b}^{\prime}\right.$ and $\mathrm{NH}), 3.56-3.38\left(\mathrm{~m}, 3 \mathrm{H}, \mathrm{NH}\right.$ and $\left.\mathrm{PCH}_{2}\right), 3.10-2.83\left(\mathrm{~m}, 4 \mathrm{H}, \mathrm{Phe}-\mathrm{CH}_{2}\right), 2.58-2.51\left(\mathrm{~m}, 1 \mathrm{H}, \mathrm{H}-2 \mathrm{a}^{\prime}\right)$, $2.10\left(\mathrm{~d}, J=15.0 \mathrm{~Hz}, 1 \mathrm{H}, \mathrm{H}-2 \mathrm{~b}^{\prime}\right), 1.65-1.55\left(\mathrm{~m}, 4 \mathrm{H}, \mathrm{OCH}_{2} \mathrm{CH}_{2} \mathrm{CH}_{3}\right), 0.92-0.86(\mathrm{~m}, 6 \mathrm{H}$, $\left.\mathrm{OCH}_{2} \mathrm{CH}_{2} \mathrm{CH}_{3}\right) .{ }^{13} \mathrm{C}$ NMR (125 MHz, acetone- $\left.d_{6}\right)$ : 174.0, 173.5 (Phe-CO), $157.8\left(\mathrm{~d},{ }^{2} J_{\mathrm{F}, \mathrm{C}}=26.7\right.$ Hz, C-4), 149.9 (C-2), 141.0 (d, $\left.{ }^{1} J_{\mathrm{F}, \mathrm{C}}=230.4 \mathrm{~Hz}, \mathrm{C}-5\right), 138.2$, 138.0, 130.5, 130.4, 129.1, 129.0, 127.43, $127.41(\mathrm{Ar}-C), 125.9\left(\mathrm{~d},{ }^{2} J_{\mathrm{F}, \mathrm{C}}=34.6 \mathrm{~Hz}, \mathrm{C}-6\right), 86.5\left(\mathrm{C}-1^{\prime}\right), 80.8\left(\mathrm{~d},{ }^{3} J_{\mathrm{P}, \mathrm{C}}=11.1 \mathrm{~Hz}, \mathrm{C}-3^{\prime}\right)$, $74.3\left(\mathrm{C}-4^{\prime}\right), 61.1\left(\mathrm{OCH}_{2} \mathrm{CH}_{2} \mathrm{CH}_{3}\right), 66.6\left(\mathrm{~d},{ }^{1} J_{\mathrm{P}, \mathrm{C}}=136.6 \mathrm{~Hz}, \mathrm{PCH}_{2}\right), 55.1,54.8(\mathrm{Phe}-\mathrm{CH}), 41.3$, $41.2\left(\mathrm{Phe}^{-\mathrm{CH}_{2}}\right), 39.0\left(\mathrm{C}-2^{\prime}\right), 22.6,22.5\left(\mathrm{OCH}_{2} \mathrm{CH}_{2} \mathrm{CH}_{3}\right), 10.64,10.59\left(\mathrm{OCH}_{2} \mathrm{CH}_{2} \mathrm{CH}_{3}\right) .{ }^{31} \mathrm{P} \mathrm{NMR}$ (121 MHz, acetone- $\left.d_{6}\right): \delta$ 19.9. HRMS: $[\mathrm{M}+\mathrm{H}]^{+}$calcd for $\mathrm{C}_{33} \mathrm{H}_{43} \mathrm{FN}_{4} \mathrm{O} 9 \mathrm{P}, 689.2746$; found, 689.2745 .

$1^{\prime} \alpha$-(5-methylcytosin-1-yl)-2'-deoxy-3'-O-diisopropylphosphonomethyl-L-threose (38). To a solution of $37(0.20 \mathrm{~g}, 0.51 \mathrm{mmol}), \mathrm{Et}_{3} \mathrm{~N}(0.22 \mathrm{~mL}, 1.54 \mathrm{mmol})$ and $N$-Methylpyrrolidine $(0.11$ $\mathrm{mL}, 1.02 \mathrm{mmol})$ in $3 \mathrm{~mL}$ of $\mathrm{CH}_{2} \mathrm{Cl}_{2}$ was added $\mathrm{TsCl}(0.20 \mathrm{~g}, 1.02 \mathrm{mmol})$ at $0{ }^{\circ} \mathrm{C}$. After stirring at rt for $2 \mathrm{~h}, 10 \mathrm{~mL}$ of $35 \%$ aq. $\mathrm{NH}_{3}$ was added. The reaction mixture was stirred at $\mathrm{rt}$ for overnight and concentrated. The residue was purified by column chromatography (20:1 to 10:1, $\mathrm{DCM} / \mathrm{MeOH})$ to give product 38 (0.15 g, 75\% yield) as white foam. ${ }^{1} \mathrm{H}$ NMR (300 MHz, DMSO- 
$d_{6}$ ): $\delta 7.47$ (s, 1H, H-6), 7.21 (brs, $\left.1 \mathrm{H}, \mathrm{NH} H_{2}\right), 6.74$ (brs, 1H, NH$H_{2}$ ), 6.09 (dd, $J=8.0,2.3 \mathrm{~Hz}, 1 \mathrm{H}$, H-1'), 4.66-4.50 [m, 2H, CH(CH$)_{2}$ ], 4.28-4.17 (m, 2H, H-3' and H-4a'), 3.87-3.68 (m, 3H, PCH and $\left.\mathrm{H}_{-}-4 \mathrm{~b}^{\prime}\right), 2.55-2.40$ (m, 1H, H-2a', overlap with DMSO), 1.89 (d, J=15.2 Hz, 1H, H-2b'), 1.85 (s, 3H, Me-5), 1.18-1.26 [m, 12H, CH(CH3)2]. ${ }^{13} \mathrm{C}$ NMR (75 MHz, DMSO-d6): $\delta 165.4$ (C-4), 155.2 (C-2), 138.6 (C-6), 100.9 (C-5), 84.7 (C-1'), 80.2 (d, $\left.{ }^{3} J_{\mathrm{P}, \mathrm{C}}=13.4 \mathrm{~Hz}, \mathrm{C}-3^{\prime}\right), 72.5$ (C-4'), 70.2 $\left[\mathrm{CH}\left(\mathrm{CH}_{3}\right)_{2}\right], 63.0\left(\mathrm{~d},{ }^{1} \mathrm{~J}_{\mathrm{P}, \mathrm{C}}=166.0 \mathrm{~Hz}, \mathrm{PCH}_{2}\right), 38.0\left(\mathrm{C}-2^{\prime}\right), 23.7\left[\mathrm{CH}\left(\mathrm{CH}_{3}\right)_{2}\right], 13.3(\mathrm{Me}-5) .{ }^{31} \mathrm{P}$ NMR (121 MHz, DMSO-d6): $\delta$ 19.3. HRMS: $[\mathrm{M}+\mathrm{H}]^{+}$calcd for $\mathrm{C}_{16} \mathrm{H}_{29} \mathrm{~N}_{3} \mathrm{O}_{6} \mathrm{P}, 390.1788$; found, 390.1789 .

1' $\alpha$-(5-methylcytosin-1-yl)-2'-deoxy-3'-O-phosphonomethyl-L-threose (39). This compound was prepared as described for 7. Obtained from $38(150 \mathrm{mg}, 0.39 \mathrm{mmol})$ and iodotrimethylsilane (0.44 mL, $3.08 \mathrm{mmol})$ as a white foam. Yield 51\% (80 mg). ${ }^{1} \mathrm{H}$ NMR (300 MHz, $\left.\mathrm{D}_{2} \mathrm{O}\right): \delta 7.75$ (s, 1H, H-6), 6.18 (d, $J=7.8$ Hz, 1H, H-1'), 4.45-4.37 (m, 2H, H-3' and H-4a'), 3.98 (d, $J=10.3 \mathrm{~Hz}$, 1H, H-4b'), 3.62-3.48 (m, 2H, PCH $H_{2}, 2.65-2.52$ (m, 1H, H-2a'), 2.26 (d, J = 15.2 Hz, 1H, H-2b'), 1.99 (s, 3H, Me-5), ${ }^{13} \mathrm{C}$ NMR (75 MHz, D $\left.2 \mathrm{O}\right): \delta 165.7$ (C-4), 157.2 (C-2), 139.5 (C-6), 104.0 (C5), $86.0\left(\mathrm{C}-1^{\prime}\right), 79.6\left(\mathrm{~d},{ }^{3} J_{\mathrm{P}, \mathrm{C}}=11.6 \mathrm{~Hz}, \mathrm{C}-3^{\prime}\right), 73.6\left(\mathrm{C}-4^{\prime}\right), 64.7\left(\mathrm{~d},{ }^{1} J_{\mathrm{P}, \mathrm{C}}=159.2 \mathrm{~Hz}, \mathrm{PCH}_{2}\right), 36.9$ (C-2'), 12.2 (Me-5). ${ }^{31} \mathrm{P}$ NMR (121 MHz, $\left.\mathrm{D}_{2} \mathrm{O}\right): \delta$ 15.2. HRMS: [M-H] $]^{-}$calcd for $\mathrm{C}_{10} \mathrm{H}_{15} \mathrm{~N}_{3} \mathrm{O}_{6} \mathrm{P}$, 304.0704; found, 304.0705.

\section{$1^{\prime} \alpha$-(5-methylcytosin-1-yl)-2'-deoxy-3'-O-[N,N'-bis(n-propyl-L-}

phenylalaninate)]methylphosphonobisamidate]-L-threose (40). This compound was prepared as described for $\mathbf{8}$. Obtained from $39(20 \mathrm{mg}, 0.049 \mathrm{mmol})$ as a white solid. Yield 30\% (10 mg). ${ }^{1} \mathrm{H}$ NMR (600 MHz, acetone- $\left.d_{6}\right): \delta 7.61(\mathrm{~s}, 1 \mathrm{H}, \mathrm{H}-6), 7.30-7.19(\mathrm{~m}, 10 \mathrm{H}, \mathrm{ArH}), 6.17$ (dd, $J=8.0$, $\left.2.6 \mathrm{~Hz}, 1 \mathrm{H}, \mathrm{H}-1^{\prime}\right), 4.26-4.95\left(\mathrm{~m}, 8 \mathrm{H}\right.$, Phe- $\mathrm{CH}, \mathrm{OCH}_{2} \mathrm{CH}_{2} \mathrm{CH}_{3}, \mathrm{H}-3^{\prime}$ and $\left.\mathrm{H}-4 \mathrm{a}^{\prime}\right), 3.78(\mathrm{~d}, J=8.0$ Hz, 1H, H-4b'), 3.35-3.27 (m, 2H, PCH $H_{2}$, 3.08-2.79 (m, 4H, Phe-CH2), 2.50-2.49 (m, 1H, H-2a'), $1.99\left(1 \mathrm{H}, \mathrm{H}-2 \mathrm{~b}^{\prime}\right.$, overlap with acetone), $1.65-1.54\left(\mathrm{~m}, 4 \mathrm{H}, \mathrm{OCH}_{2} \mathrm{CH}_{2} \mathrm{CH}_{3}\right), 0.92-0.85(\mathrm{~m}, 6 \mathrm{H}$, $\left.\mathrm{OCH}_{2} \mathrm{CH}_{2} \mathrm{CH}_{3}\right) .{ }^{13} \mathrm{C}$ NMR (150 MHz, acetone- $\left.d_{6}\right)$ : 173.8, 173.6 (Phe-CO), 166.5 (C-4), 156.2 (C2), 140.1 (C-6), 138.2, 138.1, 130.6, 130.5, 129.1, 127.5 (Ar-C), 101.9 (C-5), 86.4 (C-1'), 81.3 (d, $\left.{ }^{3} J_{\mathrm{P}, \mathrm{C}}=12.1 \mathrm{~Hz}, \mathrm{C}-3^{\prime}\right), 73.8\left(\mathrm{C}-4^{\prime}\right), 67.1\left(\mathrm{OCH}_{2} \mathrm{CH}_{2} \mathrm{CH}_{3}\right), 66.7\left(\mathrm{~d},{ }^{1} J_{\mathrm{P}, \mathrm{C}}=137.1 \mathrm{~Hz}, \mathrm{PCH}_{2}\right), 55.2$, 54.9 (Phe- $\mathrm{CH}), 41.4,41.2\left(\mathrm{Phe}-\mathrm{CH}_{2}\right), 39.0\left(\mathrm{C}-2^{\prime}\right), 22.6,22.5\left(\mathrm{OCH}_{2} \mathrm{CH}_{2} \mathrm{CH}_{3}\right), 13.6(\mathrm{Me}-5), 10.7$, $10.6\left(\mathrm{OCH}_{2} \mathrm{CH}_{2} \mathrm{CH}_{3}\right) .{ }^{31} \mathrm{P} \mathrm{NMR}\left(121 \mathrm{MHz}\right.$, acetone- $\left.d_{6}\right): \delta$ 19.8. HRMS: $[\mathrm{M}+\mathrm{H}]^{+}$calcd for $\mathrm{C}_{34} \mathrm{H}_{47} \mathrm{~N}_{5} \mathrm{O}_{8} \mathrm{P}, 684.3157$; found, 684.3148. 
HIV Antiviral Assay. Evaluation of the antiviral activity of the compounds against HIV-1 strain $\mathrm{III}_{\mathrm{B}}$ and HIV-2 strain ROD in MT-4 cells was performed using the MTT assay as previously described. ${ }^{25,26}$ Stock solutions (10× final concentration) of test compounds were added in $25 \mu \mathrm{L}$ volumes to two series of triplicate wells so as to allow simultaneous evaluation of their effects on mock- and HIV-infected cells at the beginning of each experiment. Serial 5-fold dilutions of test compounds were made directly in flat-bottomed 96-well microtiter trays using a Biomek 3000 robot (Beckman instruments, Fullerton, CA). Untreated HIV- and mock-infected cell samples were included as controls. HIV-1( $\left.\mathrm{III}_{\mathrm{B}}\right)$ stock $(50 \mu \mathrm{L})$ at $100-300 \mathrm{CCID}_{50}(50 \%$ cell culture infectious doses) or culture medium was added to either the infected or mock-infected wells of the microtiter tray. Mock-infected cells were used to evaluate the effects of test compound on uninfected cells in order to assess the cytotoxicity of the test compounds. Exponentially growing MT-4 cells were centrifuged for $5 \mathrm{~min}$ at $220 \mathrm{~g}$, and the supernatant was discarded. The MT-4 cells were resuspended at $6 \times 10^{5}$ cells $/ \mathrm{mL}$, and $50 \mu \mathrm{L}$ volumes were transferred to the microtiter tray wells. Five days after infection, the viability of mock-and HIV-infected cells was examined spectrophotometrically using the MTT assay. The MTT assay is based on the reduction of yellow colored 3-(4,5-dimethylthiazol-2-yl)-2,5-diphenyltetrazolium bromide (MTT) (Acros Organics) by mitochondrial dehydrogenase activity in metabolically active cells to a blue-purple formazan that can be measured spectrophotometrically. The absorbances were read in an eight-channel computer-controlled photometer (Infinite M1000, Tecan) at two wavelengths (540 and $690 \mathrm{~nm}$ ). All data were calculated using the median absorbance value of three wells. The $50 \%$ cytotoxic concentration $\left(\mathrm{CC}_{50}\right)$ was defined as the concentration of the test compound that reduced the absorbance (OD540) of the mock-infected control sample by 50\%. The concentration achieving $50 \%$ protection against the cytopathic effect of the virus in infected cells was defined as the $50 \%$ effective concentration $\left(\mathrm{EC}_{50}\right)$.

HBV Antiviral Assay. The primary anti-HBV assay was performed as previously described ${ }^{28,29}$ with modifications to use a quantitative blot hybridization assay to measure extracellular HBV DNA copy number associated with virions released from HepG2 2.2.15 cells. The HepG2 2.2.15 cell line is a stable human hepatoblastoma cell line that contains two copies of the HBV wild-type strain ayw1 genome and constitutively produces high levels of HBV. ${ }^{27}$ Briefly, HepG2 2.2.15 cells were plated in 96-well microtiter plates at $1.5 \times 10^{4}$ cells/well in Dulbecco's Modified Eagle's Medium supplemented with 2\% FBS, $380 \mu \mathrm{g} / \mathrm{mL}$ G418, $2.0 \mathrm{mM}$ L glutamine, 100 units $/ \mathrm{mL}$ 
penicillin, $100 \mu \mathrm{g} / \mathrm{mL}$ streptomycin, and $0.1 \mathrm{mM}$ nonessential amino acids. Only the interior wells are utilized to reduce "edge effects" observed during cell culture; the exterior wells are filled with complete medium to help minimize sample evaporation. After 16-24 h, the confluent monolayer of HepG2 2.2.15 cells was washed and the medium was replaced with complete medium containing various concentrations of a test compound in triplicate. Lamivudine (3TC) was used as the positive control, while media alone was added to cells as a negative control (virus control, VC). Three days later, the culture medium is replaced with fresh medium containing the appropriately diluted test compounds. Six days following the initial administration of the test compound, the cell culture supernatant was collected, treated with Pronase and then used in a quantitative blot hybridization assay. The PCR-amplified HBV DNA was detected in real-time by monitoring increases in fluorescent signal that result from the exonucleolytic degradation of a quenched fluorescent probe molecule that hybridized to the amplified HBV DNA. For each PCR amplification, a standard curve was simultaneously generated using dilutions of purified HBV DNA. Antiviral activity was calculated from the reduction in HBV DNA levels $\left(\mathrm{EC}_{50}\right.$ and EC90 values determined). A tetrazolium dye (MTS; 3-(4,5-dimethylthiazol-2-yl)-5-(3carboxymethoxyphenyl)-2-(4-sulfophenyl)-2H-tetrazolium; CellTiter96 Reagent, Promega) uptake assay was then employed to measure cell viability, which was used to calculate toxicity $\left(\mathrm{CC}_{50}\right)$.

\section{Acknowledgements}

Chao Liu thanks the China Scholarship Council (CSC) for funding (grant 201306220065). We thank Prof. Jef Rozenski (KU Leuven) for providing HRMS data. Mass spectrometry was made possible by the support of the Hercules Foundation of the Flemish Government (grant 201002257). We thank Kristien Erven and Kris Uyttersprot for dedicated technical assistance. We thank Luc Baudemprez for technical assistance. Testing against HBV was conducted using federal funds from the Division of Microbiology and Infectious Diseases (DMID), NIAID/NIH under contract HHSN272201100008 entitled 'In Vitro Assessment for Antimicrobial Activity' awarded to Georgetown University.

$\dagger$ Electronic supplementary information (ESI) available: ${ }^{1} \mathrm{H}$ and ${ }^{13} \mathrm{C}$ NMR spectra of all novel compounds. 


\section{References}

1 E. De Clercq and A. Holý, Nat. Rev. Drug Discovery, 2005, 4, 928-940.

2 F. Pertusati, M. Serpi and C. McGuigan, Antivir. Chem. Chemother., 2012, 22, 181-203.

3 E. De Clercq, Clin. Microbiol. Rev., 2003, 16, 569-596.

4 C. U. Kim, B. Y. Luh and J. C. Martin, J. Org. Chem., 1991, 56, 2642-2647.

5 T. Cihlar, A. S. Ray, C. G. Boojamra, L. Zhang, H. Hui, G. Laflamme, J. E. Vela, D. Grant, J. Chen, F. Myrick, K. L. White, Y. Gao, K. Y. Lin, J. L. Douglas, N. T. Parkin, A. Carey, R. Pakdaman and R. L. Mackman, Antimicrob. Agents Chemother., 2008, 52, 655-665.

6 T. F. Wu, M. Froeyen, V. Kempeneers, C. Pannecouque, J. Wang, R. Busson, E. De Clercq and P. Herdewijn, J. Am. Chem. Soc., 2005, 127, 5056-5065.

7 C. Liu, S. G. Dumbre, C. Pannecouque, C. S. Huang, R. G. Ptak, M. G. Murray, S. De Jonghe and P. Herdewijn, J. Med. Chem., 2016, 59, 9513-9531.

8 S. G. Dumbre, M. Y. Jang and P. Herdewijn, J. Org. Chem., 2013, 78, 7137-7144.

9 D. Viña, T. Wu, M. Renders, G. Laflamme and P. Herdewijn, Tetrahedron, 2007, 63, 26342646.

10 Q. Huang and P. Herdewijn, Nucleosides, nucleotides nucleic acids, 2009, 28, 337-351.

11 E. De Clercq and G. D. Li, Clin. Microbiol. Rev., 2016, 29, 695-747.

12 D. M. Margolis, A. L. Mukherjee, C. V. Fletcher, E. Hogg, D. Ogata-Arakaki, T. Petersen, D. Rusin, A. Martinez and J. W. Mellors, AIDS, 2007, 21, 2025-2032.

13 B. M. Gripshover, H. Ribaudo, J. Santana, J. G. Gerber, T. B. Campbell, E. Hoggs, B. Jarocki, S. M. Hammer and D. R. Kuritzkes, Antiviral Ther., 2006, 11, 619-623.

14 J. Homsi and C. R. Garrett, Cancer Control, 2006, 13, 42-47.

15 A. B. Eldrup, M. Prhavc, J. Brooks, B. Bhat, T. P. Prakash, Q. L. Song, S. Bera, N. Bhat, P. Dande, P. D. Cook, C. F. Bennett, S. S. Carroll, R. G. Ball, M. Bosserman, C. Burlein, L. F. Colwell, J. F. Fay, O. A. Flores, K. Getty, R. L. LaFemina, J. Leone, M. MacCoss, D. R. McMasters, J. E. Tomassini, D. Von Langen, B. Wolanski and D. B. Olsen, J. Med. Chem., 2004, 47, 5284-5297.

16 M. M. Bio, F. Xu, M. Waters, J. M. Williams, K. A. Savary, C. J. Cowden, C. H. Yang, E. Buck, Z. G. J. Song, D. M. Tschaen, R. P. Volante, R. A. Reamer and E. J. J. Grabowski, J. 
Org. Chem., 2004, 69, 6257-6266.

17 S. S. Carroll, S. Ludmerer, L. Handt, K. Koeplinger, N. Y. R. Zhang, D. Graham, M. E. Davies, M. MacCoss, D. Hazuda and D. B. Olsen, Antimicrob. Agents Chemother, 2009, 53, 926-934.

18 Y. L. Chen, Z. Yin, J. Duraiswamy, W. Schul, C. C. Lim, B. Liu, H. Y. Xu, M. Qing, A. Yip, G. Wang, W. L. Chan, H. P. Tan, M. Lo, S. Liung, R. R. Kondreddi, R. Rao, H. Gu, H. He, T. H. Keller and P. Y. Shi, Antimicrob. Agents Chemother., 2010, 54, 2932-2939.

19 J. L. Ruth and Y. C. Cheng, Mol. Pharmacol., 1981, 20, 415-422.

20 K. A. Watanabe, T. L. Su, R. S. Klein, C. K. Chu, A. Matsuda, M. W. Chun, C. Lopez and J. J. Fox, J. Med. Chem., 1983, 26, 152-156.

21 F. Seela and X. H. Peng, Curr. Top. Med. Chem., 2006, 6, 867-892.

22 P. Naus, P. Perlikova, A. Bourderioux, R. Pohl, L. Slavetinska, I. Votruba, G. Bahador, G. Birkus, T. Cihlar and M. Hocek, Bioorg. Med. Chem., 2012, 20, 5202-5214.

23 P. Naus, O. Caletkova, P. Konecny, P. Dzubak, K. Bogdanova, M. Kolar, J. Vrbkova, L. Slavetinska, E. Tloust'ova, P. Perlikova, M. Hajduch and M. Hocek, J. Med. Chem., 2014, 57, 1097-1110.

24 P. Naus, O. Caletkova, P. Perlikova, L. P. Slavetinska, E. Tloustova, J. Hodek, J. Weber, P. Dzubak, M. Hajduch and M. Hocek, Bioorg. Med. Chem., 2015, 23, 7422-7438.

25 R. Pauwels, J. Balzarini, M. Baba, R. Snoeck, D. Schols, P. Herdewijn, J. Desmyter and E. Declercq, J. Virol. Methods, 1988, 20, 309-321.

26 C. Pannecouque, D. Daelemans and E. De Clercq, Nat. Protoc., 2008, 3, 427-434.

27 M. A. Sells, M. L. Chen and G. Acs, Proc. Natl. Acad. Sci. U.S.A. 1987, 84, 1005-1009.

28 B. E. Korba and G. Milman, Antiviral Res., 1991, 15, 217-228.

29 B. E. Korba and J. L. Gerin, Antiviral Res., 1992, 19, 55-70. 